Dwight José Cabrera Salas

\title{
Automação e Otimização do Projeto de um Oscilador Controlável por Tensão para Aplicações em Rádio Frequência
}

Dissertação apresentada à Escola Politécnica

da Universidade de São Paulo para obtenção do Título de Mestre em Engenharia Elétrica. 

Dwight José Cabrera Salas

\title{
Automação e Otimização do Projeto de um Oscilador Controlável por Tensão para Aplicações em Rádio Frequência
}

\author{
Dissertação apresentada à Escola \\ Politécnica da Universidade de São \\ Paulo para obtenção do Título de Mestre \\ em Engenharia Elétrica. \\ Área de concentração: \\ Microeletrônica \\ Orientador: \\ Prof. Dr \\ José Vieira do Vale Neto
}


Este exemplar foi revisado e alterado em relação à versão original, sob responsabilidade única do autor e com a anuência de seu orientador.

São Paulo, de. 20

Assinuatura do autor

Assinuatura do orientador

FICHA CATALOGRÁFICA

Cabrera, Dwight José Salas

Automação e Otimização do Projeto de um Oscilador Controlável por Tensão para Aplicações em Rádio Frequência / C. S. Dwight. -São Paulo, 2010.

72 p.

Dissertação (Mestrado) - Escola Politécnica da Universidade de São Paulo. Departamento de Engenharia de Sistemas Eletrônicos.

1.Programação geométrica 2. Circuitos integrados MOS 3. Osciladores. I.Universidade de São Paulo. Escola Politécnica. Departamento de Engenharia de Sistemas Eletrônicos II.t. 
Dedico esta dissertação a Deus!!

Edison, ao pai e ao irmão

as mulheres da minha vida, Viviana, Natalia e Damaris... 



\section{Agradecimentos}

Ao professor José Vieira pelos seus valiosos conselhos e sugestões os quais enriqueceram este trabalho. Ao professor Elkim Roa, seu animo e visão serviram como um forte respaldo ao iniciar meus estudos de pós-graduação. À CAPES pelo suporte financeiro, e FAPESP por financiar a fabricação do protótipo. Aos colegas e amigos no CIDIC, LME, LSI e DH-LSITec e, em geral a todas aquelas pessoas que contribuíram na minha formação profissional e pessoal.

À Minha família, pelo seu amor e valioso apóio na última parte deste trabalho. À Viviana, quem tem sido minha companheira de caminho, por seu amor e compreensão. Finalmente, ao mais importante, a Deus pelo seu maravilhoso amor e misericórdia, por ter me sustentado neste tempo, por ter me permitido conhecer, aprender e desfrutar desta experiência. 

Pois toda carne é como a erva, e toda a sua glória como flor da erva. A erva secou-se e a flor caiu, mas a palavra do Senhor permanece para sempre. 1 Pedro 1:24-25a 



\section{Resumo}

Nesta dissertação os conceitos e técnicas relacionadas com a automação e otimização do projeto de um oscilador controlável por tensão para aplicações de rádio frequência são apresentados. O problema de projeto do oscilador foi formulado como um problema de otimização matemática conhecido como programa geométrico. Uma abordagem à aplicação da programação geométrica no projeto de um circuito simples foi feita primeiro. Dessa forma, as ventagens e limitações da metodologia são identificadas e, propostas para lidar com esses problemas são revisados. Com uma idéia clara da metodologia, o problema de projeto do oscilador como um programa geométrico é apresentado. Um requerimento importante da aplicação de programação geométrica no projeto de circuitos é a necessidade de contar com modelos dos dispositivos que sejam compatíveis com a forma matemática do problema de otimização. Nesse sentido, neste trabalho se mostra como foram obtidos esses modelos para parâmetros do transistor e de um indutor quadrado simétrico onchip. Finalmente, aplicou-se a metodologia no projeto de um VCO na banda ISM $2.4 \mathrm{GHz}$ numa tecnologia CMOS $0.35 \mu \mathrm{m}$ padrão de 4 metais, simulações do circuito mostraram uma figura de mérito de $180 \mathrm{dBc} / \mathrm{Hz}$ com o ruído de fase de $-130 \mathrm{dBc} / \mathrm{Hz}$ a $3 \mathrm{MHz}$ de offset da portadora. Finalmente, o layout do protótipo de um VCO foi feito e fabricado. Testes experimentais foram desenvolvidos. Os resultados obtidos mostraram boa correlação com as simulações póslayout do circuito. 



\section{Abstract}

In this work the concepts and techniques related to the optimization and automation of the design of a controlled voltage oscillator intended for radio frequency applications are presented. The design problem of the oscillator was cast as a mathematical optimization problem known as geometric programming. As a first approach, the application of geometric programming in the design of simple circuits was first done. Thus, the advantages and limitations of the methodology were first reviewed and strategies to overcome theses problems were also presented. With a better understanding of the methodologies, the formulation of the oscillator as a geometric program was presented. One of the most important requirements in the application of geometric programming in circuit design is the needed of device models suitable with the mathematical form of a geometric program. Thus, in this work the techniques used to obtain theses models for transistor and inductor parameters were presented. Using the proposed methodology, a VCO for the $2.4 \mathrm{GHz}$ ISM frequency band was designed in a standard 4 metals 0.35um CMOS technology. From simulations results, the VCO achieved a figure of merit of $180 \mathrm{dBc} / \mathrm{Hz}$ with a phase noise of $-130 \mathrm{dBc} / \mathrm{Hz}$ at $3 \mathrm{MHz}$ of offset frequency. A prototype of a VCO was fabricated and experimental tests were developed. From the obtained results good agreement with post layout simulations were observed. 



\section{Lista de Figuras}

1.1 Diagrama simplificado de um transceptor de conversão direta. . . . . . . . . . 2

2.1 Esquemático do amplificador fonte comum com carga ativa. . . . . . . . . . 9

2.2 Circuito para a modelagem do transistor NMOS. . . . . . . . . . . . . . 14

2.3 Corrente de dreno Vs tensão dreno-fonte para diferentes valores de largura do transistor. . . . . . . . . . . . . . . . . . . . 16

3.1 VCO LC diferencial complementar. . . . . . . . . . . . . . . . 20

3.2 Esquemático do LC-VCO com modelo simplificado de banda estreita do ressoador. . . . . . . . . . . . . . . . . . . 21

3.3 Capacitância no varactor PMOS de acumulação . . . . . . . . . . . . . . 22

3.4 Modelo simplificado do varactor. . . . . . . . . . . . . . . . . . . 22

3.5 Modelo de pequenos sinais do VCO LC complementar . . . . . . . . . . 23

3.6 Modelo equivalente para o oscilador. . . . . . . . . . . . . . 23

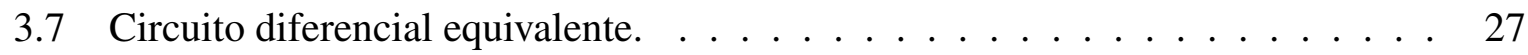

3.8 a) Espectro do sinal gerado pelo VCO. b) Distribuição do ruído de fase. . . . . 29

3.9 Oscilador LC complementar com fontes de ruído $\ldots \ldots$. . . . . . . . . . 30

3.10 Circuito do VCO incluindo a polarização. . . . . . . . . . . . . . . . . 32

3.11 Valor quadrático médio da ISF da corrente de ruído em $I_{T A I L} \ldots \ldots \ldots$

4.1 (a) Indutor quadrado. (b) Indutor octogonal. (c) Indutor simétrico. . . . . . . . . 38

4.2 Tipos de conexão: (a) Diferencial, (b) Uma porta aterrada. . . . . . . . . . . . 38

4.3 (a) Modelo- $\Pi$ simples [33] e (b) Modelo-2П [34] . . . . . . . . . . . . . . . 38

4.4 Estruturas simétricas: (a) Conexão série de dois indutores assimétricos, (b) In-

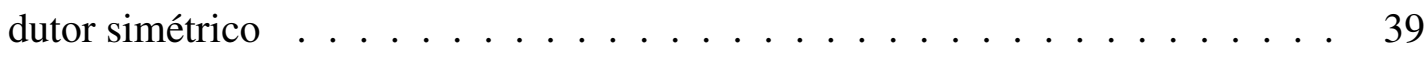


4.5 Modelo- $\Pi$ simplificado . . . . . . . . . . . . . . . . . . . . . 41

4.6 Modelo- $\Pi$ simplificado em aplicações diferenciais. . . . . . . . . . . . . . . . 41

4.7 Representação circuital de duas portas a partir dos parâmetros $Y \quad$. . . . . . . 44

4.8 Parâmetros $\mathrm{Y}$ do indutor fnd047. . . . . . . . . . . . . . . 45

4.9 Fator de qualidade e indutância do indutor fnd047. . . . . . . . . . . . . . 46

4.10 Parâmetros $\mathrm{Y}$ do indutor fnd060. . . . . . . . . . . . . . . . . 46

4.11 Fator de qualidade e indutância do indutor fnd060 . . . . . . . . . . . . . 47

4.12 Espaço de projeto. . . . . . . . . . . . . . . . . 47

4.13 Parâmetros de Desempenho obtidos. . . . . . . . . . . . . . . . . . . . . 48

5.1 Fluxo de projeto proposto. . . . . . . . . . . . . . . . . . 52

5.2 Consumo de potência Versus diâmetro exterior do indutor para diferentes fatores de oscilação. . . . . . . . . . . . . . . . . . . . . . . . . 57

5.3 Fator de qualidade do indutor @ 2.45GHz para diferentes valores do diâmetro exterior do indutor. . . . . . . . . . . . . . . . . . 58

5.4 Consumo de potência para diferentes especificações de ruído de fase, considerando o ruído do circuito de polarização (linha contínua) sem considerar o ruído do circuito de polarização (linha tracejada). . . . . . . . . . . . . . 58

5.5 Consumo de potência para diferentes tamanhos do transistor $W_{c m} . \quad \ldots \ldots$. . . 58

5.6 Layout do VCO com buffer diferencial. . . . . . . . . . . . . . . 59

5.7 Etapa de saída do VCO. . . . . . . . . . . . . . . . . . . . 60

5.8 Testbench para simulações póslayout. . . . . . . . . . . . . . 60

5.9 Corrente $I_{T A I L}$ e tensão diferencial na saída do buffer. . . . . . . . . . . . . . 61

5.10 (Esquerda) Ruído de fase do VCO+buffer para uma frequência de oscilação de $2.45 \mathrm{GHz}$. (Direita) Frequência de oscilação versus tensão de controle $V_{C T R}$. . 62

5.11 Microfotografia do protótipo fabricado. . . . . . . . . . . . 62

5.12 Estação de prova RF cascade . . . . . . . . . . . . . . . 63

5.13 Medidas on-die do protótipo. . . . . . . . . . . . . . . 64 
5.14 Espectro do sinal em uma das saídas do buffer. Frequência central: $2.293 \mathrm{GHz}$, Span: $69 \mathrm{MHz}$, Resolution Bandwith: $680 \mathrm{KHz}$. . . . . . . . . . . . . . . . . 64

5.15 Faixa de sintonia do VCO . . . . . . . . . . . . . . . . . 65 



\section{Lista de Tabelas}

2.1 Especificações. . . . . . . . . . . . . . . . . . . . . . . . 12

2.2 Comparação entre os diferentes tipos de modelo. . . . . . . . . . . . . . . . . 13

2.3 Variáveis ótimas. . . . . . . . . . . . . . . . . . . . . . 18

2.4 Desempenho do circuito. . . . . . . . . . . . . . . . . . . . 18

4.1 Parâmetros da tecnologia. . . . . . . . . . . . . . . . . . . . . 43

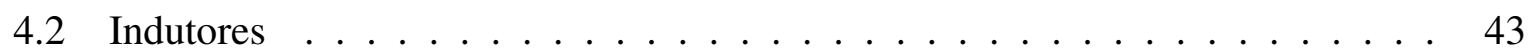

4.3 Modelo dos parâmetros do indutor simétrico compatíveis com programação geométrica. . . . . . . . . . . . . . . . . . . . 49

5.1 Tecnologia AMS C35B4C3 $0.35 \mu \mathrm{m}$ CMOS . . . . . . . . . . . . . 52

5.2 Especificações de projeto e desempenho do VCO estimado da solução do programa geométrico e verificado por simulações em spectreRF. . . . . . . . . . . 54

5.3 Desempenho e tamanhos-ótimos dos dispositivos estimados na solução do programa geométrico e verificados por simulações em spectreRF . . . . . . . . . . 54

5.4 Geometria e desempenho do indutor estimadas pelo programa geométrico e verificados em ASITIC . . . . . . . . . . . . . . . . . . . . 55

5.5 Comparação com outros trabalhos presentados. . . . . . . . . . . . . . . . 56 



\section{Lista de símbolos}

$\alpha \quad$ Fator de oscilação do VCO.

$\phi \quad$ Fase do sinal de saída do VCO.

$\Phi \quad$ Metade do angulo de condução dos transistores no par diferencial PMOS.

$\lambda_{n} \quad$ Constante de ruído térmico do transistor NMOS.

$\lambda_{p} \quad$ Constante de ruído térmico do transistor PMOS.

$\Gamma \quad$ Função de sensibilidade ao impulso.

$\Gamma_{r m s} \quad$ Valor quadrático médio da função de sensibilidade ao impulso.

$1 / f^{2} \quad$ Região onde o ruído de fase do VCO diminui em proporção ao quadrado da frequência.

$1 / f^{3} \quad$ Região onde o ruído de fase do VCO diminui em proporção ao cubo da frequência.

AMS Austria Micro systems.

$A_{d} \quad$ Amplitude da tensão diferencial de saída do VCO.

$A_{v} \quad$ Ganho.

BSIM Modelo IGFET de canal curto da Berkeley.

$B W \quad$ Largura de banda.

$C_{d b, n} \quad$ Capacitância dreno-corpo do transistor NMOS.

$C_{d b, p} \quad$ Capacitância dreno-corpo do transistor PMOS.

$C_{g s, n} \quad$ Capacitância porta-fonte do transistor NMOS.

$C_{g s, p} \quad$ Capacitância porta-fonte do transistor PMOS.

$C_{g d, n} \quad$ Capacitância porta-dreno do transistor NMOS.

$C_{g d, p} \quad$ Capacitância porta-dreno do transistor PMOS.

$C_{\text {par }} \quad$ Capacitância parasita.

$C_{V} \quad$ Capacitância parasita do varactor.

$C_{V_{\max }} \quad$ Máxima capacitância do varactor.

$C_{V_{\max }} \quad$ Mínima capacitância do varactor.

$C_{\text {tank }} \quad$ Capacitância do modelo equivalente do VCO.

$C_{I N D} \quad$ Capacitância parasita do indutor.

$C_{L} \quad$ Capacitância de carga.

$C_{L O A D} \quad$ Capacitância de carga do VCO.

$C_{N M O S}$ Capacitância devida ao par diferencial NMOS.

$C_{P M O S}$ Capacitância devida ao par diferencial PMOS.

C-QP Programação quadrática com restrições.

$I_{B I A S} \quad$ Corrente de polarização.

$I_{R E F} \quad$ Corrente de referência.

ITAIL Corrente pelo core do VCO.

ISF Impulse Sensitive Function. 



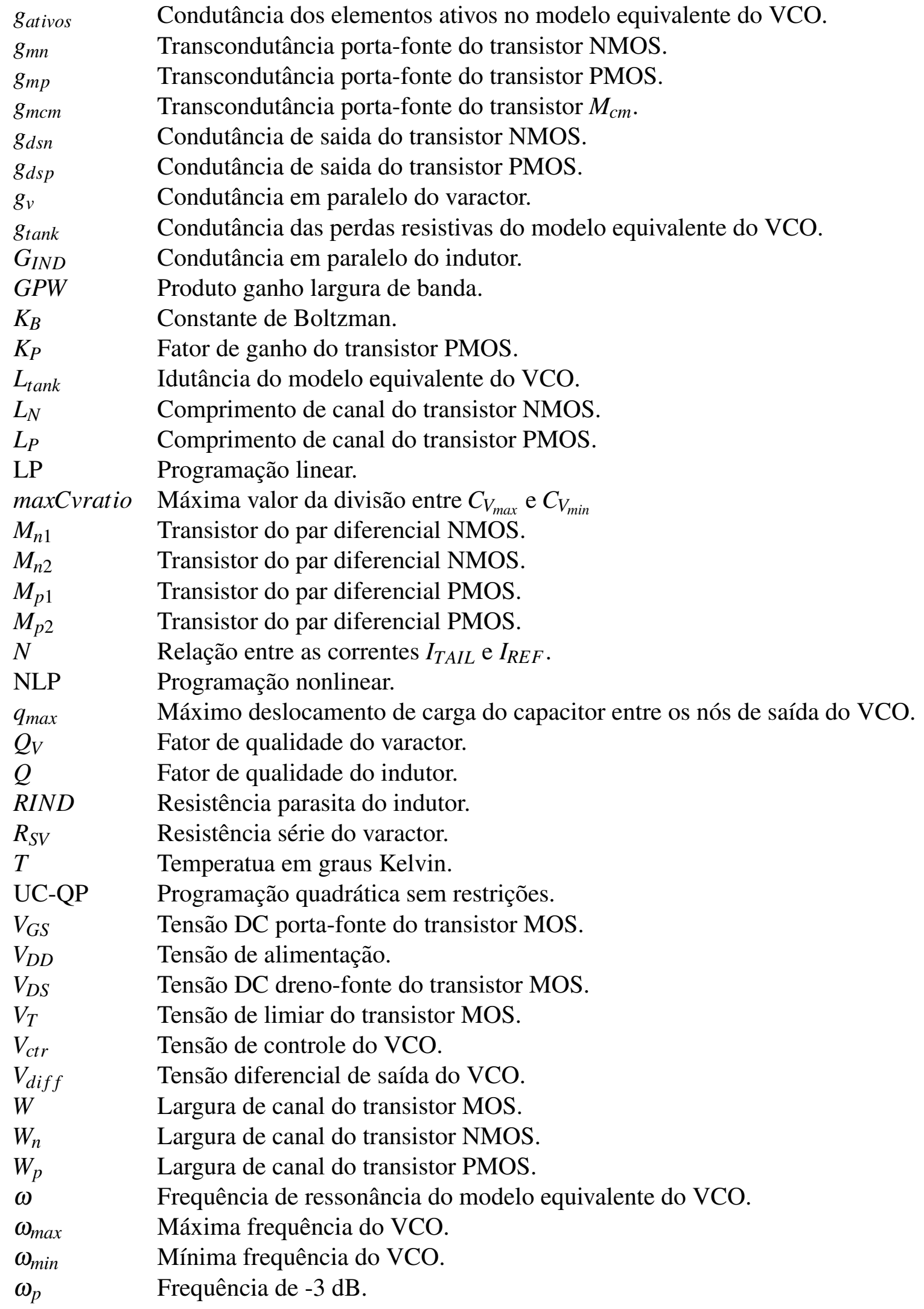





\section{Sumário}

1 Introdução 1

1.1 Levantamento do problema . . . . . . . . . . . . . . . . 3

1.2 Organização do documento . . . . . . . . . . . . . . . . . 4

2 Programação geométrica 5

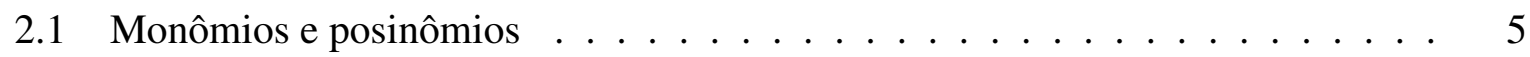

2.2 Forma padrão de um $\mathrm{PG} \ldots \ldots \ldots$

2.2 .1 A forma convexa de um PG .............. 6

2.3 Arimética entre posinômios e monômios . . . . . . . . . . . . 7

2.4 Solução de um programa geométrico . . . . . . . . . . . . . . 8

2.5 Aplicação da programação geométrica no projeto de um amplificador fonte comum ............................... 9

2.5.1 Parâmetros de desempenho do circuito . . . . . . . . . . . . . . . 10

2.5.2 Modelos do transistor . . . . . . . . . . . . . . . 11

2.5.3 Modelos do transistor compatíveis num programa geométrico . . . . . 14

2.5.4 Formulação do programa geométrico . . . . . . . . . . . . . 16

2.5.5 Resultados ....................... 17

3 Projeto de um VCO como um programa geométrico 19

3.1 Oscilador diferencial LC complementar . . . . . . . . . . . . . . . . 19

3.2 Parâmetro de desempenho . . . . . . . . . . . . . . 20

3.2 .1 Ressoador ........................... 20

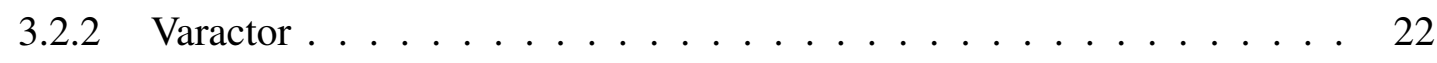


3.2.3 Modelo de pequenos sinais . . . . . . . . . . . . . . . 22

3.2 .4 Condição de oscilação . . . . . . . . . . . . . . . . . . . . 25

3.2.5 Frequência de ressonância . . . . . . . . . . . . . . . . 25

3.2 .6 Faixa de sintonia . . . . . . . . . . . . . . . 25

3.2 .7 Amplitude ... . . . . . . . . . . . . . . 26

3.2.8 Ruído de fase . . . . . . . . . . . . . . . . . . . . . . . . 27

3.2 .9 Polarização do VCO . . . . . . . . . . . . . . . . . . . 31

3.2 .10 ISF da corrente de ruído em $I_{T A I L} \ldots \ldots \ldots$. . . . . . . . . . . 32

3.3 Consumo de potência . . . . . . . . . . . . . . . . 34

3.4 O projeto do VCO LC complementar como um programa geométrico . . . . . 34

4 Indutor onchip e modelo compatível num programa geométrico 37

4.1 Modelo- $\ldots \ldots \ldots \ldots \ldots$. . . . . . . . . . . . . . . . . 38

4.1 .1 Modelo- $\Pi$ simplificado . . . . . . . . . . . . . . . . . . 41

4.2 Obtenção de modelos de indutores simétricos compatíveis com um PG . . . . . 42

4.2.1 Ferramenta de simulação eletromagnética . . . . . . . . . . . . . . 43

4.2.2 Espaço de projeto e desempenho . . . . . . . . . . . . . . . 47

4.2 .3 Modelos do indutor a $2.45 \mathrm{GHz} \ldots \ldots \ldots$. . . . . . . . . . 48

5 Projeto de um VCO na banda ISM $2.4 \mathrm{GHz}$

5.1 Projeto e análise dos resultados . . . . . . . . . . . . . . 53

5.2 Comparação com outros trabalhos . . . . . . . . . . . . . . . 55

5.3 Curvas de trade-off para o VCO LC complementar . . . . . . . . . 56

5.4 Layout e protótipo . . . . . . . . . . . . . . . . . . 59

5.5 Resultados experimentais . . . . . . . . . . . . . . . . . 61

6 Conclusões e recomendações para trabalhos futuros 67 


\section{Introdução}

O desempenho que oferecem as atuais tecnologias na indústria dos semicondutores tem permitido a integração de sistemas cada vez mais complexos num mesmo chip. Este fato estimulou uma agressiva incursão de soluções integradas em mercados de alto consumo (como multimídia e telecomunicações) que demandam cada vez menos tempo no ciclo de projeto de um circuito integrado. Atualmente, complexos sistemas com circuitos digitais, analógicos, sinal-misto e RF são integrados num mesmo chip. No projeto deste tipo de sistema o uso de ferramentas CAD (Computer Assisted Design) é decisivo para atingir as necessidades do mercado [1].

$\mathrm{O}$ projeto de circuitos analógicos/ $\mathrm{RF}^{1}$ encerra características como:

- Alta complexidade nos modelos dos dispositivos (ativos ou passivos).

- Alto número de parâmetros de desempenho que no pior dos casos estão comprometidos entre si.

- Grande sensibilidade às variações do processo. Pequenas variações podem causar mudanças dramáticas no desempenho do circuito.

- Dificuldade para obter expressões matemáticas explícitas das medidas de desempenho dos circuitos.

Estas características podem tornar a tarefa de projeto em problemas de alta complexidade, mesmo em circuitos de aparência simples (opamps, fontes de referências, comparadores, etc), levando ao projetista a usar modelos matemáticos simplificados (sacrificando a exatidão) que permitem "estimar"o comportamento do circuito. Uma vez estimado este comportamento, o projetista faz uso do simulador ${ }^{2}$ num longo processo iterativo na busca de um projeto que atinja as especificações; este processo facilmente pode durar semanas. Estes fatores evidenciam a importância, e ao mesmo tempo carência, de ferramentas computacionais que assistam o projeto

\footnotetext{
${ }^{1}$ Aqui faz referência ao processo de determinação das geometrias dos elementos (passivos ou ativos) de uma célula básica para atingir determinadas especificações.

${ }^{2}$ Neste caso poderia ser visto como uma ferramenta de verificação e não de projeto.
} 


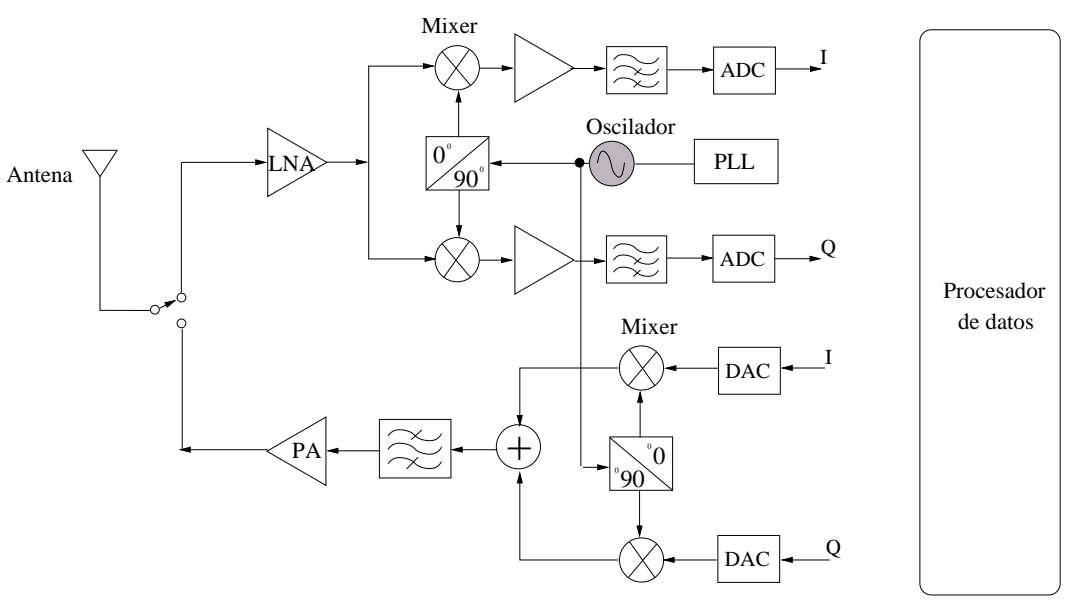

Figura 1.1: Diagrama simplificado de um transceptor de conversão direta.

de CIs analógicos/RF. Grandes esforços estão sendo feitos para incorporar estas ferramentas como parte do fluxo de projeto, no entanto a eficácia deste processo depende maiormente das aplicações comerciais disponíveis [1].

Na figura 1.1 se observa um exemplo do tipo de sistemas que atualmente podem ser integrados num mesmo chip. A figura corresponde a um transceptor; este tipo de sistema que conta com circuitos analógicos (operando em banda base e RF), de sinal-misto e digital encerra grande complexidade no momento de ser projetado. Em termos de tempo, é desejável para o projetista trabalhar no nível de sistema (escolher de forma adequada as especificações de cada bloco) e não se preocupar com o projeto de cada bloco. Embora atingir o dito nível de automação pareça impossível, resultados em outros tipos de sistema, também de alto impacto no mercado, já são visíveis na literatura recente [2]. O interesse deste trabalho é contribuir nesse objetivo, especificamente procura-se implementar uma metodologia que partindo de uma topologia de circuito permita auxiliar o projeto do oscilador destacado na figura 1.1. A implementação desta metodologia numa ferramenta computacional permitiria ao projetista, entre outros:

- A oportunidade de perceber/analisar os compromissos (trade-off) entre especificações e desta forma fazer a melhor escolha na busca de um maior desempenho.

- Projeto fácil e rápido do oscilador para diferentes arquiteturas de sistema e padrões de comunicação.

- Adaptação fácil em novas tecnologias ${ }^{3}$.

\footnotetext{
${ }^{3}$ A migração de projetos existentes para novas tecnologias é um fator decisivo em termos de competitividade no paradigma time-to-market
} 


\subsection{Levantamento do problema}

Uma das muitas aplicações dos osciladores se encontra em sistemas de comunicação sem fio. A figura 1.1 mostra uma arquitetura típica de um transceptor, ali se observam os blocos encarregados da recepção, processamento e transmissão de sinais. No receptor, o sinal RF recebido pela antena é acoplado ao amplificador de baixo ruído (LNA) para depois ser deslocado para baixas freqüências pelo misturador, quem usa o sinal gerado pelo oscilador para este fim. Uma vez em baixas freqüências o sinal é levado para o domínio digital para ser demodulado e processado. Por outro lado, no transmissor o sinal percorre o caminho contrário chegando até o amplificador de potência (PA) para ser transmitido pela antena.

Um dos blocos usados tanto na recepção como na transmissão é o oscilador. Este bloco, junto com o PLL, está encarregado de gerar um dos sinais de entrada do misturador. A freqüência do sinal gerada pelo oscilador é variável e ajustada pelo PLL, dai que um nome mais acertado para o oscilador da figura seja "oscilador controlado por tensão", ou $\mathrm{VCO}^{4}$ (voltage controlled oscillator).

No nível de sistema, as especificações de projeto deste bloco são determinadas a partir das características do padrão de comunicação e variam de acordo com a arquitetura do sistema. Do padrão de comunicação são é importante para o oscilador: a freqüência da portadora, a largura de banda do canal, o BER, a sensibilidade e os sinais de interferência [3]. Além disso especificações próprias do oscilador como: amplitude do sinal, condição de oscilação, ganho e consumo de potência fazem parte do projeto deste bloco.

Percebe-se desta maneira um cenário para o oscilador que envolve diferentes especificações de projeto que dependem de fatores como o padrão de comunicação e arquitetura do sistema. Estas características encerram um campo idôneo para a aplicação de metodologias que permitam automatizar a tarefa de projeto. Umas das chaves para conseguir automatizar o projeto de circuitos RF, está na possibilidade de integrar a complexidade dos modelos dos dispositivos dentro de um tipo de problema matemático que possa ser resolvido eficientemente. A otimização convexa se mostra como uma boa opção nesta busca devido às qualidades que possui: o problema tem um ótimo global que pode ser obtido eficientemente, capacidade de detectar se o problema tem ou não solução, não precisa de pontos iniciais, e conta com implementações de solvers ${ }^{5}$ comerciais ou de código aberto [4, 5, 6, 7, 8, 9].

A otimização convexa é conhecida como uma classe especial dentro dos problemas de

\footnotetext{
${ }^{4}$ Neste documento quando for usada a palavra oscilador se faz referência a um oscilador controlado por tensão; igualmente será usado o acrônimo VCO significando o mesmo.

${ }^{5}$ Termo usado para os algoritmos que solucionam o problema de otimização.
} 
otimização matemática. Por sua vez, a otimização convexa agrupa diferentes tipos de problemas de otimização (convexos) diferenciados entre si pelas característica matemáticas das funções que os compõem; dentro destes subconjuntos se tem a programação geométrica ${ }^{6}[5]$. A forma matemática dos programas geométricos (PGs) permite usar expressões teóricas comuns derivadas do projeto de circuitos (digitais, analógico, sinal-misto e RF), permitindo modelar o projeto como um problema de otimização. Assim, o problema de projeto pode ser solucionado eficientemente $[10,11,12,13]$. Vale a pena destacar [14] onde esta metodologia se aplicou no projeto de um oscilador controlado por tensão.

Neste trabalho se aplicará a metodologia proposta por [14] no desenvolvimento de uma ferramenta computacional para o projeto do oscilador. Fazendo uso da ferramenta se projetará um oscilador controlado por tensão operando na banda ISM $2.4 \mathrm{GHz}$ numa tecnologia de quatro metais CMOS $0.35 \mu \mathrm{m}$. Para este fim é fundamental aproveitar a experiência adquirida num trabalho prévio onde se aplicou esta metodologia na automação e otimização de três topologias de amplificadores operacionais ${ }^{7}[15]$.

\subsection{Organização do documento}

O desenvolvimento do trabalho e os resultados obtidos estão organizados da seguinte maneira: O capítulo 2 revê conceitos e resultados básicos sobre a programação geométrica e sua aplicação no projeto de um amplificador fonte comum. A partir deste exemplo, são apresentadas as vantagens e limitações da metodologia no projeto de circuitos. No capítulo 3 a topologia do VCO junto com seus parâmetros de desempenho são apresentados. Assumindo que o ressoador pode ser modelado como uma rede RLC paralelo, o capítulo mostra que especificações de projeto como: condição de oscilação, amplitude, frequência de ressonância, faixa de sintonia, potência entre outros, podem ser levados como restrições de um programa geométrico. O capítulo 4 mostra que sobre algumas considerações, um modelo físico e escalável do indutor pode ser simplificado a uma rede RLC paralelo com os elementos do modelo sendo descritos por funções compatíveis com um programa geométrico. O capítulo 5 descreve em detalhe um projeto do VCO na banda ISM 2.45GHz. Considerações adicionais de projeto são apresentadas e formuladas como restrições do programa geométrico. Resultados de simulação, o layout do VCO e um protótipo fabricado são apresentados. Finalmente, conclusões gerais da dissertação e propostas para novos trabalhos são resumidas no capítulo 6 .

\footnotetext{
${ }^{6}$ Estritamente falando a programação geométrica só é convexa após uma serie de transformações matemáticas.

${ }^{7}$ Os resultados obtidos em testes experimentais motivaram a extensão da metodologia para circuitos de radio freqüência como é o oscilador.
} 


\section{Programação geométrica}

A programação geométrica é um tipo de problema de otimização matemática, onde a função objetivo e as restrições cumprem com algumas condições específicas. A programação geométrica e suas principais características definiram-se faz mais de 40 anos, contudo, a inexistência de algoritmos eficientes para sua solução impedia aplicá-la em problemas práticos. É interessante observar que algumas situações no campo da engenharia já eram formulados como um programa geométrico [5].

Sendo matematicamente rigoroso, um programa geométrico (PG) é um problema de otimização não convexo. No entanto, através de mudanças de variáveis e transformações das funções envolvidas, um PG pode virar um problema convexo e dessa forma aproveitar todas as vantagens e propriedades da otimização convexa. A otimização convexa tem três propriedades fundamentais:

- capacidade de encontrar o ótimo global da função objetivo sem necessidade de pontos iniciais,

- algoritmos eficientes com alta velocidade de convergência para a solução dos problemas, e

- capacidade de distinguir se o problema tem ou não solução.

Nesta seção se expõem os fundamentos e conceitos necessários para a formulação e posterior solução dos programas geométricos. Para uma apresentação formal consultar $[5,16]$.

\subsection{Monômios e posinômios}

Sejam $x_{1}, \ldots, x_{n} n$ variáveis reais e positivas, e seja $x=\left(x_{1}, \ldots, x_{n}\right)$ um vetor com componentes $x_{i}$. Uma função real $g(x)$ da forma: 


$$
g(x)=c x_{1}^{a_{1}} x_{2}^{a_{2}} \ldots x_{n}^{a_{n}}
$$

onde $c \geq 0$ e $a_{i}$ é qualquer número real, é chamada função monômio das variáveis $x_{1}, \ldots, x_{n}$. No monômio, $c$ é o coeficiente do monômio e os $a_{i}$ são conhecidos como expoentes do monômio.

Uma função formada pela soma de vários monômios, conhece-se como um posinômio. Então um posinômio tem a forma:

$$
f(x)=\sum_{k=1}^{K} c_{k} x_{1}^{a_{1}{ }_{k}} x_{2}^{a_{2}} \ldots x_{n}^{a_{n_{k}}}
$$

onde $c_{k}>0$; um posinômio de um termo é um monômio.

\subsection{Forma padrão de um PG}

Um programa geométrico é um problema de otimização da forma:

$$
\begin{array}{cl}
\operatorname{minimizar} & f_{0}(x) \\
\text { sujeito a } & f_{i}(x) \leq 1, \quad i=1, \ldots, m \\
& g_{i}(x)=1, \quad i=1, \ldots, p \\
& x \geq 0,
\end{array}
$$

chama-se $f_{0}$ a função objetivo, $f_{i}$ a função na desigualdade, e $g_{i}$ a função na igualdade. Num programa geométrico na forma padrão, as funções $f_{0}, \ldots, f_{m}$ são posinômios (2.2) e as funções $g_{1}, \ldots, g_{p}$ são monômios (2.1). Finalmente, a variável $x \in R^{n}$ tal que $x=\left(x_{1}, \ldots, x_{n}\right)$ é a variável de otimização. O domínio de um programa geométrico na forma padrão são os números reais positivos.

\subsubsection{A forma convexa de um PG}

O objetivo desta seção é mostrar como um programa geométrico na forma padrão é levado a um problema de otimização convexa. É importante lembrar que os algoritmos que permitem solucionar um PG de forma rápida e eficiente trabalham sobre o problema na forma convexa. Não obstante os solvers que implementam estes algoritmos recebem como entrada a descrição do PG em forma padrão e fazem a transformação à forma convexa internamente, ficando assim imperceptível para o usuário.

Caso para a variável de otimização $x \in R^{n}$ em (2.3) existe $y \in R^{n}$ da forma $y=\left(y_{1}, \ldots, y_{n}\right)$, 
tal que:

$$
\left(y_{1}, \ldots, y_{n}\right)=\left(\ln \left(x_{1}\right), \ldots, \ln \left(x_{n}\right)\right)
$$

e fazendo em (2.3) a substituição:

$$
\left(x_{1}, \ldots, x_{n}\right)=\left(e^{y_{1}}, \ldots, e^{y_{n}}\right)
$$

para depois tomar o logaritmo natural nas funções objetivo $f_{0}$, nas funções desigualdade $f_{i}$ e nas funções igualdade $g_{i}$, deriva-se o seguinte problema de otimização:

$$
\begin{array}{rlr}
\operatorname{minimizar} & \hat{f}_{0}(y)=\ln \left(\sum_{k=1}^{K_{0}} e^{a_{0_{k}}^{T} y+b_{0_{k}}}\right) & \\
\text { sujeito a } & \hat{f}_{i}(y)=\ln \left(\sum_{k=1}^{K_{i}} e^{a_{i_{k}}^{T} y+b_{i_{k}}}\right) \leq 0, & i=1, \ldots, m \\
& \hat{g}_{i}(y)=a_{i}^{T} y+\ln c_{i}=0, & i=1, \ldots, p
\end{array}
$$

em relação ao PG em forma padrão (2.3), tem-se para a função objetivo:

$$
\begin{gathered}
b_{0 k}=\ln \left(c_{0 k}\right) \\
k=1, \ldots, K_{0}
\end{gathered}
$$

para as funções nas desigualdades:

$$
\begin{gathered}
b_{i k}=\ln \left(c_{i k}\right) \\
k=1, \ldots, K_{i}
\end{gathered}
$$

onde os termos $a^{T} y$ representam o produto escalar entre $a$ e $y$, observando em (2.3) que $a \in R^{n}$. É possível demostrar que (2.4) é um problema de otimização convexa [5].

\subsection{Arimética entre posinômios e monômios}

Esta seção é importante porque mostra como levar restrições que poderiam aparecer no projeto de um circuito à forma padrão de um PG. Se $f(x)$ é um posinômio e $g(x)$ um monômio, a divisão $f(x) / g(x)$ é um posinômio. Desta forma, uma restrição do tipo:

$$
f(x) \leq g(x)
$$

pode ser escrita como:

$$
\frac{f(x)}{g(x)} \leq 1
$$

sendo ainda compatível com um PG na forma padrão (mesmo no caso que a função $g$ seja uma constante positiva). De forma equivalente, a divisão de dois monômios $g_{1}(x)$ e $g_{2}(x)$ é um 
monômio, então a restrição:

$$
g_{1}(x)=g_{2}(x)
$$

pode ser escrita como:

$$
\frac{g_{1}(x)}{g_{2}(x)}=1
$$

sendo compatível com a forma padrão de um PG. De outro lado, a divisão de um monômio $g(x)$ entre um posinômio $f(x)$ é conhecido como um posinômio inverso, e uma restrição da forma:

$$
\frac{g(x)}{f(x)} \leq 1
$$

não pode ser parte de um PG na forma padrão. Por último, a análise anterior pode ser estendida à multiplicação entre monômios, posinômios e monômios-posinômios. Lembrando, num PG na forma padrão (2.3) as restrições na igualdade só podem ser monômios, e as restrições na desigualdade só podem ser posinômios ou monômios.

\subsection{Solução de um programa geométrico}

A solução de um programa geométrico está baseada em algoritmos eficientes projetados para a solução de problemas de otimização convexa. Na atualidade existem diferentes empresas de software e grupos de pesquisa que põem a disposição ferramentas para a solução de PGs. O processo de transformação de um PG para um problema convexo pode parecer uma tarefa tediosa, mas felizmente esta tarefa é feita automaticamente de maneira que a entrada de dados para o otimizador é feita diretamente a partir do PG em forma padrão. A continuação se expõem dois pacotes de software que podem ser usados na solução de um programa geométrico.

\section{MOSEK}

Este pacote está projetado para solucionar problemas de otimização de grande escala [6]. Temse disponíveis student-licenses de 90 dias com a possibilidade de renovação. O coração do solver está baseado num avançado algoritmo de ponto interior [17]. É possível usar MOSEK através de bibliotecas em aplicações: C/C++, Fortran, Python, MATLAB (versions R2006a, R2006b, and R2007a), Java, .NET.

\section{CVX}

Pacote GNU (general public license) baseado em Matlab para a solução de problemas convexos $[7,8,9]$. CVX torna Matlab numa linguagem de modelagem para otimização convexa, assim é 


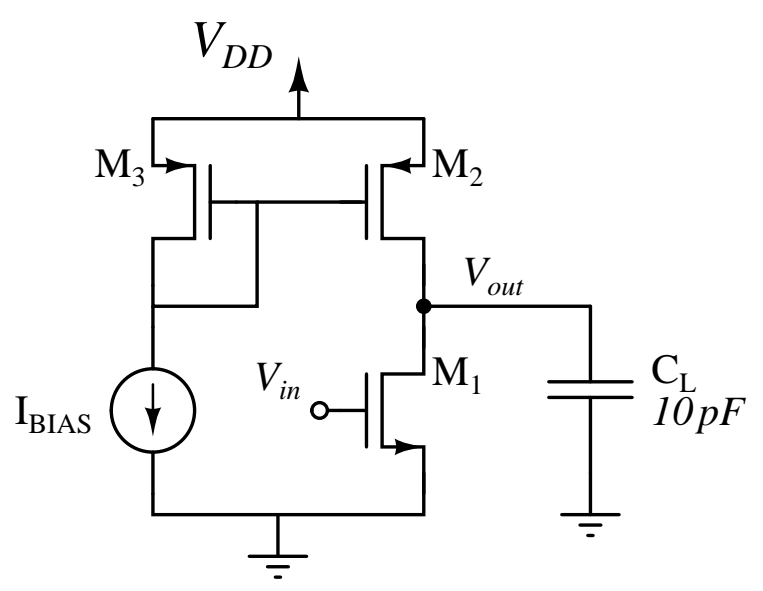

Figura 2.1: Esquemático do amplificador fonte comum com carga ativa.

possível representar restrições e funções objetivos através de expressões de Matlab. Este pacote está em contínuo desenvolvimento, tendo até esta data a versão 1.2.

\subsection{Aplicação da programação geométrica no projeto de um amplificador fonte comum}

Nesta seção mostra-se um exemplo simples da aplicação da programação geométrica no projeto de um circuito, neste caso selecionou-se o amplificador fonte comum da figura 2.1. Quando se quer formular o projeto de um circuito como um problema de optimização, escolhe-se minimizar (ou maximizar) um parâmetro de desempenho do circuito, por exemplo a potência dissipada, expressando as especificações de projeto (largura de banda, ganho) como restrições a serem cumpridas. Como caso particular, modela-se o projeto do amplificador como um problema de otimização que: minimizará a potência dissipada sujeito a um ganho $\left(A_{v}\right)$ e largura de banda $(B W)$ mínimos:

minimizar Potência dissipada

$$
\begin{aligned}
& \text { sujeito a }\left|A_{v}\right| \geq\left|A_{v, \text { min }}\right| \\
& B W \geq B W_{\text {min }}
\end{aligned}
$$




\subsubsection{Parâmetros de desempenho do circuito}

Os parâmetros de desempenho de um circuito são medidas que caracterizam o funcionamento de um circuito. No problema (2.5) a função a minimizar (ou função objetivo) é a potência dissipada, e a partir de especificações mínimas no ganho e largura de banda se derivam duas restrições de desigualdade. Fazendo o paralelo com a forma padrão de um PG (2.3), tem-se que as funções nas desigualdades, neste caso $\left|A_{v, \min }\right| /\left|A_{v}\right|$ e $B W_{\min } / B W$, devem ser posinômios ou monômio das variáveis de projeto. Dependendo da forma matemática destas funções uma determinada restrição não poderia fazer parte do PG.

\section{Potência:}

A potência dissipada depende das correntes $I_{B I A S}$ e $I_{M 2}$ :

$$
P=\left(I_{B I A S}+I_{M 2}\right) V_{D D}
$$

sendo $I_{B I A S}$ a corrente de referência na figura 2.1, $I_{M 2}$ a corrente pelo transistor $M_{2}$ e $V_{D D}$ a tensão de alimentação. A partir de (2.2) observa-se que a potência é um posinômio em função das variáveis de projeto $I_{B I A S}$ e $I_{M 2}$. Neste exemplo $V_{D D}=3 \mathrm{~V}$.

\section{Ganho DC:}

O ganho deste circuito está determinado por:

$$
\left|A_{v}\right|=\frac{g_{m 1}}{g_{d s_{1}}+g_{d s_{2}}}
$$

sendo $g_{m 1}$ a transcondutância do transistor $M_{1}, g_{d s_{1}}$ e $g_{d s_{2}}$ a condutância de saida dos transistores $M_{1}$ e $M_{2}$ respectivamente. Para uma restrição do ganho mínimo se tem:

$$
\frac{\left|A_{v, \text { min }}\right|}{\left|A_{v}\right|}=\frac{\left(g_{d s_{1}}+g_{d s_{2}}\right)}{g_{m 1}}\left|A_{v, \text { min }}\right| \leq 1
$$

\section{Largura de banda:}

Considerando o valor da capacitância de carga $C_{L}$, o pólo associado no nó de saída é dominante. Assim, a frequência de $-3 \mathrm{~dB}^{1}$ é:

$$
\omega_{p}=\frac{g_{d 1}+g_{d 2}}{C_{L}}
$$

\footnotetext{
${ }^{1}$ Frequência angular para a qual o ganho cai à metade.
} 
Para uma especificação de largura de banda mínima, tem-se:

$$
\frac{\omega_{p, \min }}{\omega}=\frac{C_{L}}{g_{d 1}+g_{d 2}} \omega_{p, \min } \leq 1
$$

Uma forma alternativa de considerar a largura de banda é usar a expressão do produto "ganho largura de banda" (GBW). A partir de (2.7) e (2.9):

$$
G B W=\frac{g_{m 1}}{C_{L}}
$$

para uma especificação de $G B W_{\min }$ se tem:

$$
\frac{C_{L}}{g_{m_{1}}} G B W_{\min } \leq 1
$$

\section{Polarização e outras considerações}

No amplificador fonte comum as características de pequenos sinais dependem do ponto de polarização, daí a importância de descrever adequadamente a polarização do circuito. A partir da figura (2.1) se deriva:

$$
\begin{aligned}
V_{G S_{3}} & =V_{G S_{2}} \\
V_{D S_{1}} & =V_{D S_{2}}=1.5 \mathrm{~V} \\
\frac{I_{B I A S}}{\left(\frac{W}{L}\right)_{3}} & =\frac{I_{M 2}}{\left(\frac{W}{L}\right)_{2}} \\
L_{2} & =L_{3} \\
I_{B I A S} & \geq 1 \mu \mathrm{A}
\end{aligned}
$$

sendo $V_{G S_{2,3}}$ a tensão porta-fonte dos transistores $M_{2,3} ; V_{D S_{1,2}}$ a tensão dreno-fonte dos transis-

tores $M_{1,2} ;\left(\frac{W}{L}\right)_{3,2}$ representa a relação largura a comprimento de canal dos transistores $M_{2,3}$. Finalmente, impõem-se algumas restrições na geometria:

$$
\begin{array}{lr}
W_{1,2,3} \geq 0.6 \mu \mathrm{m} & L_{1,2,3} \geq 0.3 \mu \mathrm{m} \\
W_{1,2,3} \leq 500 \mu \mathrm{m} & L_{1,2,3} \leq 10 \mu \mathrm{m}
\end{array}
$$

\subsubsection{Modelos do transistor}

Como se mostrou na seção 2.2, para que o problema de otimização derivado do projeto do amplificador fonte comum (2.5) seja um programa geométrico, as funções do lado esquerdo das restrições (2.8), (2.10) e (2.11) devem ser posinômios (ou monômios). Os parâmetros do 


\begin{tabular}{cc}
\hline Parâmetro & Especificação \\
\hline Potência [W] & Minimizar \\
Ganho [V/V] & $\geq 100$ \\
Freq. ganho unitário [Mrad/s] & $\geq 100$ \\
\hline
\end{tabular}

Tabela 2.1: Especificações.

transistor como $g_{m}$ ou $g_{d s}$ dependem da geometria e da polarização, e a relação exata desta dependência está determinada pelo modelo usado do transistor. Por exemplo, na restrição de ganho mínimo (2.8) o modelo do transistor deve garantir que o termo:

$$
\frac{g_{d s_{1}}+g_{d s_{2}}}{g_{m 1}}
$$

seja um posinômio em função das variáveis de projeto (dimensões e a polarização dos transistores). De forma equivalente, a restrição de largura de banda mínima (2.10) requer que o termo:

$$
\frac{1}{g_{d s_{1}}+g_{d s_{2}}}
$$

seja um posinômio.

Observando detidamente os fatores (2.14) e (2.15) percebe-se que os dois não podem ser posinômios; quando um deles é posinômio o outro será um posinômio inverso e, de acordo com a seção 2.3, só uma das restrições (2.8), (2.10) poderá ser parte de um PG. Desta perspectiva a única solução é que o fator (2.15) seja um monômio, não obstante esta consideração carece de sentido físico e qualquer aproximação a um modelo desse tipo traria consigo muitos erros. Por outro lado, se o fator (2.14) é um posinômio tanto (2.8) como (2.11) cumprem com os requerimentos de um $\mathrm{PG}$, e dessa maneira é possível considerar uma especificação mínima para o ganho e a largura de banda (de forma indireta) dentro do programa geométrico.

A partir da análise anterior é possível identificar duas limitações da aplicação da programação geométrica no projeto de circuitos:

- A forma matemática do modelo do transistor (relação corrente-tensão) e seus parâmetros $\left(g_{m}, g_{d s}\right.$, etc) devem ser compatível com a forma matemática das funções da programação geométrica: monômios e posinômios.

- Mesmo que os parâmetros do transistor possam ter uma forma matemática adequada, a forma algébrica como esses parâmetros aparecem nas restrições pode fazer com que uma restrição não possa ser levada a um PG. 


\begin{tabular}{|c|c|c|c|c|}
\hline Modelo & Erro & Tempo & Otimização & Solver (Disponibilidade) \\
\hline Monômio & Alto* & Muito baixo & LP & Alta \\
\hline Posinômio & Baixo* & Alto & NLP & Baixo \\
\hline$p w l_{-j i n}$ & Baixo* & Muito Alto & C-QP & Alta \\
\hline pwl_ale & Baixo* & Médio & UC-QP & Alta \\
\hline
\end{tabular}

*Sujeito ao comportamento convexo do logaritmo dos dados.

Tabela 2.2: Comparação entre os diferentes tipos de modelo.

As implicações destas características são significativas. Por exemplo, a consideração sobre a forma matemática do modelo do transistor e seus parâmetros é uma condição difícil de cumprir, sobre tudo para modelos compactos do transistor ${ }^{2}$ que consideram efeitos de canal curto, degradação da mobilidade, etc; o modelo BSIM [18] é um claro exemplo. Varias estratégias tem surgido na literatura recente para tratar essas limitações:

- Programas geométrico reversos [19]: A idéia básica desta proposta é permitir funções signômios $^{3}$ nas restrições desigualdade, permitindo assim que posinômios apareçam nas igualdade. O problema de otimização resultante não pode ser levado a um problema convexo e conseqüentemente a solução deste tipo de problemas está limitado ao uso de algoritmos especializados que poderiam demandar maior tempo na solução do problema. As vantagens dessa técnica é que permite por exemplo incorporar modelos do transistor operando em inversão fraca e inversão forte, cobrindo um espaço de projeto maior.

- Forçar o transistor a operar numa região de operação e usar modelos do transistor (físicos ou ajustados numericamente) para essa região [15]: Em trabalhos prévios se mostrou que trabalhando numa região especifica o modelo do transistor tem um comportamento que pode ser descrito com monômios. Não obstante, ao ignorar outras regiões de trabalho limita-se o espaço de projeto, tendo que o projeto ótimo alcançado poderia estar sobredimensionado, ou o ótimo global encontrado ser realmente um ótimo local.

Neste trabalho foi aplicada a segunda opção. A partir de técnicas numéricas obtiveramse modelos para transistores na região de saturação, em inversão forte. É por isso que uma parte fundamental da metodologia aplicada neste trabalho consiste em modelar os parâmetros do transistor $\left(g_{m}, g_{d s}\right.$, etc.) com funções compatíveis com a programação geométrica.

\footnotetext{
${ }^{2}$ Estes modelos descrevem o comportamento do transistor nas possíveis regiões de operação (saturação/linear) de acordo com o nível de inversão de carga no canal: sub-limiar, inversão fraca e inversão forte

${ }^{3}$ Um signômio pode ser definido como um posinômio que pode ter coeficientes negativos.
} 


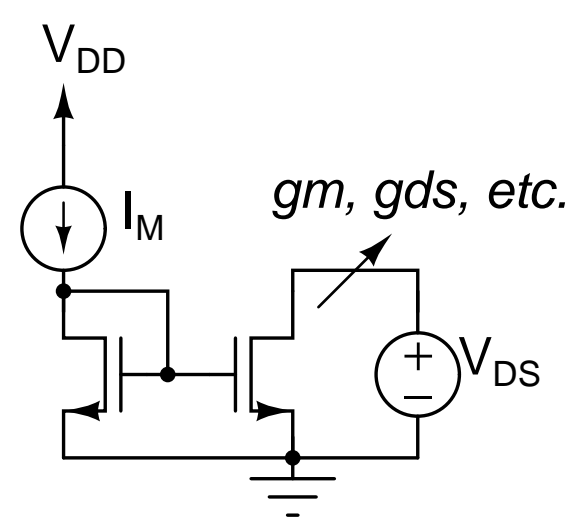

Figura 2.2: Circuito para a modelagem do transistor NMOS.

\subsubsection{Modelos do transistor compatíveis num programa geométrico}

O processo de modelagem consiste em aplicar técnicas numéricas para ajustar uma função a valores de parâmetros do transistor obtidos por simulação. Estudaram-se três tipos de funções que são compatíveis com programas geométricos: monômios (2.1), posinômios (2.2) e funções máximo de monômios (max_monômios) [16, 20, 21]. Para um determinado parâmetro do transistor, a modelagem com uma função max monômio pode ser feita sempre e quando um modelo posinomial também possa ser ser usado; o procedimento para usar um modelo max_monômio dentro de um programa geométrico padrão está descrito em [16]. Como se observou no caso do amplificador fonte comum, dependendo das restrições um parâmetro do transistor $\left(g_{m}, g_{d s}\right.$, etc) vai requerer um modelo específico. Por exemplo as três opções para modelar $g_{d s}$ seriam:

- monômio

$$
g_{d s}\left(W, L, V_{D S}, I\right)=c W^{\alpha 1} L^{\alpha_{2}} V_{D S}^{\alpha_{3}} I^{\alpha_{4}}
$$

- posinômio

$$
g_{d s}\left(W, L, V_{D S}, I\right)=\sum_{k=1}^{K} c_{k} W^{\alpha_{1, k}} L^{\alpha_{2, k}} V_{D S}^{\alpha_{3, k}} I^{\alpha_{4, k}}
$$

- max_monômio

$$
g_{d s}\left(W, L, V_{D S}, I\right)=\max _{1 \ldots K}\left\{c_{k} W^{\alpha_{1, k}} L^{\alpha_{2, k}} V_{D S}^{\alpha_{3, k}} I^{\alpha_{4, k}}\right\}
$$

O valor de cada coeficiente e expoente nas expressões anteriores são escolhidos de forma a minimizar algum critério de erro; por exemplo o erro quadrático médio. $\mathrm{O}$ ajuste de funções tipo monômio pode ser formulado como um problema de otimização linear (LP) quando é tomado o logaritmo dos dados. Sendo a otimização linear um subconjunto da optimização convexa, o tempo que leva a obtenção de um modelos monomiais é pouco. No caso de ajuste de funções posinomiais o ajuste vira num problema de otimização não-linear e não-convexa (NLP), o tempo 
que leva gerar modelos deste tipo é alto.

No caso de funções max_monômios estudaram-se dois tipos de técnicas diferentes, cada uma delas descrita em $[20,21]$. Nas duas técnicas se solucionam de forma iterativa problemas de otimização quadrática (QP, quadratic programming). No caso de [20] os problemas de otimização não tem restrições (UC-QP, unconstrained quadratic programming). Os problemas de otimização a resolver no algoritmo proposto em [21] tem um número alto de restrições que incrementa com o número de iteração (C-QP, constrained quadratic programming). Observouse que a técnica proposta em [20] teve melhor desempenho em termos de tempo-erro na geração dos modelos max_monômios. A tabela 2.2 mostra uma comparação entre os diferentes tipos de modelos estudados. Os modelos gerados a partir de [20] pwl_ale e a partir de [21] são chamados $p w l_{\text {jin }}$. Os dados usados na geração dos modelos foram obtidos a partir de simulações usando o modelo BSIM3v3 da tecnologia AMS $0.35 \mu \mathrm{m}$ de transistores em saturação. A figura 2.2 mostra o tipo de circuito usado para a geração dos dados. Como exemplo dos modelos obtidos, a figura 2.3 mostra a curva de $I_{D S}$ em função de $V_{D S}$ usando o modelo monomial:

$$
V_{G S_{f i t}}=5.0722 I^{0.2177} V_{D S}{ }^{-0.018} W^{-0.2171} L^{0.155}
$$

O modelo foi gerado sob 9600 pontos na seguinte região:

$$
\begin{aligned}
0.7 \mathrm{~V} & \leq V_{G S} \leq 1.3 \mathrm{~V} \\
V_{G S}-V_{T} & \leq V_{D S} \leq 1.5 \mathrm{~V} \\
1 \mu \mathrm{m} & \leq W \leq 20 \mu \mathrm{m} \\
0.35 \mu \mathrm{m} & \leq L \leq 2 \mu \mathrm{m}
\end{aligned}
$$

sendo $V_{T}$ a tensão de limiar, e de acordo as especificações da tecnologia, o valor típico é 0.5 e 0.65 para o transistor NMOS e PMOS respectivamente. O tempo para gerar o modelo (2.19) foi de uns poucos segundos.

Especificamente, para o projeto do amplificador fonte comum foram gerados modelos tipo pwl_ale para $\frac{1}{g_{m 1}}, g_{d s_{1}}, g_{d s_{2}}$ e modelos tipo monômio para $V_{G S_{1}}, V_{G S_{2}}$ e $V_{G S_{3}}$. Para ter maior precisão, no modelo de $V_{G S_{3}}$ considerou-se um transistor com $V_{G S}=V_{D S}$. Os resultados obtidos foram:

$$
\begin{aligned}
& V_{G S_{1}}=3.88 I_{M 2}{ }^{0.17} V_{D S_{1}}{ }^{0.55} W_{1}^{-0.17} L_{1}^{0.15} \\
& V_{G S_{2}}=4.83 I_{M 2}{ }^{0.14} V_{D S_{1}}{ }^{0.64} W_{2}^{-0.15} L_{2}^{0.15} \\
& V_{G S_{3}}=5.01 I_{B I A S}{ }^{0.14} W_{3}{ }^{-0.14} L_{3}^{0.13}
\end{aligned}
$$




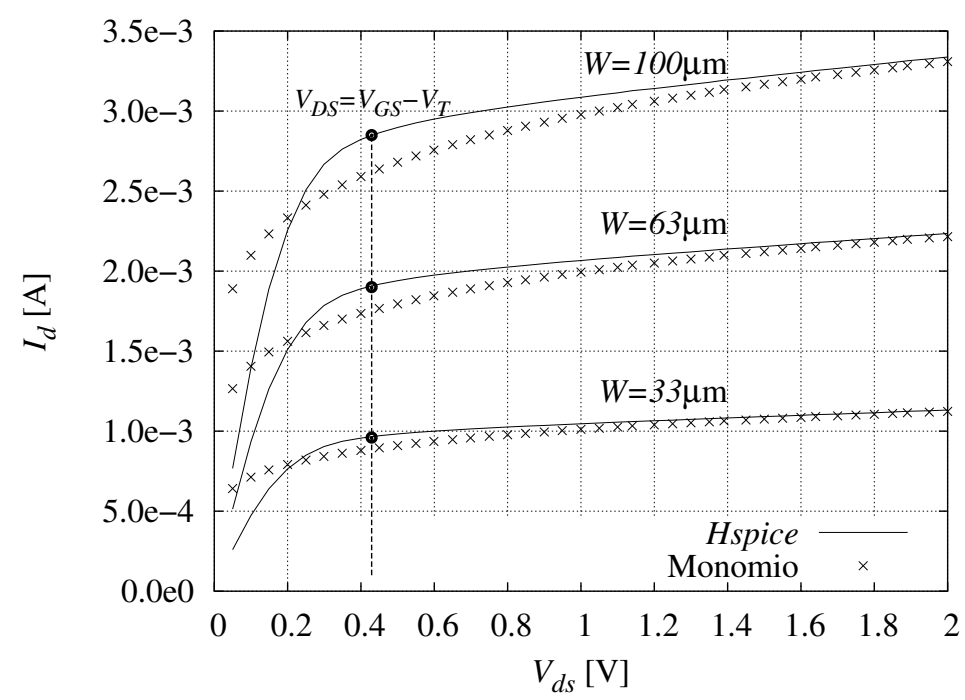

Figura 2.3: Corrente de dreno Vs tensão dreno-fonte para diferentes valores de largura do transistor.

$$
\begin{aligned}
g_{m_{1}}^{-1}=\max \left\{97.44 I_{M 2}^{-0.37} W_{1}^{-0.63} L_{1}^{0.55},\right. & \left.15.77 I_{M 2}^{-0.44} W_{1}^{-0.57} L^{0.57}\right\} \\
g_{d s_{1}}=\max \{ & 3.51 e-8 I_{M 2}^{9.34 e-1} V_{D S_{1}}^{-1.11} W_{1}^{6.77 e-2} L_{1}^{-9.82 e-1}, \\
& 1.11 e-5 I_{M 2}^{6.99 e-1} V_{D S_{1}}^{-3.35 e-1} W_{1}^{3.08 e-1} L_{1}^{-5.79 e-1}, \\
& 1.05 e-5 I_{M 2}^{8.820 e-1} V_{D S_{1}}^{-9.44 e-1} W_{1}^{1.220 e-1} L_{1}^{-5.73 e-1}, \\
& 2.53 e-15 I_{M 2}^{6.88 e-1} V_{D S_{1}}^{-2.24 e-1} W_{1}^{3.18 e-1} L_{1}^{-2.17}, \\
& 2.37 e-13 I_{M 2}^{8.09 e-1} V_{D S_{1}}^{-7.47 e-1} W_{1}^{1.96 e-1} L_{1}^{-1.85}, \\
& \left.3.25 e-09 I_{M 2}^{7.16 e-1} V_{D S_{1}}^{-4.34 e-1} W_{1}^{2.91 e-1} L_{1}^{-1.17}\right\} \\
g_{d s_{2}}=\max \left\{5.87 e-5 I_{M 2}^{1.41} V_{D S_{1}}^{-1.82} W_{2}^{-4.03 e-1} L_{2}^{-4.33 e-1},\right. & 2.39 e-7 I_{M 2}^{1.08} V_{D S_{1}}^{-6.91 e-1} W_{2}^{-7.648 e-2} L_{2}^{-8.85 e-1}, \\
& 7.07 e-1 I_{M 2}^{1.57} V_{D S_{1}}^{-2.56} W_{2}^{-5.35 e-1} L_{2}^{2.92 e-1}, \\
& 1.81 e-15 I_{M 2}^{7.29 e-1} V_{D S_{1}}^{-2.67 e-1} W_{2}^{2.83 e-1} L_{2}^{-2.24}, \\
& \left.1.29 e-10 I_{M 2}^{9.61 e-1} V_{D S_{1}}^{-5.34 e-1} W_{2}^{3.93 e-2} L_{2}^{-1.44}\right\}
\end{aligned}
$$

\subsubsection{Formulação do programa geométrico}

Neste exemplo procura-se minimizar a potência DC do circuito sujeito a especificações de ganho mínimo e GBW mínimo. A partir de (2.8), (2.11), (2.12), (2.13) e os modelos em (2.21)- 
(2.24), deriva-se o seguinte programa geométrico:

$$
\begin{aligned}
& \text { minimizar } \quad V_{D D}\left(I_{M 2}+I_{B I A S}\right) \\
& \text { sujeito a } \quad \frac{\left(g_{d s_{1}}+g_{d s_{2}}\right)\left|A_{v, \text { min }}\right|}{g_{m 1}} \leq 1 \\
& \frac{C_{L} G B W_{\min }}{g_{m_{1}}} \leq 1 \\
& \frac{V_{G S_{3}}}{V_{G S_{2}}}=1 \\
& 3.88 I_{M 2}{ }^{0.17} V_{D S_{1}}{ }^{0.55} W_{1}^{-0.17} L_{1}^{0.15}=V_{G S_{1}} \\
& \frac{I_{B I A S}}{I_{M 2}} \frac{\left(\frac{W}{L}\right)_{2}}{\left(\frac{W}{L}\right)_{3}}=1 \\
& \frac{L_{2}}{L_{3}}=1 \\
& 1 *\left(10^{-6}\right) I_{B I A S}^{-1} \leq 1 \\
& 0.6 *\left(10^{-6}\right) W_{1,2,3}^{-1} \leq 1 \\
& 0.3 *\left(10^{-6}\right) L_{1,2,3}^{-1} \leq 1 \\
& 2 *\left(10^{3}\right) W_{1,2,3} \leq 1 \\
& 1 *\left(10^{5}\right) L_{1,2,3} \leq 1
\end{aligned}
$$

\subsubsection{Resultados}

A continuação se mostram os resultados obtidos com a solução de 2.25 para as especificações da tabela 2.1. O programa geométrico resultante foi implementado em MOSEK. As variáveis ótimas obtidas são apresentadas na tabela 2.3. O desempenho do circuito usando as variáveis ótimas é verificado mediante simulação com $\mathrm{HSPICE}^{4}$; os resultados são apresentados na tabela 2.4. Na última fila da tabela observa-se um discrepância significativa na tensão DC de saída, $V_{O U T}$. Este erro pode estar relacionado a alta resistência de saída dos transistores $M_{1}$ e $M_{2}$. Pe-

\footnotetext{
${ }^{4}$ Nestas simulações foram usados os modelos BSIM3v3 dos transistores fornecidos pela foundry.
} 


\begin{tabular}{cc}
\hline Variáveis & $\mathrm{PG}$ \\
\hline$I_{\text {BIAS }}$ & $1 \mu \mathrm{A}$ \\
$I_{M 1}$ & $104.831 \mu \mathrm{A}$ \\
$V g s_{1}$ & $750 \mathrm{mV}$ \\
$V g s_{2}$ & $959.723 \mathrm{mV}$ \\
$V g s_{3}$ & $959.723 \mathrm{mV}$ \\
$W_{1}$ & $17.846 \mu \mathrm{m}$ \\
$W_{2}$ & $100 \mu \mathrm{m}$ \\
$W_{3}$ & $1.209 \mu \mathrm{m}$ \\
$L_{1}$ & $0.484 \mu \mathrm{m}$ \\
$L_{2}$ & $2 \mu \mathrm{m}$ \\
$L_{3}$ & $2 \mu \mathrm{m}$ \\
\hline
\end{tabular}

Tabela 2.3: Variáveis ótimas.

\begin{tabular}{ccccc}
\hline Parâmetros do circuito & Espec. & PG & Hspice (nível 49) & Erro \\
\hline Potência $[\mu \mathrm{W}]$ & Minimizar & 317.4943 & 331.3908 & $4.19 \%$ \\
Ganho $[\mathrm{V} / \mathrm{V}]$ & $\geq 100$ & 100 & 100.7525 & $0.75 \%$ \\
GBW $[\mathrm{Mrad} / \mathrm{s}]$ & $\geq 100$ & 104.47 & 104.47 & $4.28 \%$ \\
V & 1.5 & 1.5 & 2.2243 & $32.56 \%$ \\
\hline
\end{tabular}

Tabela 2.4: Desempenho do circuito.

quenas discrepâncias na estimação da corrente podem levar a altos erros nas tensões DC em nós de alta resistência. As conseqüência deste comportamento são significativas já que poderiam mudar a região de trabalho dos transistores, que inicialmente foram modelados para trabalhar em saturação. É importante reconhecer para cada circuito como solucionar esta situação. No caso particular do amplificador fonte comum, modificando a tensão DC de entrada $V_{I N}$, ajustouse a tensão de saida para $1.5 \mathrm{~V}$. Os valores reportados para consumo de potência, ganho e GBW na tabela 2.3 foram medidos quando $V_{O U T}=1.5 \mathrm{~V}$. 


\section{Projeto de um VCO como um programa geométrico}

No capítulo anterior mostrou-se como o projeto de um amplificador fonte comum pode ser formulado como um programa geométrico. Da mesma forma, este capítulo descreve como o projeto de um VCO pode ser formulado como um programa geométrico [14, 22]. A diferença do amplificador fonte comum, o VCO além de dispositivos ativos (transistores) tem dispositivos passivos que cumprem um papel importante no desempenho do VCO. É fundamental que os modelos elétricos destes dispositivos também possam ser descritos com funções compatíveis com um PG (monômios e posinômios)

\subsection{Oscilador diferencial LC complementar}

A figura 3.1 mostra a topologia do VCO usada neste trabalho. Esta arquitetura conta com grande aceitação devido ao bom desempenho que apresenta em termos consumo de potência e pureza espectral do sinal gerado. Neste oscilador o ressoador corresponde ao circuito tanque formado pela conexão em paralelo de $C_{V}$ e $L$. Espera-se de um circuito tanque ideal que uma vez em ressonância seja capaz de manter-se oscilando indefinidamente, sendo que a magnitude da oscilação vai depender da carga total (energia) presente no circuito. Não obstante, implementações reais de indutores e capacitores apresentam perdas resistivas que dissiparão a energia do tanque e consequientemente as oscilações cessarão. Precisamente para evitar este efeito, os transistores dos pares cruzados $M_{n 1, n 2}$ e $M_{p 1, p 2}$, de acordo com a tensão em suas portas, permitirão o fluxo de energia desde a fonte de tensão até o circuito tanque, renovando assim a energia dissipada no ressoador periodicamente. Desta forma os transistores provêem de realimentação positiva ao circuito. Essa realimentação pode ser modelada como uma resistência negativa em paralelo com o ressoador que cancelará os efeitos resistivos do circuito, permitindo assim oscilações permanentes [23]. 


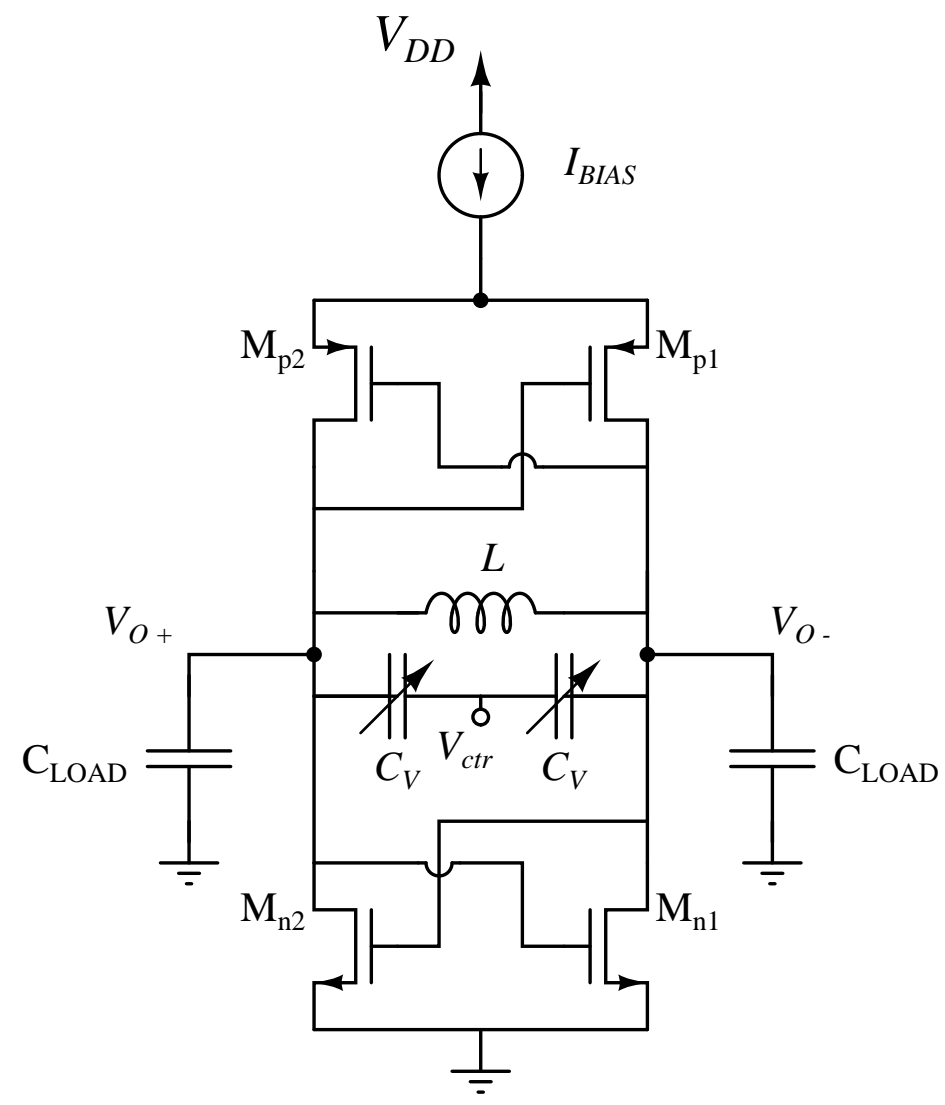

Figura 3.1: VCO LC diferencial complementar.

\subsection{Parâmetro de desempenho}

Nesta seção se mostrará como especificações mínimas (ou máximas) em parâmetros de desempenho de um VCO podem ser formuladas como restrições válidas num programa geométrico. Parâmetros como: condição de oscilação, potência, frequência de ressonância, sintonia, amplitude e ruído de fase foram revisados e suas expressões em função das variáveis de projeto apresentadas.

\subsubsection{Ressoador}

O desempenho de um VCO depende da qualidade do ressoador. Na busca de maior capacidade de integração implementações onchip do ressoador são desejáveis embora a qualidade possa ser menor em comparação a implementações offchip [24, 25]. Para uma faixa estreita de frequência o circuito tanque pode ser modelado como mostrado na figura 3.2. Como será apresentado no próximo capítulo, em virtude da implementação onchip do indutor, além de um efeito indutivo desejado se terá um efeito capacitivo e resistivo não desejados que definirão a qualidade do indutor. Estes efeitos podem ser modelados com uma resistência $R_{I N D}$ e uma capacitância 


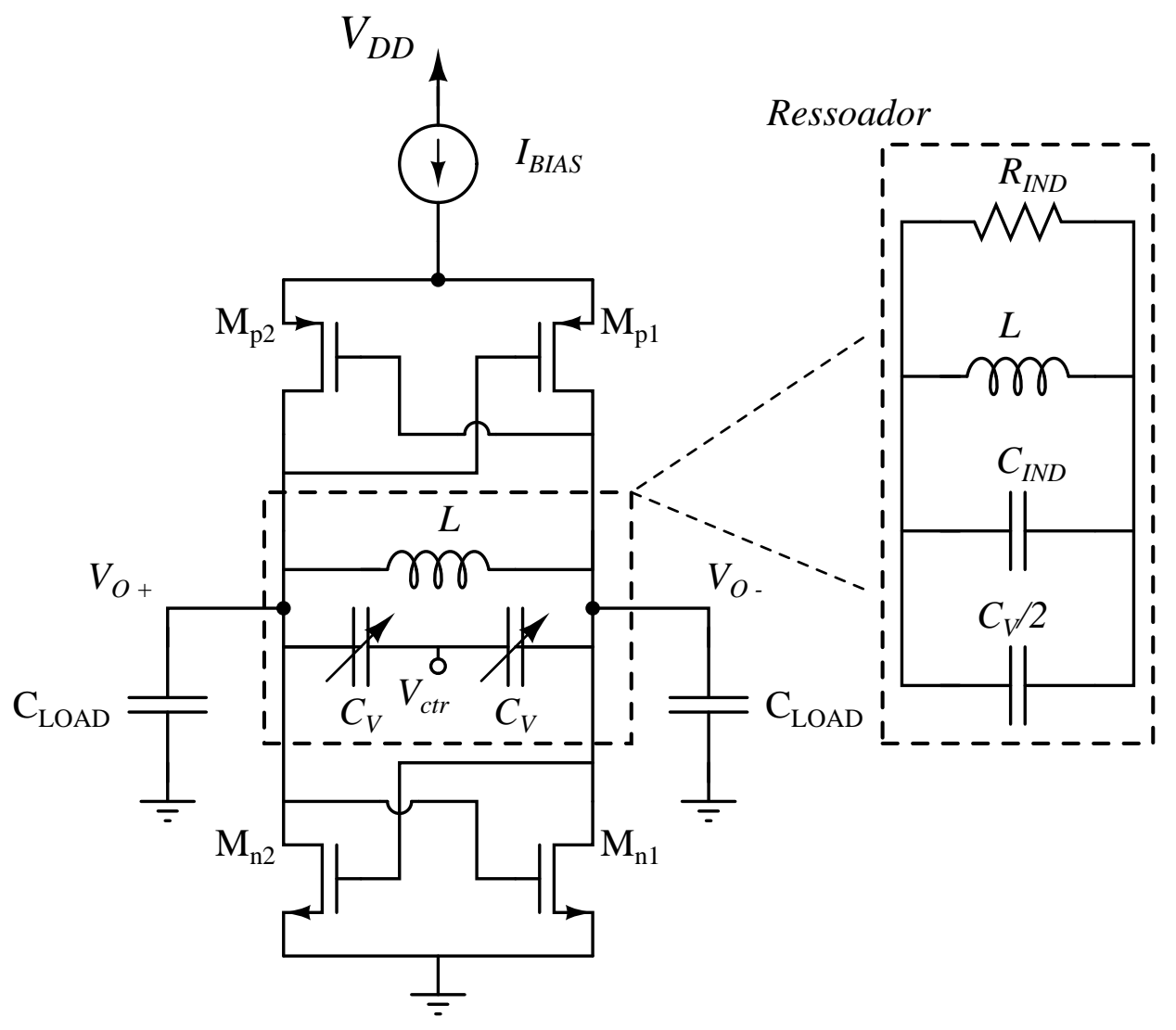

Figura 3.2: Esquemático do LC-VCO com modelo simplificado de banda estreita do ressoador. 


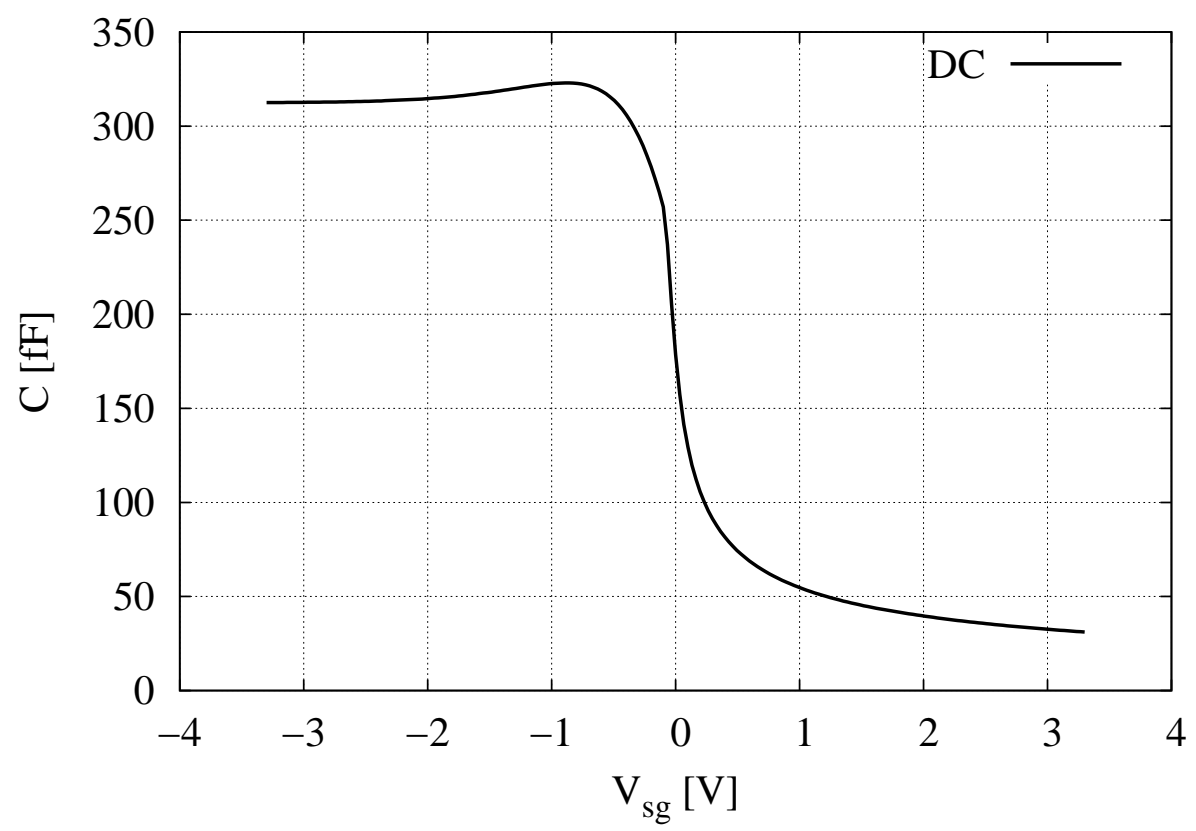

Figura 3.3: Capacitância no varactor PMOS de acumulação

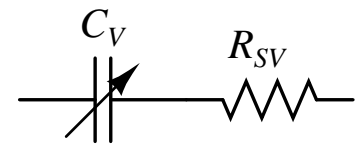

Figura 3.4: Modelo simplificado do varactor.

parasita $C_{I N D}$.

\subsubsection{Varactor}

A figura 3.3 mostra o valor de capacitância em função da tensão de controle do varactor PMOS de acumulação. Esta curva foi obtida a partir de simulações usando um modelo fornecido pela foundry para este tipo de varactor. Os valores de capacitância podem ser escalados com a área do dispositivo, no entanto a relação da capacitância máxima a capacitância mínima permanece constante. Em virtude do fator de qualidade deste varactor $(\sim 40)$, a contribuição da resistência série na resistência do ressoador não é significativa, e para efeitos de projeto pode ser ignorada.

\subsubsection{Modelo de pequenos sinais}

Ainda quando a oscilação na saída do VCO pode ir de alguns milivolts até $V_{D D}$ (rail-to-rail), no momento quando as oscilações vão começar o circuito trabalha com sinais pequenos e nestas 


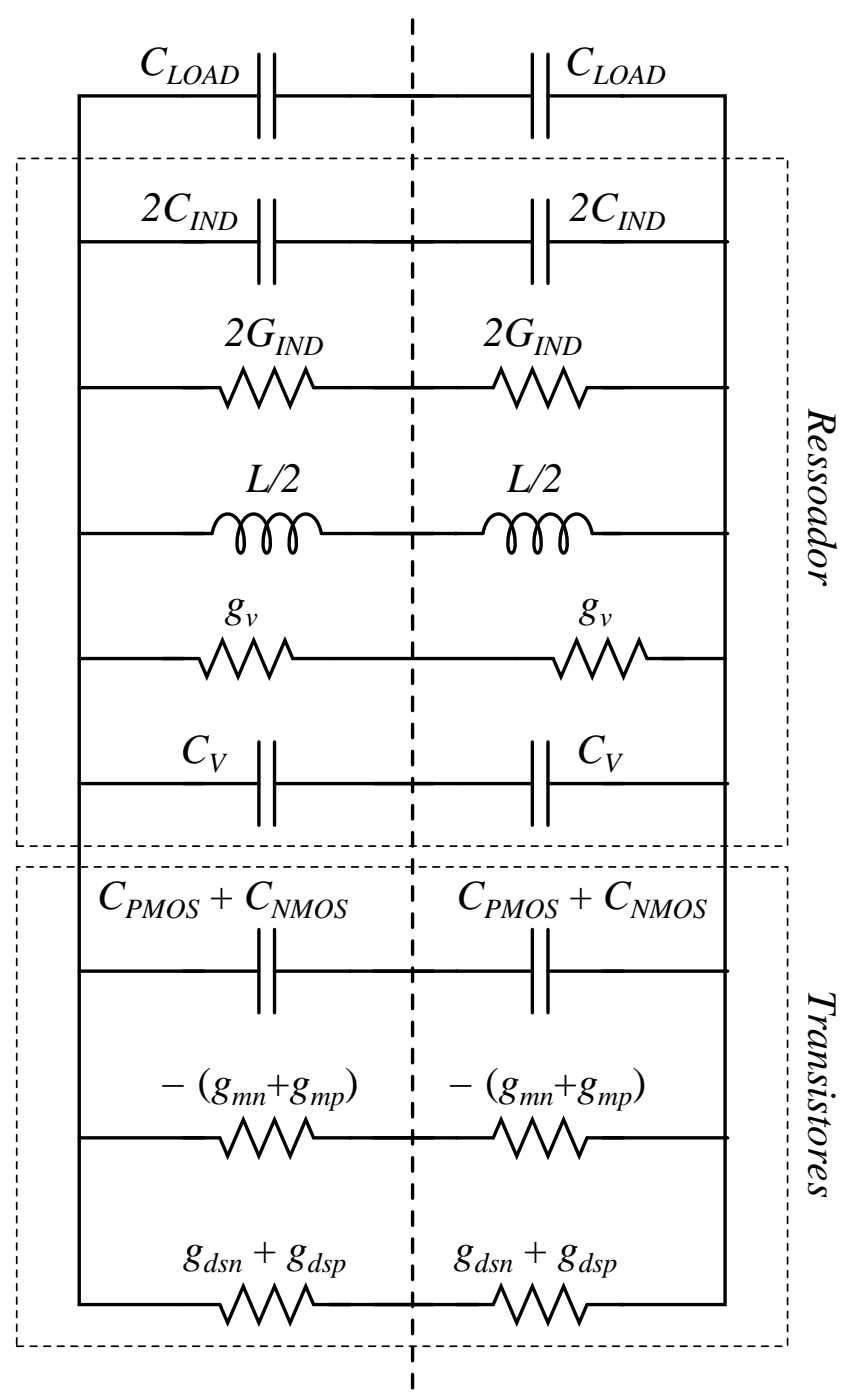

Figura 3.5: Modelo de pequenos sinais do VCO LC complementar

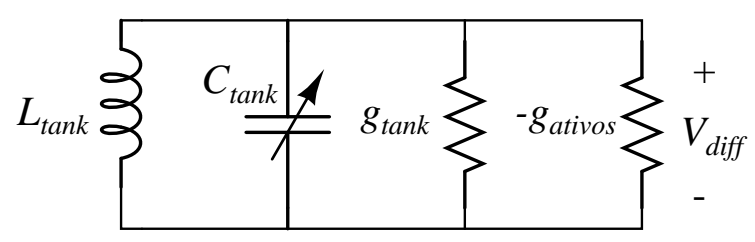

Figura 3.6: Modelo equivalente para o oscilador. 
condições um modelo de pequenos sinais é válido. A figura 3.5 mostra o modelo de pequenos sinais do VCO, destaca-se na figura o modelo do ressoador e dos transistores. O modelo de pequenos sinais do VCO pode ser simplificado ao circuito da figura $3.6 \mathrm{com}$ os elementos do modelo dados por:

$$
\begin{aligned}
2 g_{\text {tank }} & =g_{d s n}+g_{d s p}+g_{v}+2 G_{I N D} \\
2 g_{\text {ativos }} & =g_{m n}+g_{m p} \\
L_{\text {tank }} & =L \\
2 C_{\text {tank }} & =C_{N M O S}+C_{P M O S}+C_{V}+2 C_{I N D}+C_{L O A D}
\end{aligned}
$$

onde $g_{d s n}$ e $g_{d s p}$ representam a condutância de saída do transistor NMOS e PMOS respectivamente; da mesma forma $g_{m n}$ e $g_{m p}$ representam a transcondutância. $G_{I N D}, L, C_{I N D}$ e $C_{V}$ correspondem aos elementos do ressoador na figura 3.2. $g_{\text {tank }}$ corresponde as perdas totais do VCO; $g_{\text {ativos }}$ a condutância dos elementos ativos; e finalmente $L_{\text {tank }}$ e $C_{\text {tank }}$ corresponde a indutância e capacitância equivalente do VCO. As capacitâncias $C_{N M O S}$ e $C_{P M O S}$ correspondem às capacitâncias devidas ao par NMOS e PMOS respectivamente:

$$
\begin{aligned}
C_{N M O S} & =C_{g s, n}+C_{d b, n}+4 C_{g d, n} \\
C_{P M O S} & =C_{g s, p}+C_{d b, p}+4 C_{g d, p} \\
g_{v} & =\frac{C_{V} \omega}{Q_{V}}
\end{aligned}
$$

sendo $C_{g s}, C_{d b}$ e $C_{g d}$ as capacitâncias porta-fonte, dreno-corpo e porta-dreno do transistor. $Q_{V}$ é o fator de qualidade do varactor, e $g_{v}$ a condutância parasita em paralelo ao varactor. Se $C_{V}$ é uma variável de projeto e assumindo um fator de qualidade do varactor constante, a condutância $g_{\text {tank }}$ pode ser representada como um posinômio ${ }^{1}$ sempre que $G_{I N D}$ possa ser modelada com funções compatíveis num PG. Em relação à capacitância do tanque:

$$
C_{\text {tank }}=2 C_{g d, n}+\frac{1}{2} C_{g s, n}+\frac{1}{2} C_{d b, n}+2 C_{g d, p}+\frac{1}{2} C_{g s, p}+\frac{1}{2} C_{d b, p}+\frac{1}{2} C_{L O A D}+C_{I N D}+\frac{1}{2} C_{V}
$$

que pode ser representada como:

$$
C_{\text {tank }}=C_{\text {par }}+\frac{1}{2} C_{V}
$$

Se $C_{p a r}$ é posinômio, $C_{\text {tank }}$ será um posinômio também.

Uma representação equivalente do oscilador em função das expressões obtidas mostra-se na figura 3.6.

\footnotetext{
${ }^{1}$ No capítulo 2 se mostrou que o inverso da resistência de saída de um transistor pode ser modelado com um posinômio.
} 


\subsubsection{Condição de oscilação}

Da figura 3.6 se infere que para garantir oscilações no circuito, é preciso que a transcondutância dos elementos ativos $\left(g_{\text {ativos }}\right)$ seja maior que as perdas do circuito $\left(g_{\text {tank }}\right)$. Esta consideração se conhece como condição de oscilação:

$$
g_{\text {ativos }} \geq \alpha g_{\text {tank }}
$$

onde $\alpha$ é conhecido como fator de oscilação. Sendo $1 \leq \alpha \leq 3$ preciso para garantir oscilações no circuito. De acordo com [31], é possível minimizar o ruído de fase na região $1 / f^{3}$ quando a transconductância dos pares NMOS e PMOS são iguais, assim:

$$
g_{m n}=g_{m p}
$$

Sobre esta igualdade, temos que (3.5) pode ser levada a um programa geométrico pois seu lado direito tem forma posinomial.

\subsubsection{Frequência de ressonância}

A frequência de ressonância do circuito equivalente do oscilador na figura 3.6:

$$
\omega=\frac{1}{\sqrt{L C_{\text {tank }}}}
$$

\subsubsection{Faixa de sintonia}

Para garantir uma faixa de sintonia do VCO, a partir de (3.7) e (3.1):

$$
\begin{aligned}
& L\left(C_{\text {tank }, \min }\right) \leq 1 / \omega_{\max }^{2} \\
& L\left(C_{\text {tank,max }}\right) \geq 1 / \omega_{\min }^{2}
\end{aligned}
$$

de acordo com (3.4) se tem:

$$
\begin{aligned}
& L\left(C_{\text {par }}+\frac{1}{2} C_{V \min }\right) \leq \frac{1}{\omega_{\max }^{2}} \\
& L\left(C_{\text {par }}+\frac{1}{2} C_{V \max }\right) \geq \frac{1}{\omega_{\min }^{2}}
\end{aligned}
$$


assumindo que (3.9) sempre se cumpre em igualdade então (3.10) pode ser expressa como [14]:

$$
\begin{gathered}
L\left(C_{\text {par }}+\frac{1}{2} C_{V \min }\right) \omega_{\text {max }}^{2} \geq L_{\text {tank }}\left(C_{\text {par }}+\frac{1}{2} C_{V \max }\right) \omega_{\text {min }}^{2} \\
2(R-1) \frac{C_{\text {par }}}{C_{V \max }}+R \frac{C_{V \min }}{C_{V \max }} \leq 1
\end{gathered}
$$

para

$$
R=\frac{\omega_{\max }^{2}}{\omega_{\min }^{2}}
$$

dessa forma o lado esquerdo das restrições (3.9) e (3.11) tem forma posinomial, sendo a capacitância do varactor divida em duas variáveis de projeto, $C_{V \max }$ e $C_{V \min }$ que devem cumprir a seguinte restrição:

$$
\frac{C_{V \max }}{C_{V \min }} \leq \max C \text { vratio }
$$

onde maxCvratio é uma constante da tecnologia.

\subsubsection{Amplitude}

Considerando o comportamento oscilante da tensão nas portas dos transistores, tem-se que num período do sinal a corrente vai de um dos transistores $\mathrm{P}$ até um dos transistores $\mathrm{N}$ passando pelo ressoador. Este comportamento pode ser modelado (assumindo o transistor como uma chave) como uma onda quadrada de corrente de valor pico $I_{B I A S}$ em paralelo com o ressoador, tal como se mostra na figura 3.7. A partir do modelo, a amplitude do VCO é [26]:

$$
A_{d}=\frac{4 I_{B I A S}}{\pi g_{\text {tank }}}
$$

Segundo a expressão anterior a amplitude poderia incrementar sem limite aumentando $I_{B I A S}$ ou diminuindo $g_{\text {tank }}$. No entanto, no circuito o valor máximo de oscilação está perto da tensão de alimentação, tendo:

$$
A_{d}=\min \left\{\frac{4 I_{B I A S}}{\pi g_{\text {tank }}}, V_{D D}\right\}
$$

sempre que $g_{\text {tank }}$ seja posinômio, uma restrição sobre amplitude mínima pode ser levada como uma restrição válida de um programa geométrico. Uma restrição para a amplitude máxima pode ser considerada se um dos termos de $g_{\text {tank }}$ é consideravelmente maior em comparação aos outros termos e além disso tem forma de monômio. No casso de um indutor onchip, o termo $G_{I N D}$ será um dos mais significativo na expressão de $g_{\text {tank }}(3.1)$. 


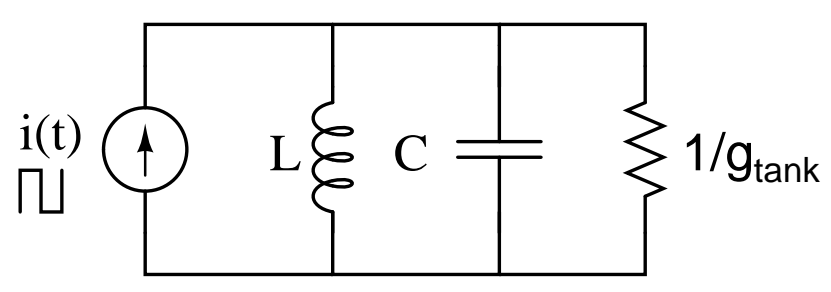

Figura 3.7: Circuito diferencial equivalente.

\subsubsection{Ruído de fase}

Assumindo operação linear, a frequiência do sinal gerado pelo $\mathrm{VCO}, v_{0}(t)$, pode ser expressa como:

$$
\omega_{\text {out }}(t)=\omega+K V_{c t r}(t)
$$

onde $\omega=2 \pi f_{c}$ corresponde à freqüência no centro da faixa de sintonia e $K$ o ganho ou sensibilidade do VCO em rad/Vs. A sintonização do VCO para uma frequiência $\omega_{\text {out }}$ é feita ajustando a tensão de controle do varactor.

$$
v_{0}(t)=A_{d} \cos \left[\omega t+K \int_{t_{0}}^{t} V_{c r t}(t) d t\right]
$$

para uma tensão de controle constante $V_{0}$ no varactor:

$$
v_{0}(t)=A_{d} \cos \left[\left(\omega+K V_{0}\right) t+\phi\right]
$$

A partir de (3.17) se espera que a potência do sinal esteja concentrada num ponto de frequiência, no entanto, na realidade tem-se um comportamento como na figura 3.8, onde se observa uma distribuição de potência ao redor da portadora (sinal gerado pelo VCO). Define-se o ruído de fase como a relação entre a potência "pontual" em uma das bandas, medida a um $\Delta \omega$ da portadora, à potência da portadora;

$$
\mathscr{L}(\Delta \omega)=10 \cdot \log \left[\frac{\mathscr{P}_{\text {banda }}(\omega+\Delta \omega, 1 H z)}{\mathscr{P}_{\text {portadora }}}\right]
$$

no caso ideal um VCO teria ruído de fase zero. A figura 3.8 mostra o comportamento do ruído de fase em função de $\Delta \omega$. A partir da figura se identificam três regiões: nas duas primeiras o ruído de fase diminui em razão de $1 / f^{3}$ e $1 / f^{2}$ respectivamente, na terceira região tem-se um piso de potência constante.

Uma das causas para estes componentes de potência não desejadas perto da portadora são as fontes de ruído presentes no circuito (derivadas dos elementos ativos e passivos) que causam 
pequenas variações de $\phi$ em (3.17) [23]. Para a região $1 / f^{2}$, o modelo proposto por Hajimiri $[26,27,28,29]$ considera um comportamento linear e variante no tempo entre as perturbações causadas pelo ruído e a fase do sinal gerado $(\phi)$. A expressão para o ruído de fase na região $1 / f^{2}$ gerado pela corrente de ruído $\overline{i_{n}^{2}}$ sob estas considerações é:

$$
\mathscr{L}(\Delta \omega)=10 \log \left(\frac{\frac{\overline{i_{n}^{2}}}{\Delta \omega} \Gamma_{r m s}^{2}}{2 q_{\max }^{2} \Delta \omega^{2}}\right)
$$

onde $\frac{\overline{i_{n}^{2}}}{\Delta \omega}$ é a densidade de potência da fonte de ruído, $q_{\max }$ é o máximo deslocamento de carga do capacitor entre os nós do sinal de interesse. $\Gamma_{r m s}$ é o valor quadrático médio da função de sensibilidade ao impulso (ISF ${ }^{2}$ ). A ISF é adimensional, periódica (período $2 \pi$ ) e não depende da freqüência nem da amplitude do sinal oscilante. Esta função encerra a natureza linear e variável no tempo da fase $\phi$ respeito a um impulso de corrente com área $\Delta q$ aplicado no nó em questão. A ISF pode ser calculada a partir de simulações do circuito [26]. Para isto mede-se o deslocamento da fase no sinal de saída (em estado estável) produzido pelo impulso de corrente aplicado num tempo $\tau$. No final se terá uma função do tipo $\phi(\omega \tau)$ e a partir dela a ISF pode ser determinada assim:

$$
\Gamma(\omega \tau)=\frac{\phi(\omega \tau)}{\frac{\Delta q}{q_{\max }}}
$$

A partir da expressão de ruído fase 3.19, identificam-se 3 formas para diminuir o ruído de fase gerado pela corrente $\overline{i_{n}^{2}}$ :

- diminuir a potência do sinal de ruído $\overline{i_{n}^{2}}$,

- aumentar a amplitude do sinal oscilante na saída do oscilador, assim a carga $q_{\max }$ aumen$\operatorname{tará}^{3}$.

- diminuir o fator de conversão do sinal de ruído em ruído de fase, diminuindo o fator $\Gamma_{r m s}^{2}$.

As duas primeiras estratégias já eram conhecidas antes do modelo de Hajimiri. Contudo, técnicas de projeto claras aplicando a última estrategia só surgiram após este modelo.

As fontes de ruído presentes no circuito se mostram na figura 3.9, para cada fonte de ruído se terá associado uma ISF que determinará a contribuição da fonte de ruído no ruído de fase do

\footnotetext{
${ }^{2}$ Impulse sensitivity function.

${ }^{3} q_{\max }=C V_{\max }$ onde $C$ representa a capacitância diferencial entre os nós de saída do VCO.
} 


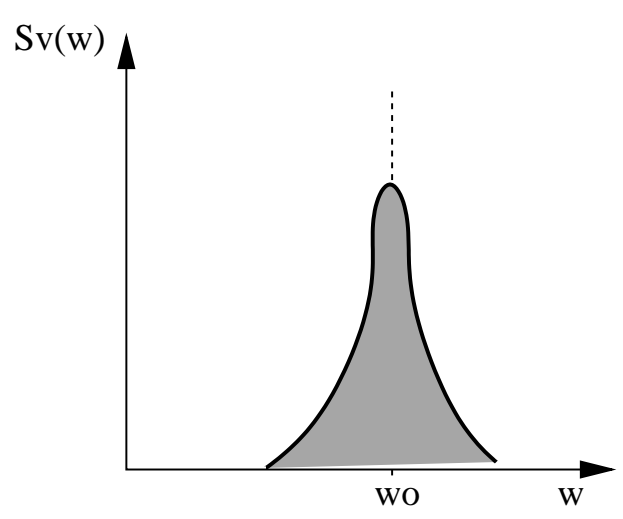

a)

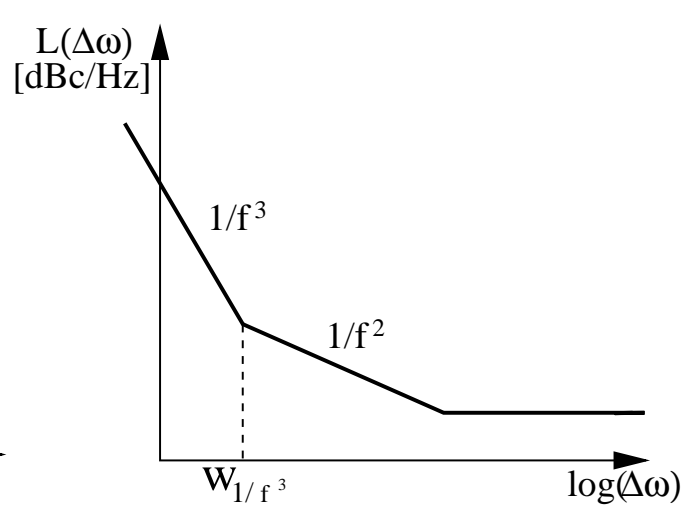

b)

Figura 3.8: a) Espectro do sinal gerado pelo VCO. b) Distribuição do ruído de fase.

VCO. Neste trabalho só se consideraram fontes de ruído térmico [30].

$$
\begin{aligned}
& \frac{\overline{i_{d}^{2}}}{\Delta f}=4 K_{B} T \lambda g_{d 0} \\
& \frac{\overline{i_{\text {ind }}^{2}}}{\Delta f}=4 K_{B} T \lambda G_{I N D} \\
& \frac{\overline{i_{\text {var }}^{2}}}{\Delta f}=4 K_{B} T \lambda g_{v}
\end{aligned}
$$

onde $K_{B}$ é a constante de Boltzman $1.38 x(10)^{-23} \mathrm{~J} / \mathrm{K}$. $T$ a temperatura em graus Kelvin, $\lambda$ a constante de ruído térmico dos transistores, e $g_{d 0}$ a condutância de saída do transistor para $V_{D S}=0$.

Outro fator importante no análise de ruído do VCO é que em virtude da magnitude dos sinais nos nós de saída, o valor da condutância $g_{d 0}$ dos transistores dos pares NMOS e PMOS varia no tempo. Assim, a potência de ruído também varia no tempo de forma periódica, tendo um sinal de ruído ciclo-estacionário. No caso do ruído gerado pelo indutor e o varactor o ruído é estacionário.

\section{Modelo \#1 para o ruído de fase}

Num trabalho inicial Hajimiri [31] considerou o ruído gerado pelos transistores como estacionário e $\Gamma_{r m s}^{2}=0.5$ para a contribuição de ruído gerado pelos transistores, indutor e varactor. Este modelo foi seguido também por [14]. A partir desta consideração tem-se o seguinte modelo 


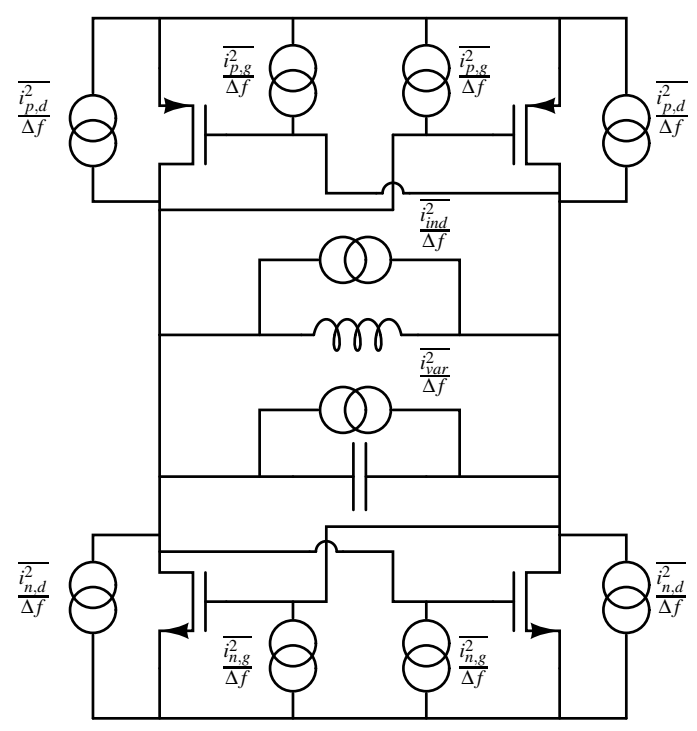

Figura 3.9: Oscilador LC complementar com fontes de ruído

para o ruído de fase:

$$
\mathscr{L}(\Delta \omega)=\frac{\Gamma_{r m s}^{2}}{2 \Delta \omega^{2}} \frac{\sum \overline{i_{n}^{2}} / \Delta \omega}{\left(C_{\text {tank }} A_{d}\right)^{2}}
$$

sendo $A d$ a amplitude da tensão de saída do VCO. $\overline{i_{n}^{2}} / \Delta \omega$ representa a corrente diferencial de ruído dos transistores, indutor e varactor. Esta expressão pode ser formulada como um posinômio em função das variáveis de projeto e uma especificação máxima de ruído de fase pode ser levado como uma restrição válida num PG.

\section{Modelo \#2 para o ruído de fase}

Num trabalho recente [32], determinou-se uma expressão para o ruído de fase na região $1 / f^{2}$ partindo de uma derivação teórica da ISF do ruído dos transistores do par e considerando o ruído dos transistores ciclo-estacionário. Esta expressão se obteve ao relacionar a ISF dos transistores com a ISF do ruído de uma resistência em paralelo com o ressoador. As considerações sobre as quais se derivou esta expressão são:

- quando todos os transistores conduzem estão em saturação,

- quando um transistor de um dos pares entra em triodo o transistor casado do outro lado do par entra em corte. 
desta forma, tem-se a seguinte expressão para o ruído de fase na região $1 / f^{2}$ devido aos transistores dos pares NMOS-PMOS e ao circuito tanque:

$$
\mathscr{L}(\Delta \omega)=\frac{K_{B} T\left(G_{I N D}+g_{v}\right)}{q_{\max }^{2}(\Delta \omega)^{2}}\left(1+\frac{\lambda_{n}+\lambda_{p}}{2}\right)
$$

Esta expressão mostra que a contribuição dos transistores ao ruído de fase na região $1 / f^{2}$ é constante e igual $\lambda$, a constante do ruído térmico dos transistores. Esta expressão tem duas características importantes:

- propõe um limite mínimo no ruído de fase que o VCO pode atingir.

- o ruído de fase mínimo atingível depende basicamente das características do ressoador.

No entanto, é necessário destacar que nesta expressão não se considerou o efeito da capacitância de carga, $C_{L O A D}$ na figura 3.2. No mesmo trabalho, o autor destaca que ao considerar o efeito da capacitância de carga a contribuição de ruído dos transistores aumenta consideravelmente. Quanto maior a relação da capacitância diferencial do VCO à capacitância de carga (conectada a terra) menor será a degradação do ruído de fase. Esta consideração tem importante repercussão na capacitância parasita do indutor $C_{I N D}$ e a capacitância $C_{L O A D}$, pois quanto maior sejam maior seria o ruído de fase mínimo atingível. Esta expressão para o ruído de fase mínimo do VCO pode ser implementada num PG.

\subsubsection{Polarização do VCO}

A figura 3.10 mostra o esquemático do VCO com a corrente $I_{B I A S}$ sendo implementada por um espelho simples de corrente. Assumindo um modelo quadrático da corrente, a corrente de ruído térmico na saída do espelho está determinada por:

$$
\frac{\overline{i_{n, t a i l}^{2}}}{\Delta f}=4 K_{B} T \lambda_{p} g_{c m}\left(N^{2}+N\right)
$$

sendo $g_{c m}$ a transcondutância porta-fonte do transistor $M_{c m}$. onde

$$
N=\frac{I_{T A I L}}{I_{R E F}}
$$

Em função da corrente $I_{T A I L},(3.25)$ pode ser expressa como:

$$
\frac{\overline{i_{n, t a i l}^{2}}}{\Delta f}=4 K_{B} T \lambda_{p} \sqrt{2 K_{p} I_{T A I L} \frac{W_{c m}}{L_{c m}}}\left(N^{3 / 2}+\sqrt{N}\right)
$$




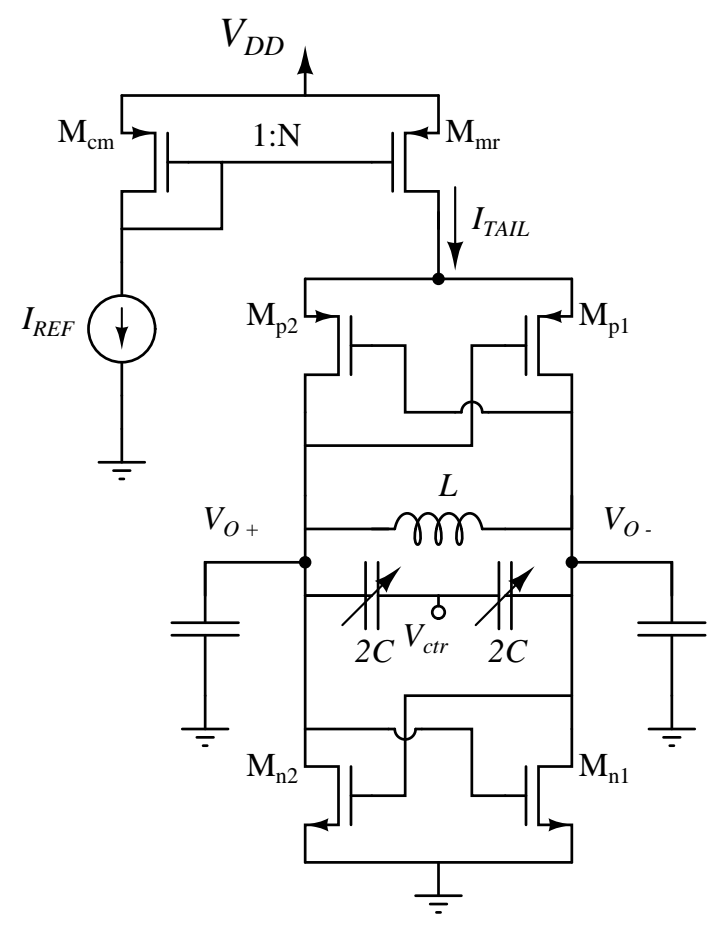

Figura 3.10: Circuito do VCO incluindo a polarização.

sendo $K_{p}=C_{o x} \mu_{p}$ o produto entre a capacitância de óxido e a mobilidade do transistor PMOS. $W_{c m}$ e $L_{c m}$ representam a largura e comprimento do canal do transistor $M_{c m}$. a partir das expressões anteriores se observa um compromisso entre a potência dissipada e a corrente de ruído na saída do espelho. Quanto maior for a relação de correntes $N$, menor será a potência dissipada e maior a corrente de ruído na saída do espelho.

\subsubsection{ISF da corrente de ruído em $I_{T A I L}$}

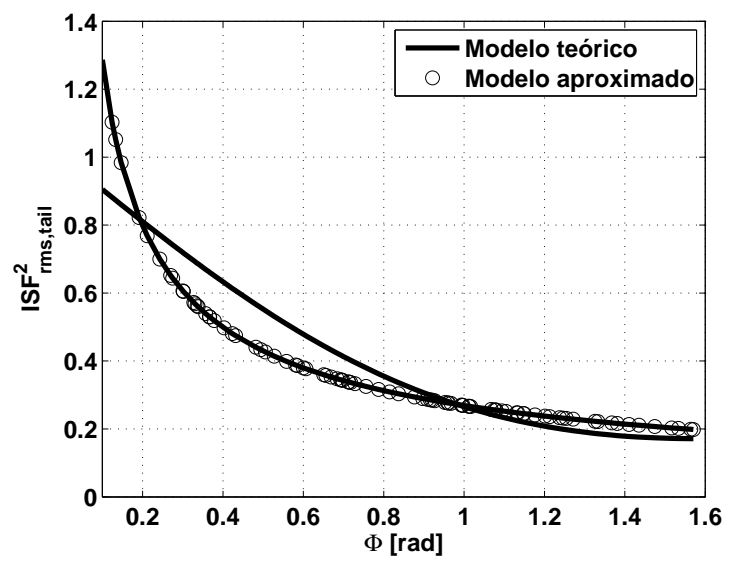

Figura 3.11: Valor quadrático médio da ISF da corrente de ruído em $I_{T A I L}$.

Em [35] se propõe uma expressão da ISF da fonte de corrente em $I_{T A I L}$, esta expressão 
derivou-se sobre as mesmas considerações feitas para a equação em (3.24):

$$
\Gamma_{\text {tail }}(\phi)= \begin{cases}\frac{\sin (\phi)}{\sqrt{2 \sin ^{2}(\Phi)-\sin ^{2}(\phi)}} \cos (\phi), & \text { for }-\Phi<\phi<\Phi \\ \cos (\phi), & \text { for } \Phi<\phi<\pi-\Phi \\ \frac{\sin (\phi)}{\sqrt{2 \sin ^{2}(\Phi)-\sin ^{2}(\phi)}} \cos (\phi), & \text { for } \pi-\Phi<\phi<\Phi+\pi \\ -\cos (\phi), & \text { for } \pi+\Phi<\phi<2 \pi-\Phi\end{cases}
$$

onde $2 \Phi$ representa o ângulo onde os transistores do par diferencial PMOS conduzem e estão saturados. A figura 3.11 mostra o valor de $\Gamma_{r m s, t a i l}^{2}(\phi)$ em função do ângulo de condução, sendo que esta curva foi obtida a partir da integração numérica de (3.26). Observa-se da figura que quanto maior o angulo de condução do transistores do par, menor a contribuição do ruído do espelho de corrente. Dessa forma, é possível aumentar a relação de correntes $N$ do espelho, minimizando a potência total, sem degradar o ruído de fase. Assumindo que a corrente drenofonte $I_{D S}$ obedece ao modelo quadrático, tem-se [32]:

$$
\begin{aligned}
& \Phi \simeq \frac{\pi}{2} \sqrt{\frac{2 I_{T A I L}}{\frac{K p W_{p}}{L_{p}} A_{d}^{2}}} \\
& \Phi \leq \frac{\pi}{2}
\end{aligned}
$$

finalmente, o valor quadrático médio da ISF em função de $\Phi$ pode estimado usando o seguinte modelo aproximado:

$$
\begin{aligned}
\Gamma_{r m s, t a i l}^{2}(\Phi) & =c_{f} \Phi^{\alpha} \\
& \simeq 0.27 \Phi^{-0.68}
\end{aligned}
$$

onde $c_{f}$ e $\alpha$ foram obtidas de forma tal que para $\Phi$ 's escolhidos aleatoriamente, o erro entre o valor estimado por (3.30) e o valor obtido usando (3.26) seja minimizado. Na figura $3.11 \mathrm{se}$ observa que o modelo proposto aproxima razoavelmente bem o modelo teórico.

A partir de (3.27) e (3.30) deriva-se uma observação importante: Diminuir a amplitude do sinal de saída do VCO minimiza a contribuição da corrente de ruído $\frac{\overline{i_{\text {n,tail }}^{2}}}{\Delta f}$ no ruído de fase. 


\section{Modelo \#2 incluindo a contribuição do circuito de polarização}

A partir de (3.24), (3.25), (3.27) e (3.30) se tem a seguinte expressão do ruído de fase considerando o aporte de ruído do espelho de corrente:

$$
\mathscr{L}(\Delta \omega)=\frac{K_{B} T\left(G_{I N D}+g_{v}\right)}{q_{\text {max }}^{2}(\Delta \omega)^{2}}\left[1+\frac{\lambda_{n}+\lambda_{p}}{2}+\frac{1}{2 K_{B} T} \frac{\overline{i_{n, t a i l}^{2}}}{\Delta f} \Gamma_{r m s, t a i l}^{2}(\Phi)\right]
$$

observa-se que uma especificação máxima de ruído de fase pode ser levada como uma restrição válida num programa geométrico.

\subsection{Consumo de potência}

A potência dissipada pelo VCO é dada por:

$$
P=I_{B I A S} * V_{D D}
$$

e considerando a implementação de $I_{B I A S}$ com um espelho de corrente:

$$
P=\left(I_{R E F}+I_{T A I L}\right) * V_{D D}
$$

esta expressão é um posinômio das variáveis $I_{T A I L}$ e $I_{R E F}$.

\subsection{O projeto do VCO LC complementar como um pro- grama geométrico}

A partir das expressões para os diferentes parâmetros de desempenho do VCO, é possível formular o projeto do VCO como um programa geométrico. Procura-se minimizar o consumo de potência do circuito, equação (3.33). Sujeito a especificações no ruído de fase máximo, equações (3.31), (3.28); assim como especificações mínimas no amplitude do sinal (3.14); faixa de sintonia (3.9), (3.11), (3.13); e condição de oscilação (3.5). Assim como também a condição para diminuir o ruído na região $1 / f^{3}$ (3.6). Como foi visto no projeto do amplificador fonte comum no capítulo anterior, estas expressões dependeram dos modelos dos dispositivos. Para os parâmetros do transistor como $g_{m}, g_{d s}$ e $V_{G S}$, obtiveram-se modelos do transistor aplicando a mesma metodologia descrita no capítulo anterior. Assim, o programa geométrico resultante será da forma: 
minimizar Consumo de Potência

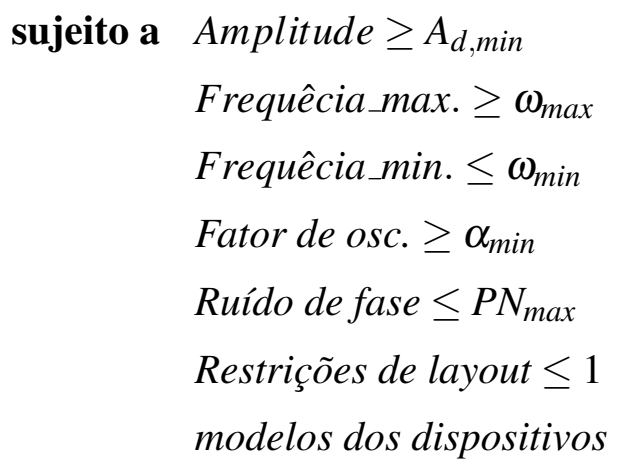

onde as restrições de layout estão relacionadas a restrições nas dimensões dos dispositivos, por exemplo mínimo comprimento de canal permitido pela tecnologia, casamento entre os tamanhos dos transistores dos pares cruzado e espelho de corrente. Da mesma forma que no projeto do amplificador fonte comum, os modelos dos dispositivos devem ser incluídos no programa geométrico. No próximo capítulo é feita uma revisão das estruturas comuns de indutores onchip e se descreve em detalhe como obter um modelo do indutor compatível com um programa geométrico. 


\section{Indutor onchip e modelo compatível num programa geométrico}

Existem diferentes estruturas para indutores integrados, algumas estruturas planas de uso comum são mostradas na figura 4.1. Em aplicações diferenciais (figura 4.2) é comum usar indutores com estruturas simétricas. Este tipo de estrutura pode ser implementado como a conexão em série de dois indutores assimétricos, como é mostrado na figura 4.4(a), ou como uma única estrutura de indutor simétrico, como é mostrado na figura 4.4(b). Uma das vantagens do uso de estruturas simétricas é a possibilidade de aplicar fontes de polarização sem alterar a simetria do circuito. Em termos de desempenho, é preferível o uso de indutores simétricos sobre indutores assimétricos em série, devido a redução da área e ao maior fator de qualidade. Como se observa na figura 4.4, o indutor simétrico tem linhas de interconexão menores e um menor número de sobreposição de metais, como conseqüência os efeitos capacitivos associados à espira são menores tendo assim um fator de qualidade maior [36].

Em virtude do amplo uso de indutores em projetos RF, a modelagem do indutor tem sido objeto de diversas pesquisas, e assim, numerosos modelos tem sido propostos na literatura [37]. Em geral, quanto mais efeitos sejam considerados no modelo maior sua complexidade. Por outro lado, para uma tecnologia de fabricação, é desejável que um modelo do indutor cumpra com as seguintes características: o modelo é valido para qualquer freqüência; o modelo é escalável e conta com expressões explicitas para o calculo dos elementos do modelo (R,L,C) a partir da geometria do indutor. Um modelo com as características anteriores permitiria o rápido projeto e/ou otimização do indutor sem a necessidade do uso de simuladores electromagnéticos. Estes simuladores poderiam ser usados só como uma ferramentas de verificação nas etapas finais do projeto. No entanto, em razão da ordem de frequências e das dimensões da estrutura, encontrar um modelo com essas características não é fácil. 

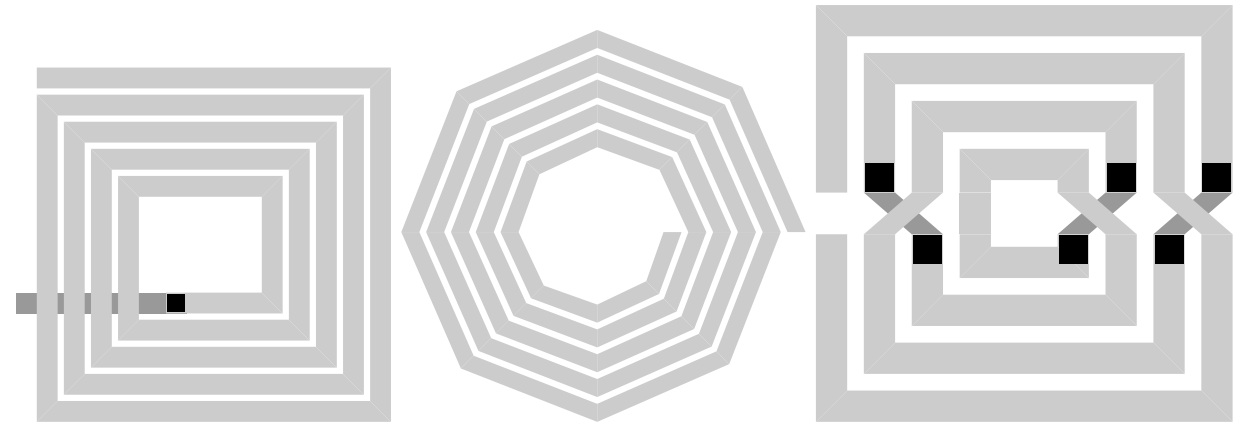

Figura 4.1: (a) Indutor quadrado. (b) Indutor octogonal. (c) Indutor simétrico.
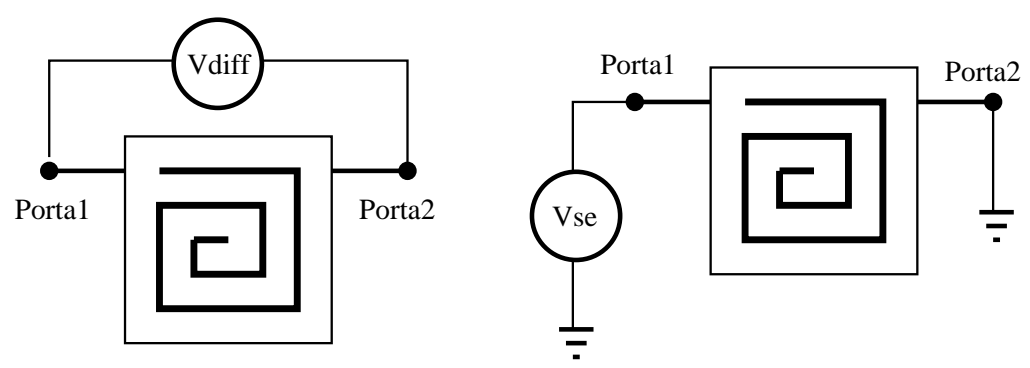

Figura 4.2: Tipos de conexão: (a) Diferencial, (b) Uma porta aterrada.

\subsection{Modelo- $\Pi$}

O modelo-П proposto por [33], e mostrado na figura 4.3, é um modelo físico e escalável onde se modela o indutor como uma rede de duas portas, com uma indutância e resistência série $\left(L_{S}\right.$, $R_{S}(f)$ ) e uma capacitância de acoplamento entre as portas (modelando o efeito de sobreposição

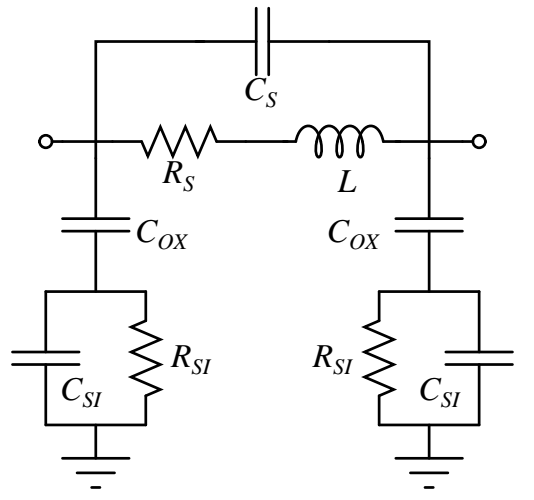

(a)

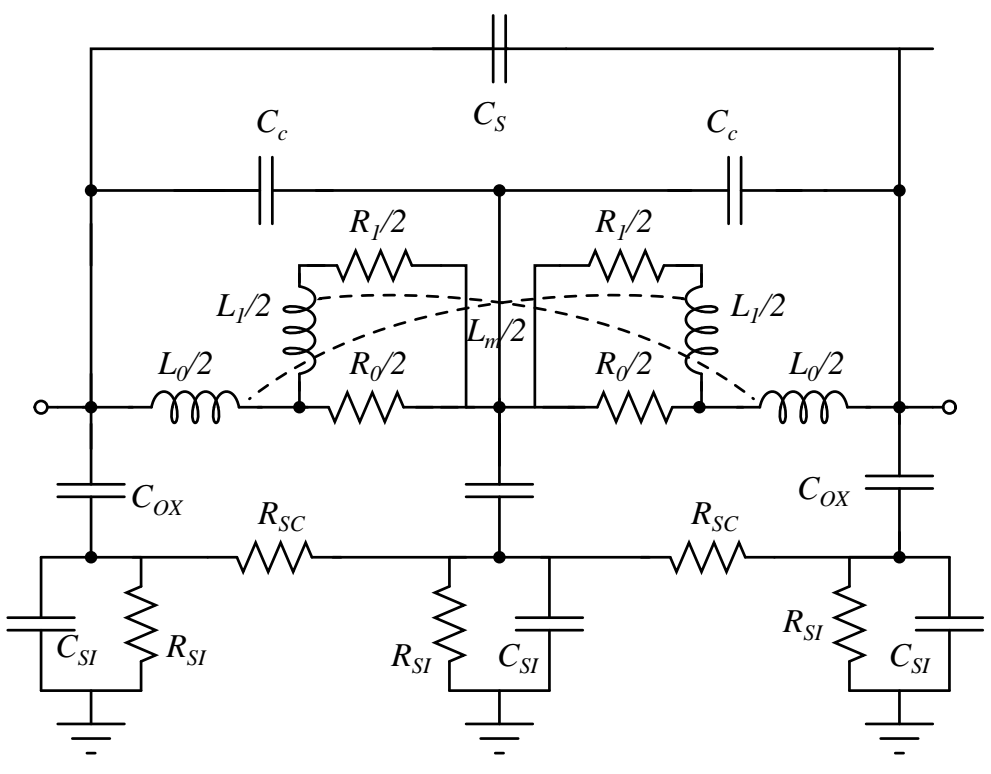

(b)

Figura 4.3: (a) Modelo-П simples [33] e (b) Modelo-2П [34]. 


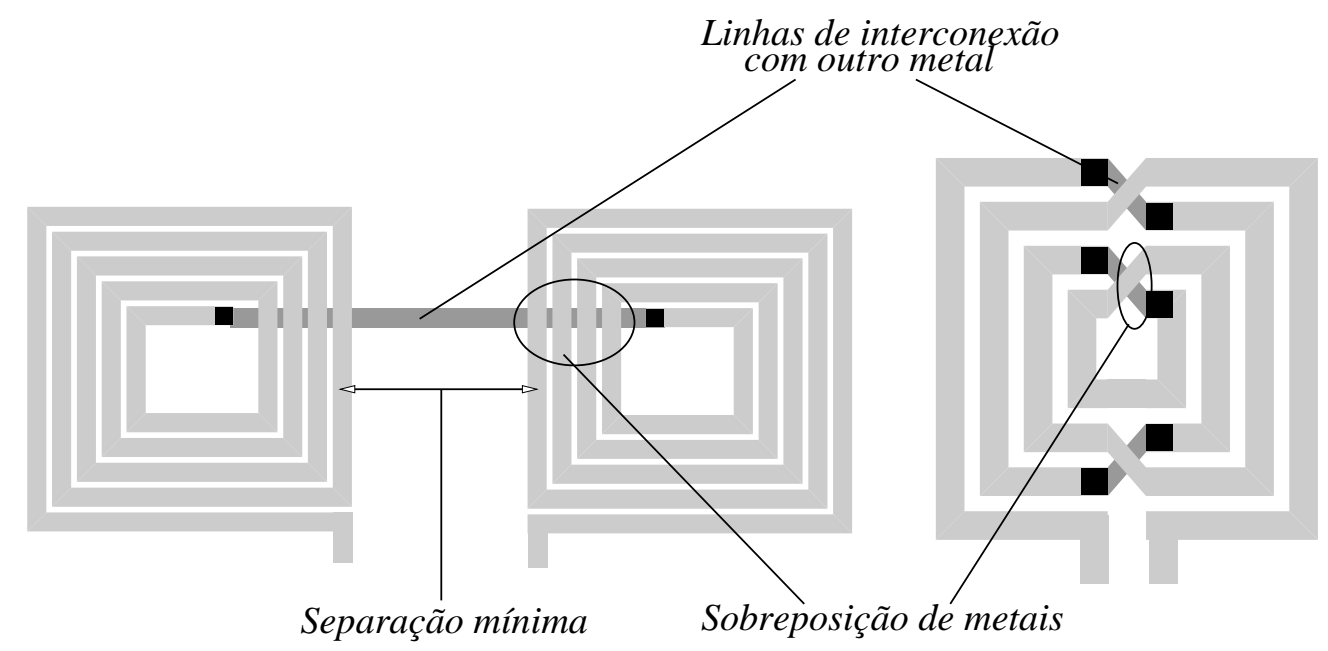

(a)

(b)

Figura 4.4: Estruturas simétricas: (a) Conexão série de dois indutores assimétricos, (b) Indutor simétrico

de metais da figura 4.4). A isolação entre o indutor e o substrato é modelado com $C_{O X}$, e o substrato é modelado como uma rede RC paralelo. O modelo- $\Pi$ considera os efeitos mínimos de um indutor onchip. No entanto, para uma descrição exata do indutor outros efeitos devem ser considerados, entre outros: a forte dependência de $L_{S}$ e $R_{S}$ com a frequência devido a proximity effects e o acoplamento capacitivo pelo substrato entre segmentos da espira; em [34] se propõe um modelo físico e escalável 2-П (figura 4.3(b)) onde são considerados estes efeitos.

Uma das características mais importante do modelo-П é que tal e como foi apresentado em [33], excetuando a expressão para a indutância série, os elementos do modelo estão relacionados com a geometria do indutor por funções compatíveis num programa geométrico (monômios e posinômios). No caso da indutância, em [38, 39] se mostrou que um modelo monomial obtido mediante técnicas de ajuste numérico sobre simulações da espira, tem boa correlação com dados experimentais. A continuação se apresenta a descrição dos elementos do modelo-П em função das variáveis geométricas do indutor:

- Diâmetro externo $\left(d_{e x t}\right)$.

- Largura da espira $\left(w_{\text {ind }}\right)$.

- Número de voltas da espira (n).

- Espaçamento entre segmentos da espira $(s)$.

- Comprimento da espira $\left(l_{\text {ind }}\right)$. 
Indutância série: Em [33, 23] se mostra a origem física de um modelo monomial para a indutância.

$$
L_{m o n}=\beta d_{\text {ext }}^{\alpha_{1}} w_{\text {ind }}^{\alpha_{2}} s^{\alpha_{3}} n^{\alpha_{4}}
$$

tendo que os valores das constantes dependem de características do layout da estrutura.

Resistência série: Considera o efeito pele no condutor.

$$
R_{S}=\frac{l_{\text {ind }}}{\sigma w_{\text {ind }} \delta\left(1-e^{-t / \delta}\right)} ; \quad \delta=\sqrt{\frac{2}{\omega_{c} \mu \sigma}}
$$

onde $\sigma$ é a condutividade da espira, $t$ a espessura da espira, $\omega_{c}$ a frequiência e $\mu=4 \pi 10^{-7}$ $[\mathrm{H} / \mathrm{m}]$ é a permitividade do espaço livre.

Capacitância entre o indutor e o substrato: Esta capacitância modela o efeitos capacitivos entre a espira e o substrato.

$$
C_{o x}=\frac{\varepsilon_{o x} w_{i n d} l_{\text {ind }}}{2 t_{o x}}
$$

onde $\varepsilon_{o x}$ é a permitividade do óxido e $t_{o x}$ a espessura do óxido entre a espira e o substrato.

Capacitância de sobreposição: Esta capacitância surge em virtude do metal que faz conexão com o terminal mais interno do indutor.

$$
C_{s}=\frac{\varepsilon_{o x} n w_{i n d}^{2}}{t_{o x, M 1-M 2}}
$$

onde $t_{o x, M 1-M 2}$ é a espessura do óxido entre o metal da espira e o metal de interconexão.

Capacitância do substrato: O substrato é modelado como uma rede RC paralelo. A capacitância deste modelo está dada por:

$$
C_{s i}=\frac{C_{s u b} l_{i n d} w_{\text {ind }}}{2}
$$

onde $C_{s u b}$ é a capacitância do substrato por unidade de área.

Resistência do substrato: A resistência devida ao substrato está dada por: 


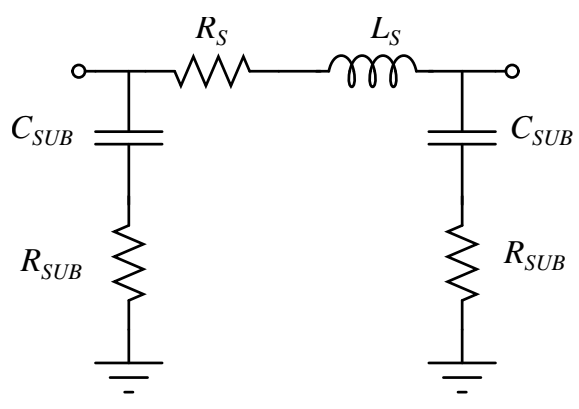

Figura 4.5: Modelo-П simplificado

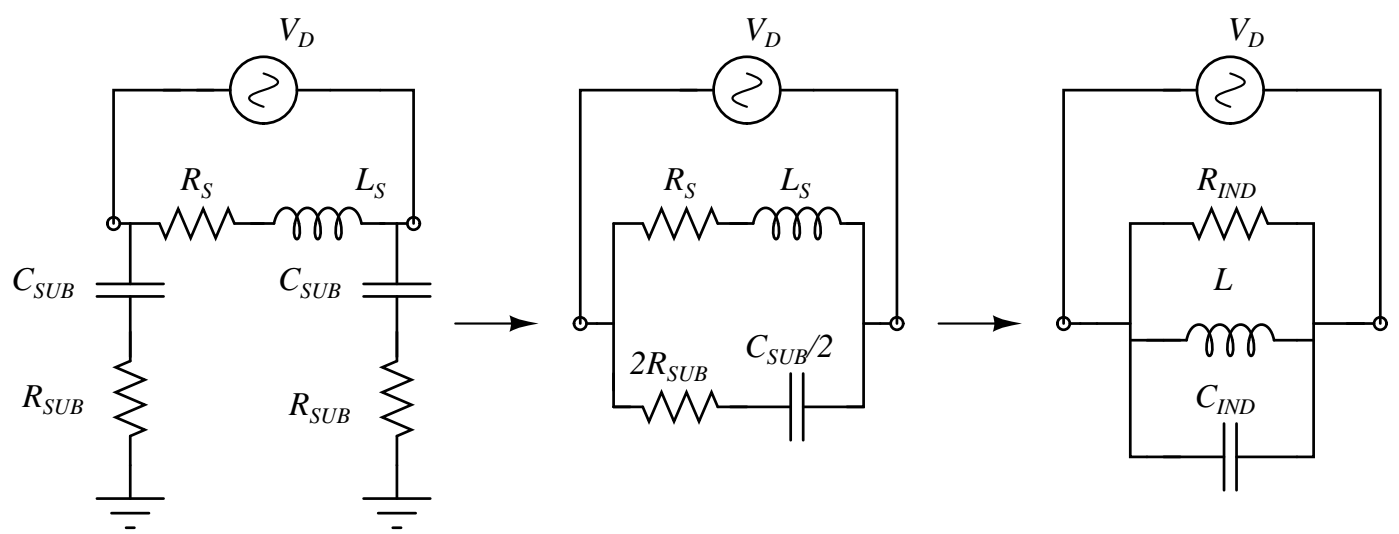

Figura 4.6: Modelo-П simplificado em aplicações diferenciais.

$$
R_{s i}=\frac{2}{G_{\text {sub }} l_{\text {ind }} w_{\text {ind }}}
$$

onde $G_{s u b}$ é a condutância do substrato por unidade de área.

\subsubsection{Modelo-П simplificado}

Em termos da impedância entre portas, para uma frequência pontual o modelo- $\Pi$ da figura 4.3(a) pode ser simplificado ao modelo da figura 4.5. Nessa representação os elementos do modelo dependem da frequência e para uma frequência específica $f_{c}$ o modelo pode representar o comportamento da espira para frequências próximas a $f_{c}$. No entanto, é importante destacar que ao tentar aplicar este modelo num amplo espectro de frequência se estaria subestimando o efeito do substrato no indutor. De acordo com [40], em aplicações diferenciais o modelosimplificado pode ser reduzido conforme a figura 4.6. Para uma frequência $\omega_{c}$, tem-se:

$$
L=L_{S}+\left(\frac{R_{S}}{\omega_{c}}\right)^{2} \frac{1}{L_{S}}
$$




$$
\begin{gathered}
\frac{1}{C_{I N D}}=\frac{1}{C_{S U B} / 2}+\left(2 \omega_{c} R_{S U B}\right)^{2} \frac{1}{C_{S U B} / 2} \\
\frac{1}{R_{I N D}}=\frac{1}{R_{P}}+\frac{1}{R_{P S U B}}
\end{gathered}
$$

onde $R_{P}$ e $R_{P S U B}$ representam a resistência equivalente em paralelo da rede RL e RC série, onde

$$
\begin{gathered}
R_{P}=\left(\omega_{c} L_{S}\right)^{2} \frac{1}{R_{S}}+R_{S} \\
R_{P S U B}=\left(\frac{1}{\omega_{c} C_{S U B} / 2}\right)^{2} \frac{1}{2 R_{S U B}}+2 R_{S U B}
\end{gathered}
$$

Por outro lado, considerando as expressões (4.3), (4.5) e (4.6) é possível demostrar que quanto maior a área do indutor a resistência $R_{S U B}$ será menor e a capacitância $C_{S U B}$ será maior (figura 4.5), e desta forma os efeitos capacitivos do substrato no indutor serão amplificados. Como consequência, esperam-se duas situações com o aumento da área do indutor: 1) Aumento da capacitância parasita do indutor $C_{I N D}$. 2) diminuição da frequência de auto ressonância do indutor.

\subsection{Obtenção de modelos de indutores simétricos com- patíveis com um PG}

Observando que o modelo- $\Pi$ aproxima o comportamento de um indutor num espectro de frequência amplo, e que os elementos do modelo estão relacionados à geometria do indutor mediante funções compatíveis com um programa geométrico, infere-se que a partir de um modelo-П simplificado de um indutor simétrico numa frequência $f_{c}$, obtido a partir de simulações eletromagnéticas da espira, é possível gerar um modelo do indutor compatível com um programa geométrico. Usando um simulador electromagnético é possível ter uma estimação mais próxima do comportamento do indutor evitando o uso de modelos mais complexos; com este enfoque se está sacrificando largura de banda do modelo por maior precisão na estimação do comportamento da espira na frequência $f_{c}$. Por outro lado, o modelo gerado ao ser compatível com um PG e com o modelo do ressoador da seção 3.2.1 poderá ser usado no programa geométrico do VCO 3.4 . 


\begin{tabular}{ccccc}
\hline Tecnologia & Substrato & $\rho_{\text {subs }}^{*}[\Omega \mathrm{cm}]$ & \# de metais & Espessura met4 $[\mu \mathrm{m}]$ \\
\hline CMOS $0.35 \mu \mathrm{m}$ & tipo P & 19 & 4 & $0.925,2.8^{*}$ \\
\hline *A tecnologia oferece a possibilidade de usar um metal mais espesso.
\end{tabular}

Tabela 4.1: Parâmetros da tecnologia.

\begin{tabular}{cccccc}
\hline Nome & Tipo & $d_{\text {ext }}[\mu \mathrm{m}]$ & $w_{\text {ind }}[\mu \mathrm{m}]$ & $s[\mu \mathrm{m}]$ & $n$ \\
\hline fnd047 & Quadrado & 180 & 8 & 2 & 4.5 \\
fnd060 & Octogonal simétrico* & 392 & 24 & 4 & 5 \\
\hline
\end{tabular}

*Feito usando metal 4 espesso.

Tabela 4.2: Indutores

\subsubsection{Ferramenta de simulação eletromagnética}

Em razão do fácil acesso e bom desempenho, escolheu-se ASITIC como ferramenta de simulação [41]. No ASITIC, as etapas básicas seguidas no análise de um indutor são:

1. descrição da tecnologia,

2. descrição da geometria do indutor,

3. análise electromagnética da estrutura numa faixa de freqüências.

A faixa de frequências é definida por uma freqüência inicial e final $\left(f_{i}, f_{o}\right)$ com incrementos $\Delta f$. Como resultado, ASITIC gera os parâmetros de duas portas $(S / Y / Z)$ do indutor para cada $f_{c}+\Delta f$ , estes parâmetros são mapeados automaticamente aos elementos do modelo simplificado da figura 4.5. De igual forma, para cada ponto de frequência o ASITIC calcula o fator de qualidade (single ended e diferencial) junto com uma estimação da frequência de auto ressonância do indutor.

Por outro lado, ao considerar que serão gerados modelos do indutor a partir de dados de simulação é importante ter uma idéia da qualidade das estimativas do simulador; especificamente sua correlação com testes experimentais. Dessa forma se compararam os resultados de ASITIC com modelos de banda larga fornecidos pela foundry para indutores pré-fabricados. A tabela 4.2 apresenta a geometria de alguns dos indutores analisados, fnd047 e fnd060. Os parâmetros relevantes da tecnologia se mostram na tabela 4.1. Todas as espiras foram feitas usando o metal de cima (metal 4) e para as interconexões se usou o metal imediatamente inferior (metal 3). Entre os indutores analisado fnd060 foi o único indutor simétrico, também é o único que usa metal espesso. Com o intuito de analisar a incidência de correntes de eddy no substrato, 
nas simulações ativou-se e desativou essa opção na configuração de ASITIC. A análise foi feita na faixa de freqüência de 1 a $5 \mathrm{Ghz}$ com incrementos de freqüências de $200 \mathrm{MHz}$. Tanto para fnd047 e fnd060, a foundry fornece um modelo circuital RLC de banda larga com valores específicos para cada indutor. A partir de simulações desses modelos obtiveram-se os parâmetros $Y$ da espira conforme mostrado na representação circuital da figura 4.7. Dos resultados dessas simulações e do comportamento estimado por ASITIC, estimou-se a indutância e o fator de qualidade de cada indutor. No caso do indutor fnd047 tem-se:

$$
\begin{gathered}
L=\frac{1}{2 \pi f} \operatorname{imag}\left\{\frac{1}{Y_{11}}\right\} \\
Q=\frac{\operatorname{imag}\left\{\frac{1}{Y_{11}}\right\}}{\operatorname{real}\left\{\frac{1}{Y_{11}}\right\}}
\end{gathered}
$$

e para o indutor simétrico fnd060, a impedância diferencial, a indutância e o fator de qualidade diferencial são dados por:

$$
\begin{gathered}
Z_{\text {diff }}=Z_{11}+Z_{22}-\left(Z_{12}+Z_{21}\right) \\
L_{\text {diff }}=\frac{1}{2 \pi f} \operatorname{imag}\left\{Z_{\text {diff }}\right\} \\
Q_{\text {diff }}=\frac{\operatorname{imag}\left\{Z_{\text {diff }}\right\}}{\operatorname{real}\left\{Z_{\text {diff }}\right\}}
\end{gathered}
$$

As figuras 4.8 - 4.11 mostram os resultados obtidos para cada espira ao comparar as simulações de ASITIC com os modelos da foundry. Nas figuras 4.8 e 4.10 mostra-se a resistência série: $R_{S}=-$ real $\left\{\frac{1}{Y_{12}}\right\}$. Observa-se que as simulações de ASITIC sem considerar correntes de eddy no substrato mostraram uma queda da resistência com o aumento da frequência muito próximo ao estimado pelo modelo da foundry; resultados contrários dos observados ao considerar correntes de eddy. Contudo, no caso do indutor fnd047 os valores absolutos da resistência nos três casos foram similares dentro da faixa de frequências considerada, enquanto

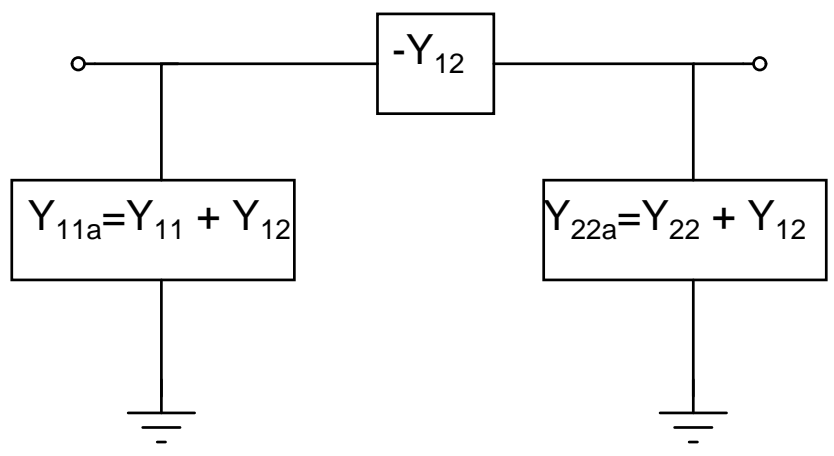

Figura 4.7: Representação circuital de duas portas a partir dos parâmetros $Y$ 

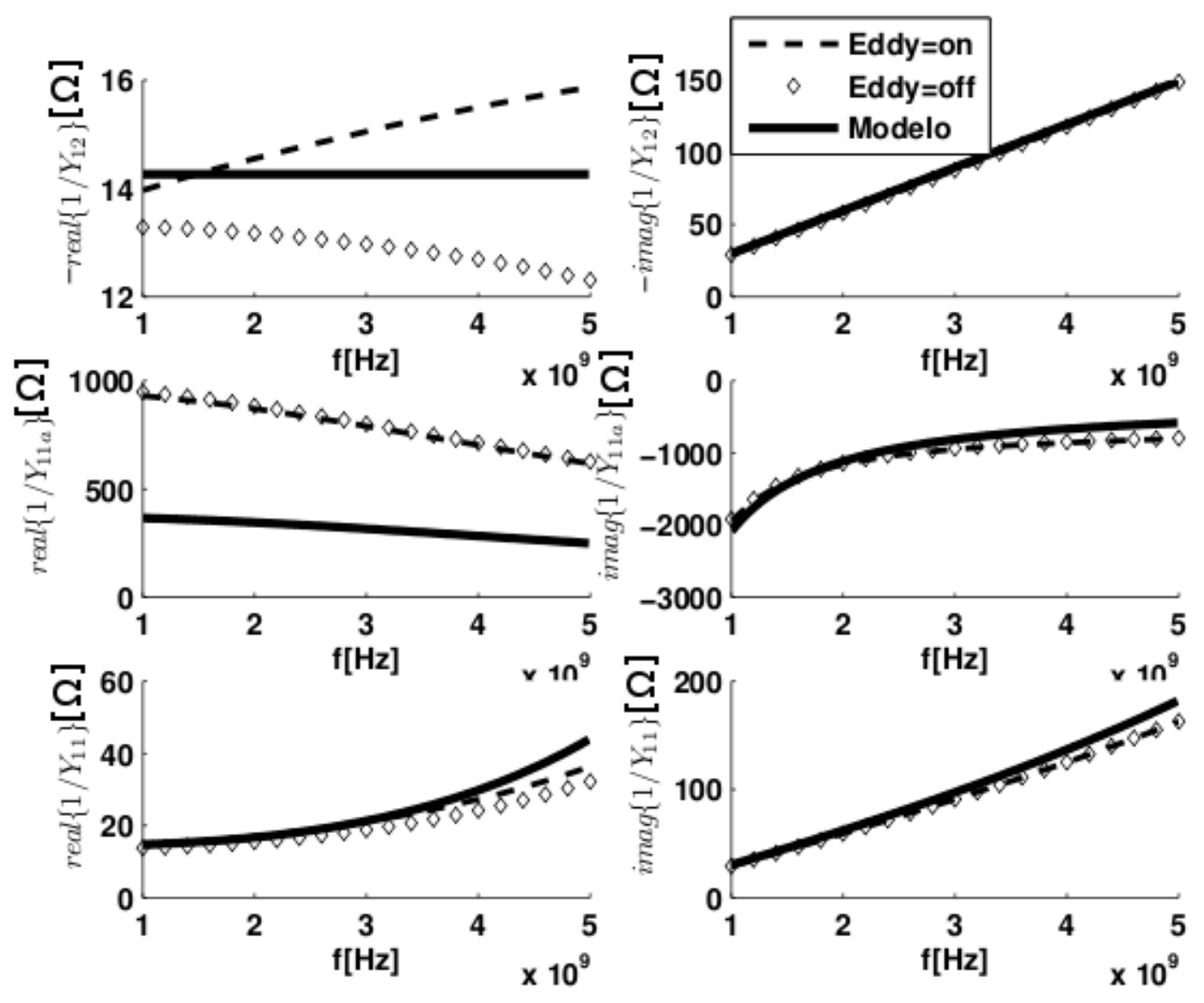

Figura 4.8: Parâmetros Y do indutor fnd047.

no indutor simétrico fnd060 as diferenças foram consideráveis.

Em relação ao fator de qualidade, figuras 4.9 e 4.11, observou-se um pior caso de ASITIC ao considerar correntes de $e d d y$ nas frequiência próximas ao valor pico do fator de qualidade. Essa observação é importante já que geralmente se quer o valor pico do fator de qualidade centrado na faixa de freqüências de operação do indutor. No caso do indutor fnd060 o valor de indutância foi próximo nos três casos até valores de frequências próximos ao pico do fator de qualidade.

Para concluir, e baseado na análise aqui apresentada, observou-se que as simulações em ASITIC de indutores pré-fabricados são comparáveis com os modelos fornecidos pela foundry tendo boa precisão na estimação de parâmetros elétricos da espira como: indutância, fator de qualidade e frequência de autoressonância. Contudo, observou-se um pior caso nas simulações ao considerar a formação de correntes de eddy no substrato e por esta razão ativou-se esta opção nas simulações feitas na próxima seção. 

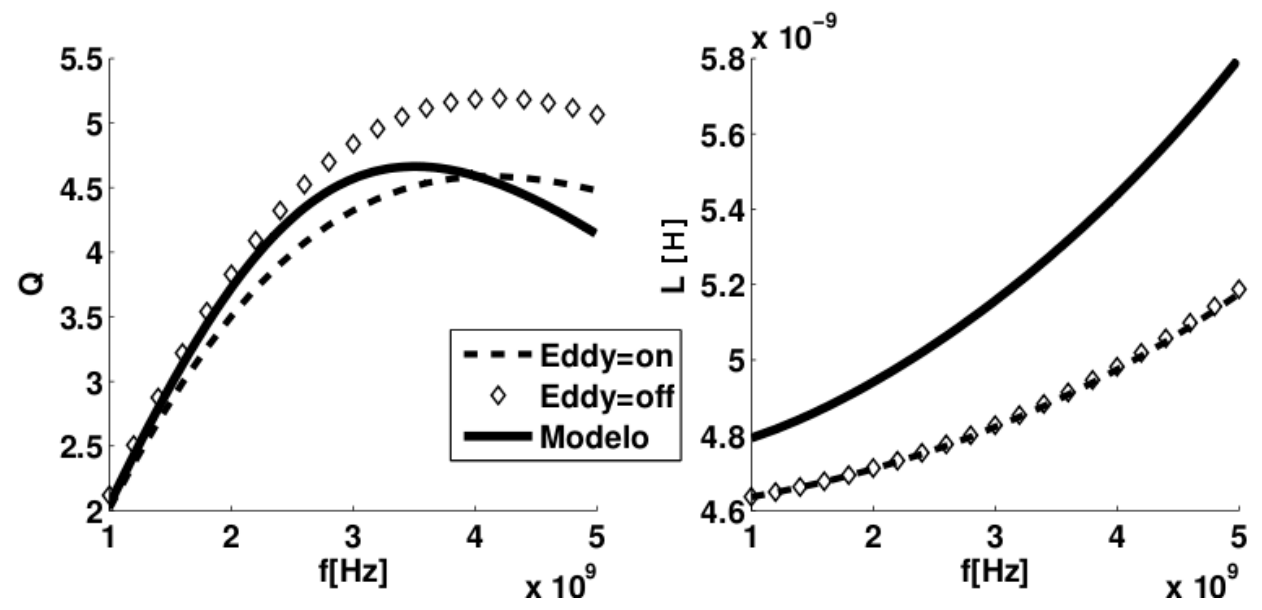

Figura 4.9: Fator de qualidade e indutância do indutor fnd047.

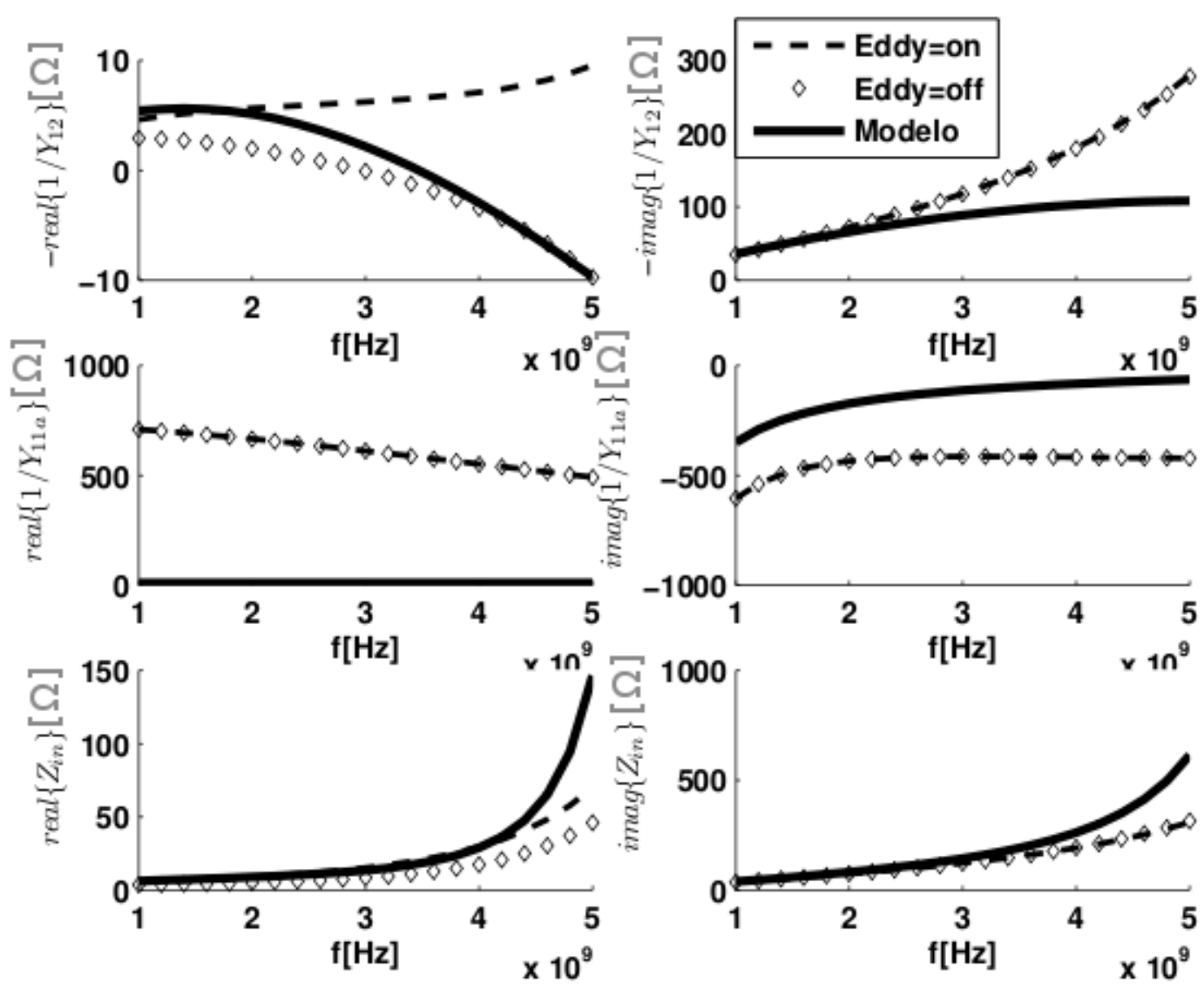

Figura 4.10: Parâmetros Y do indutor fnd060. 


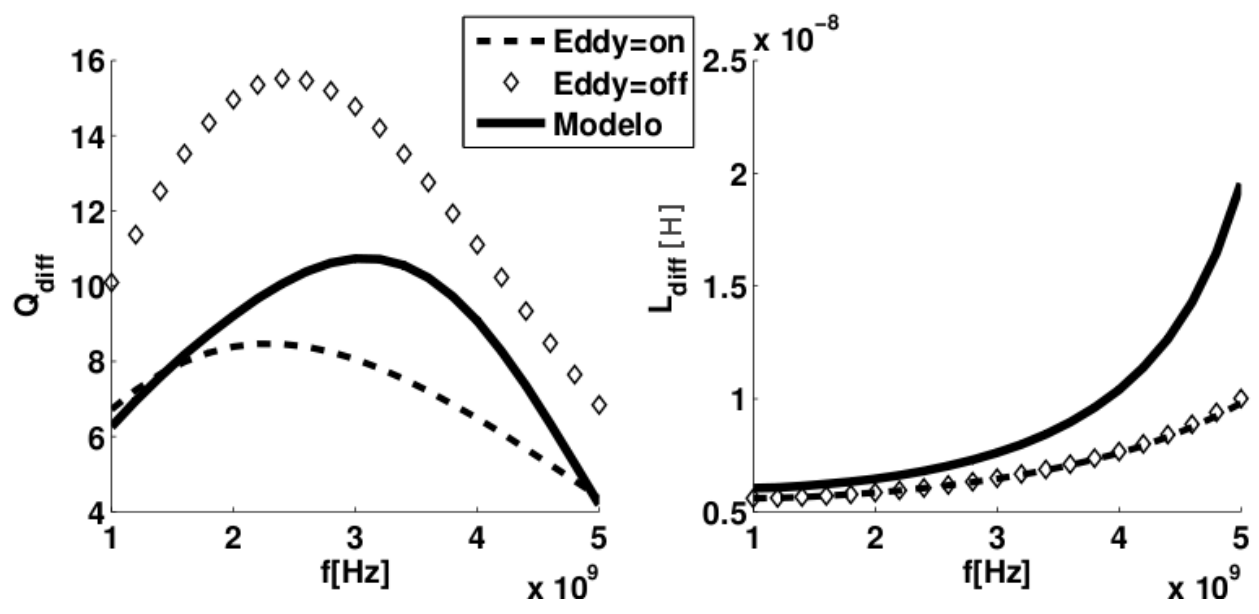

Figura 4.11: Fator de qualidade e indutância do indutor fnd060.
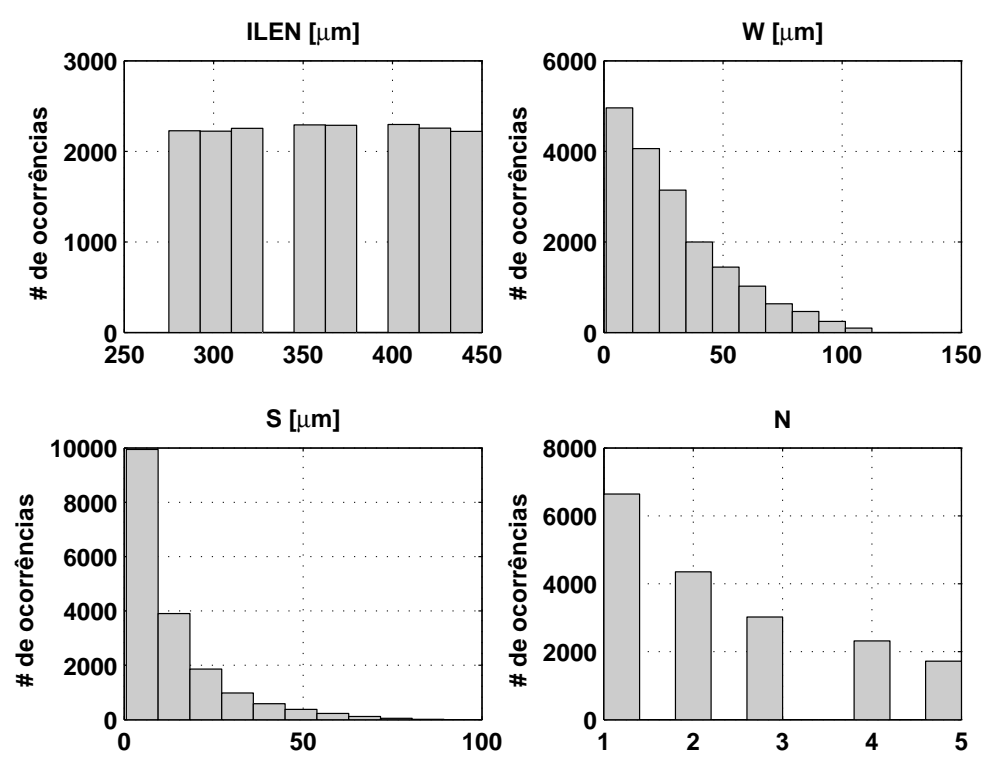

Figura 4.12: Espaço de projeto.

\subsubsection{Espaço de projeto e desempenho}

Simularam-se 18000 indutores com geometrias definidas na seguinte região, que definimos como espaço de projeto:

$$
\left.\begin{array}{rl}
275 \mu \mathrm{m} & \leq d_{\text {ext }} \leq 450 \mu \mathrm{m} \\
1 \mu \mathrm{m} & \leq w_{\text {ind }} \leq 25 \% d_{\text {ext }} \\
0.6 \mu \mathrm{m} & \leq s \leq w_{\text {ind }} \\
1 & \leq n \leq 5
\end{array}\right\} \quad \text { Espaço de projeto }
$$



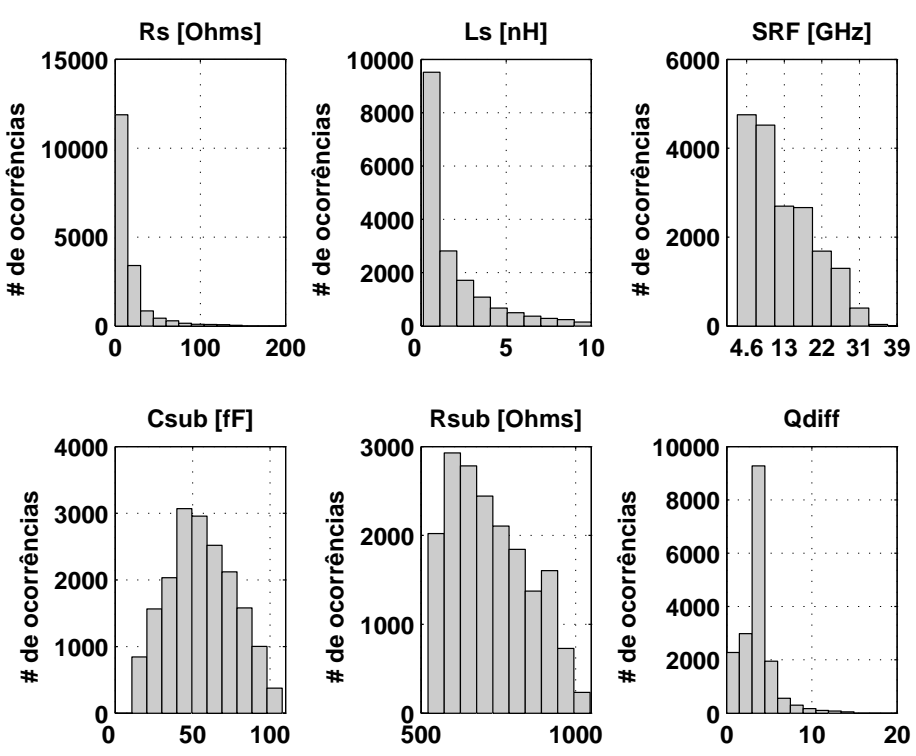

Figura 4.13: Parâmetros de Desempenho obtidos.

A idéia é explorar o desempenho dos indutores numa região tipica de projeto. Essa exploração foi completamente automatizada em scripts para MATLAB que recebem como entrada o espaço de projeto (4.17), para depois se comunicar com ASITIC através de arquivos de texto com a descrição dos indutores e o tipo de análise a fazer. Assim, depois das simulações de cada indutor os valores medidos são coletados por MATLAB.

A figura 4.12 mostra a distribuição que tomaram as variáveis de projeto nesta região. A partir da figura se observa uma distribuição uniforme do diâmetro exterior (ILEN); para as outras variáveis, valores menores tiveram maior número de ocorrência. Para cada indutor se determinou os parâmetros do modelo-П simplificado (figura 4.5) e o fator de qualidade diferencial para uma frequência de $2.45 \mathrm{GHz}$; também se estimou a frequência de autoressonância $(S R F)$. A distribuição de cada parâmetro se mostra na figura 4.13.

\subsubsection{Modelos do indutor a $2.45 \mathrm{GHz}$}

A partir dos valores do modelo- $\Pi$ simplificado de cada indutor, calcularam-se os valores do modelo diferencial da figura 4.6 de acordo com as expressões (4.7) - (4.9). Assim, para cada geometria do indutor tem-se valores de $L, C_{I N D}$ e $R_{I N D}$. A partir destes valores, obtiveramse modelos para estes parâmetros compatíveis com um programa geométrico. Para isto foram 


\begin{tabular}{ccc}
\hline Parâmetro & modelo & erro médio [\%] \\
\hline$L$ & max_monômio & 14.4 \\
$C_{I N D}$ & monômio & 4.14 \\
$1 / R_{I N D}$ & max_monômio & 23.96 \\
\hline
\end{tabular}

Tabela 4.3: Modelo dos parâmetros do indutor simétrico compatíveis com programação geométrica.

aplicadas as mesmas técnicas descritas no capítulo 2.

$$
\begin{aligned}
& \frac{1}{R_{I N D}}=\max \left\{\left(5.07 \times 10^{-7}\right) d_{\text {ext }}^{-1.46} w_{\text {ind }}^{0.027} s^{0.053} n^{-1.93},\right. \\
& \left.\left(5.13 \times 10^{-4}\right) d_{\text {ext }}^{-1.53} w_{\text {ind }}^{0.818} s^{0.116} n^{-0.74}\right\} \\
& L=\max \left\{\left(8.88 \times 10^{3}\right) d_{\text {ext }}^{1.42} w_{\text {ind }}^{2.03} s^{-0.013} n^{1.16}\right. \text {, } \\
& \left.\left(2.39 \times 10^{-7}\right) d_{\text {ext }}^{1.68} w_{\text {ind }}^{-0.67} s^{-0.048} n^{1.26}\right\} \\
& C_{I N D}=\left(4.14 \times 10^{-11}\right) d_{\text {ext }}^{0.854} w_{\text {ind }}^{0.062} s^{0.018} n^{0.039}
\end{aligned}
$$

Na tabela 4.3 mostram-se as caraterísticas dos modelos obtidos. Na tabela, o erro médio corresponde à média do erro relativo avaliado em todas as espiras, assim:

$$
\text { erro relativo }=\frac{|y-\hat{y}|}{y}
$$

onde $y$ é valor obtido por simulação e $\hat{y}$ o valor estimado pelo modelo.

Estes modelos junto com a descrição do VCO feita no capítulo completam a descrição do projeto do VCO como um programa geométrico. No capítulo seguinte apresenta-se a aplicação da metodologia ao projeto de um VCO. 


\section{Projeto de um VCO na banda ISM $2.4 \mathrm{GHz}$}

Como exemplo da aplicação da metodologia, este capítulo descreve o projeto de um VCO numa tecnologia CMOS $0.35 \mu \mathrm{m}$ de quatro metais, com espessura do último metal de $0.925 \mu \mathrm{m}$. As caraterísticas desta tecnologia são apresentadas na tabela 5.1. Os modelos do indutor obtidos no capítulo anterior, assim como restrições nas dimensões do indutor, foram incluídos no programa geométrico formulado no capítulo 3:

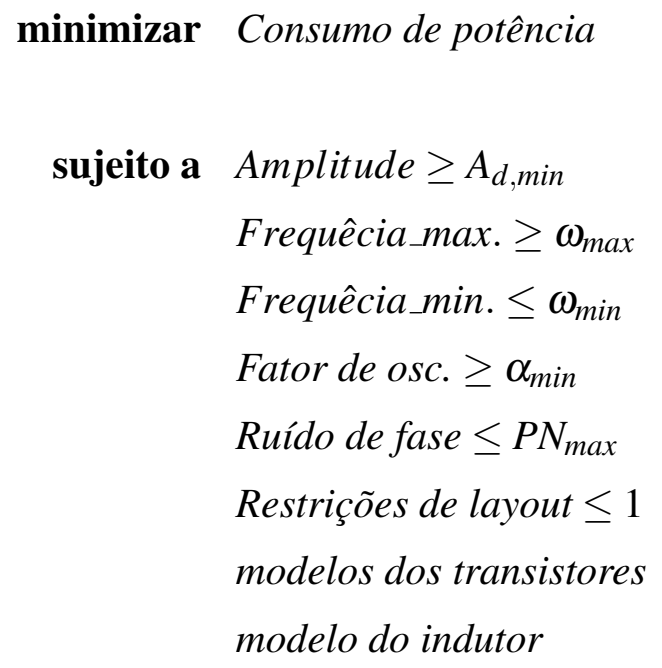

Entre as restrições de layout estão:

- Limitou-se o diâmetro exterior indutor a um valor máximo:

$$
d_{\text {ext }} \leq D_{E X T} M A X
$$

- O comprimento $(w)$ e o espaçamento $(s)$ do indutor devem cumprir:

$$
(w+s) * n \leq d_{\text {ext }} / 2
$$

onde $n$ é u número de espiras. 


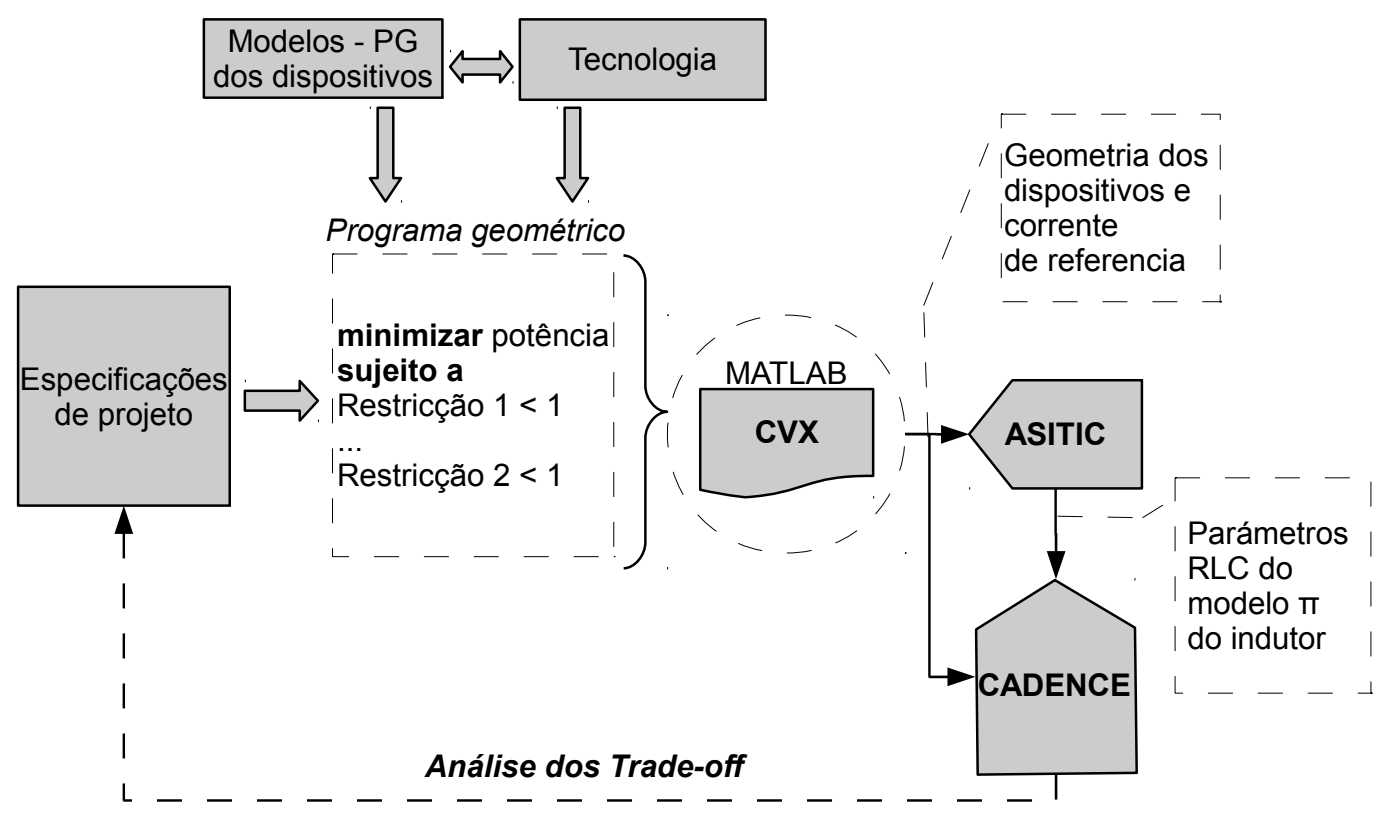

Figura 5.1: Fluxo de projeto proposto.

\begin{tabular}{ccc}
\hline Parâmetros & Unidades & Valores \\
\hline Comprimento mínimo do canal & $\mu m$ & 0.35 \\
$V_{D D}$ típico & $V$ & 3.3 \\
Mobilidade efetiva $\left(\mu_{n}, \mu_{p}\right)$ & $\frac{c m^{2}}{V \cdot s}$ & 370,126 \\
Velocidade de saturação $\left(v_{\text {sat } n}, v_{\text {sat }-p}\right)$ & $\frac{m}{s}$ & $1.388 \times\left(10^{5}\right), 1.158 \times\left(10^{5}\right)$ \\
Tensão de limiar $\left(V_{t n},-V_{t p}-\right)$ & $V$ & $0.50,0.65$ \\
Fator de ganho $\left(K_{n}, K_{p}\right)$ & $\left.\frac{\mu A}{V}\right)$ & 170,58 \\
Capacitância óxido-porta $\left(C_{o x}\right)$ & $\frac{f F}{\mu m^{2}}$ & 4.54 \\
Capacitância overlap $\left(C_{o v}\right)$ a N+, $\mathrm{P}+$ & $\frac{f F}{\mu m}$ & $0.131,0.108$ \\
Capacitância de junção $\left(C_{j o}\right) \mathrm{N}+/ \mathrm{P}, \mathrm{P}+/ \mathrm{N}$ & $\frac{f F}{\mu m^{2}}$ & $0.84,1.36$ \\
Area grading coefficient $\left(m_{j}\right) \mathrm{N}+/ \mathrm{P}, \mathrm{P}+/ \mathrm{N}$ & - & $0.34,0.54$ \\
Capacitância de união lateral $\left(C_{j s w o}\right) \mathrm{N}+/ \mathrm{P}, \mathrm{P}+/ \mathrm{N}$ & $\frac{f F}{\mu m}$ & $0.25,0.35$ \\
Sidewall grading coefficient $\left(m_{j s w}\right) \mathrm{N}+/ \mathrm{P}, \mathrm{P}+/ \mathrm{N}$ & - & $0.23,0.46$ \\
Potencial de união $\left(P_{B}\right) \mathrm{N}+/ \mathrm{P}, \mathrm{P}+/ \mathrm{N}$ & $\mathrm{V}$ & $0.69,1.02$ \\
\hline
\end{tabular}

Tabela 5.1: Tecnologia AMS C35B4C3 $0.35 \mu \mathrm{m} C M O S$ 
- Limitou-se a largura máxima do canal de todos os transistores:

$$
W_{i} \leq W_{i} M A X
$$

- Foi imposto o mínimo comprimento de canal para os transistores dos pares cruzados ${ }^{1}$ :

$$
L_{p 1, p 2}=L_{n 1, n 2}=0.35 \mu \mathrm{m}
$$

- Para os transistores do espelho de corrente foi imposto que tivessem o mesmo comprimento de canal. Além disso, limitou-se o mínimo comprimento de canal que podem ter.

$$
\begin{array}{r}
L_{c m}=L_{m r} \\
L_{c m} \geq L M I N
\end{array}
$$

e fácil demostrar que todas as restrições anteriores cumprem com a forma matemática exigida para as restrições de um programa geométrico na forma padrão.

Usou-se CVX para solucionar o programa geométrico resultante. Uma das vantagens da formulação do projeto do VCO como um programa geométrico é a possibilidade de automatizar todo o processo de projeto. Assim sendo, elaborou-se um script que recebe as especificações de projeto, parâmetros da tecnologia e os modelos dos dispositivos, para depois formar o problema de otimização. Com a solução do PG, segue a etapa de verificação que consiste primeiramente, na simulação em ASITIC da geometria do indutor. Seguidamente os valores do modelo do indutor gerado por ASITIC são usados na simulação do VCO em spectreRF da CANDENCE, verificando assim o desempenho do VCO usando os modelos BSIM3v3 dos transistores fornecidos pela foundry. Este processo foi totalmente automatizado, excetuando-se a verificação em spectreRF. A figura 5.1 ilustra o fluxo de projeto.

\subsection{Projeto e análise dos resultados}

A tabela 5.2 mostra as especificações de projeto do VCO. Nesta tabela os resultados do programa geométrico são comparados com simulações do VCO em spectreRF. O programa geométrico demorou menos de um minuto para ser solucionado em CVX, estes resultados confirmam a eficiência da metodologia. Com a solução do programa geométrico obtém-se: as dimensões dos dispositivos (transistores e indutor), o valor da capacitância máxima e mínima do varactor e o valor da corrente de referência $I_{R E F}$ que minimizam a potência do circuito,

\footnotetext{
${ }^{1}$ Os modelos da foundry destes transistores, por estarem trabalhando em altas frequências, só estão caracterizados para comprimento mínimo de canal.
} 


\begin{tabular}{cccc}
\hline Parâmetro & Especificação & PG & spectreRF \\
\hline Potência (BIAS + Core) $[\mathrm{mW}]$ & minimize & 10.2 & 10.5 \\
Frequência central [GHz] & 2.45 & 2.45 & 2.45 \\
Faixa de sintonia & $>3.5 \%$ & $3.5 \%$ & $4.1 \%$ \\
Ruído de fase @ 3MHz [dBc/Hz] & $<-130$ & -130 & -129.5 \\
Tensão diferencial de saída [mVp] & $>750$ & 937 & 995 \\
Fator de oscilação, $\alpha$ em Ecuação $(3.5)$ & $>2$ & 2 & 2.17 \\
$V_{D D}[\mathrm{~V}]$ & 2.5 & 2.5 & 2.5 \\
Capacitância de carga $[\mathrm{fF}]$ & 100 & 100 & 100 \\
FOM & - & $\sim 180^{\dagger}$ & $\sim 180^{\dagger}$ \\
\hline
\end{tabular}

${ }^{\dagger}$ Calculada sem considerar a corrente $I_{R E F}$.

Tabela 5.2: Especificações de projeto e desempenho do VCO estimado da solução do programa geométrico e verificado por simulações em spectreRF.

cumprindo com as especificações de projeto. Usou-se um varactor PMOS de acumulação. Nas simulações do VCO, usaram-se os modelos BSIM3v3 dos transistores e o modelo do varactor fornecidos pela foundry. No caso do indutor, usou-se o modelo- $\Pi$ simplificado do indutorótimo obtido mediante simulações da espira em ASITIC. Finalmente, em spectreRF usou-se o método de harmonic balance para estimação do ruído de fase.

As dimensões ótimas dos transistores estimadas pelo programa geométrico são apresentadas na tabela 5.3, aqui se mostra a transcondutância total, $g_{\text {ativos }}$, fornecida pelos transistores dos pares estimada a partir dos modelos dos transistores usados no PG e verificados na simulação do VCO. Na tabela 5.4 as dimensões ótimas do indutor são apresentadas, bem como o desempenho do indutor calculado a partir dos modelos usados no PG. Estes resultados mostraram um erro baixo ao ser comparados com simulações do indutor em ASITIC. Dos resultados obtidos,

\begin{tabular}{ccc}
\hline Variável & PG & spectreRF \\
\hline$W_{T A I L} / L_{T A I L}[\mu \mathrm{m} / \mu \mathrm{m}]$ & $1200 / 3.57$ & $1200 / 3.55$ \\
$W_{C M} / L_{C M}[\mu \mathrm{m} / \mu \mathrm{m}]$ & $500 / 3.57$ & $500 / 3.55$ \\
$W_{p} / L_{p}[\mu \mathrm{m} / \mu \mathrm{m}]$ & $239.8 / 0.35$ & $240 / 0.35$ \\
$W_{n} / L_{n}[\mu \mathrm{m} / \mu \mathrm{m}]$ & $78.4 / 0.35$ & $80 / 0.35$ \\
$C_{V \min } / C_{V \max }[\mathrm{fF}]$ & $745 / 833$ & $583 / 671$ \\
$1 / 2 *\left(g_{m_{n}}+g_{m_{p}}\right)[\mathrm{mS}]$ & 7.87 & 9.75 \\
$g_{d p} / g_{d n}[\mu \mathrm{S} / \mu \mathrm{S}]$ & $424.3 / 217.2$ & $539 / 279.3$ \\
$I_{\text {ref }}[\mathrm{mA}]$ & 1.2 & 1.2 \\
$I_{\text {tail }}[\mathrm{mA}]$ & 2.9 & 3 \\
\hline
\end{tabular}

Tabela 5.3: Desempenho e tamanhos-ótimos dos dispositivos estimados na solução do programa geométrico e verificados por simulações em spectreRF. 


\begin{tabular}{ccc}
\hline Parâmetro & PG & ASITIC \\
\hline$d_{\text {ext }}[\mu \mathrm{m}]$ & 275 & 275 \\
$w_{\text {ind }}[\mu \mathrm{m}]$ & 15.9 & 15.9 \\
$s[\mu \mathrm{m}]$ & 1 & 1 \\
$n$ & 3 & 3 \\
$L_{S}[\mathrm{nH}]$ & 3.4 & 3.7 \\
$Q_{L}$ & 4.5 & 4 \\
$G_{I N D}[\mathrm{mS}]$ & 3.5 & 4.1 \\
\hline
\end{tabular}

Tabela 5.4: Geometria e desempenho do indutor estimadas pelo programa geométrico e verificados em ASITIC.

observa-se que as estimativas do programa geométrico concordam com boa exatidão com as simulações feitas. Estes resultados confirmam que o comportamento do circuito e dos dispositivos foi modelado corretamente no programa geométrico.

Finalmente, dos resultados obtidos da solução do programa geométrico, observou-se que o ruído de fase se ajustou ao máximo valor permitido (a restrição associada a esta especificação se cumpriu em igualdade) o que indica que uma especificação mais exigente de ruído de fase poderia exigir um consumo de potência maior. O mesmo comportamento foi observado na condição de oscilação, a qual se ajustou ao mínimo especificado. Esta ultima observação é importante pois sugere que para tecnologias com menor comprimento de canal, os transistores do par cruzado podem ter a mesma transcondutância para uma corrente menor, e desta forma é possível diminuir potência requerida. O impacto destas especificações no consumo de potência do VCO serão analisados na seção 5.3.

\subsection{Comparação com outros trabalhos}

Uma medida comumente usada para avaliar o desempenho de VCOs é a figura de mérito (FOM) [32]:

$$
F O M=\mathscr{L}(\Delta f)+20 \log \left(\frac{f_{c}}{\Delta f}\right)-10 \log (P[m W])
$$

esta medida relaciona a potência dissipada pelo VCO, medida em milliwatts $P[\mathrm{~mW}]$, necessária para atingir um determinado ruído fase medido a uma frequência de offset $\Delta f$ de um sinal que oscila a uma frequência $f_{c}$. A figura de mérito do VCO projetado foi $\sim 180 \mathrm{dBc} / \mathrm{Hz}$. A tabela 5.5 compara os resultados obtidos neste trabalho com outros publicados em conferências reconhecidas. Em termos gerais, observa-se na tabela que quanto maior o fator de qualidade do indutor maior a figura de mérito do VCO. Em relação ao segundo trabalho [42], este trabalho consegue 


\begin{tabular}{cclcc}
\hline Topologia & Tecnologia & $Q_{I N D}$ reportado & $f_{c}$, Ruído de fase & FOM \\
\hline Complementar [31] & CMOS $0.25 \mu \mathrm{m}$ & $7.5 @ 1.8 \mathrm{GHz}$ & $1.8 \mathrm{GHz},-121 @ 600 \mathrm{KHz}$ & 183 \\
NMOS-only [42] & CMOS 0.35 $\mu \mathrm{m}$ & $10 @ 2 \mathrm{GHz}$ & $2.1 \mathrm{GHz},-134 @ 3 \mathrm{MHz}$ & 181 \\
PMOS-only [43] & SiGe BiCMOS 0.18 $\mu \mathrm{m}$ & $10 @ 5 \mathrm{Ghz}$ & $5.3 \mathrm{GHz},-124 @ 1 \mathrm{MHz}$ & 187 \\
NMOS-only [35] & CMOS 0.35 $\mu \mathrm{m}$ & $12 @ 2.5 \mathrm{GHz}$ & $2.9 \mathrm{GHz},-142 @ 3 \mathrm{MHz}$ & 189 \\
NMOS-only [44] & BiCMOS $0.25 \mu \mathrm{m}$ & $12 @ 2 \mathrm{GHz}$ & $2.1 \mathrm{GHz},-117.5 @ 600 \mathrm{KHz}$ & 185 \\
Class-C [45] & CMOS $0.13 \mu \mathrm{m}$ & $16-17 @ 4.9-5.52 \mathrm{GHz}$ & $5.2 \mathrm{GHz},-131 @ 3 \mathrm{MHz}$ & 193 \\
\hline Este trabalho & $\mathrm{CMOS} 0.35 \mu \mathrm{m}$ & $4 @ 2.45 \mathrm{GHz}$ & $2.45 \mathrm{GHz},-130 @ 3 \mathrm{MHz}$ & 180 \\
\hline
\end{tabular}

Tabela 5.5: Comparação com outros trabalhos presentados.

uma FOM similar para um fator de qualidade do indutor consideravelmente menor. Por outro lado, na quarta referência [35], a filtragem da corrente de ruído do circuito de polarização somado ao uso de um indutor com um fator de qualidade 3 vezes maior permitiram um incremento de $9 \mathrm{dBc} / \mathrm{Hz}$ na figura de mérito.

\subsection{Curvas de trade-off para o VCO LC complementar}

Aproveitando a rapidez com que um programa geométrico é solucionado, é possível analisar eficientemente o impacto da variação de qualquer parâmetro no PG $\left(\right.$ Par $\left._{i}\right)$ no valor mínimo atingido $\left(o p t_{i}\right)$ da função a otimizar. Desta forma, ao resolver sucessivamente o programa geométrico para cada $\mathrm{Par}_{i}$ se terá um opt $_{i}$.

No caso do projeto do VCO, dos resultados obtidos na seção 5.1 se observou que ao minimizar a potência o ruído de fase se ajustou ao máximo valor especificado. O mesmo comportamento se observou na restrição associada à condição de oscilação, que se ajustou ao mínimo valor permitido. De forma similar, tanto o diâmetro do indutor quanto a largura do transistor $M_{c m}$ se ajustaram ao máximo valor permitido. A seguir será analisado o impacto destas especificações no consumo de potência do VCO. Cabe destacar que o mesmo procedimento pode ser aplicado à análises de qualquer outro parâmetro.

A restrição que considera a condição de oscilação é a seguinte:

$$
g_{\text {ativos }} \geq \alpha g_{\text {tank }}
$$

aqui, $g_{\text {ativos }}$ representa a transcondutância total fornecida pelos transistores dos pares; e $g_{\text {tank }}$ representa a condutância equivalente do ressoador. Tal como foi mencionado no capítulo 3 , valores de $\alpha$ entre 1 e 3 são recomendados para garantir o começo das oscilações no VCO.

A figura 5.2 mostra o comportamento do consumo de potência mínimo do circuito ao incrementar a especificação do máximo diâmetro exterior do indutor, para diferentes valores de $\alpha$. Da 


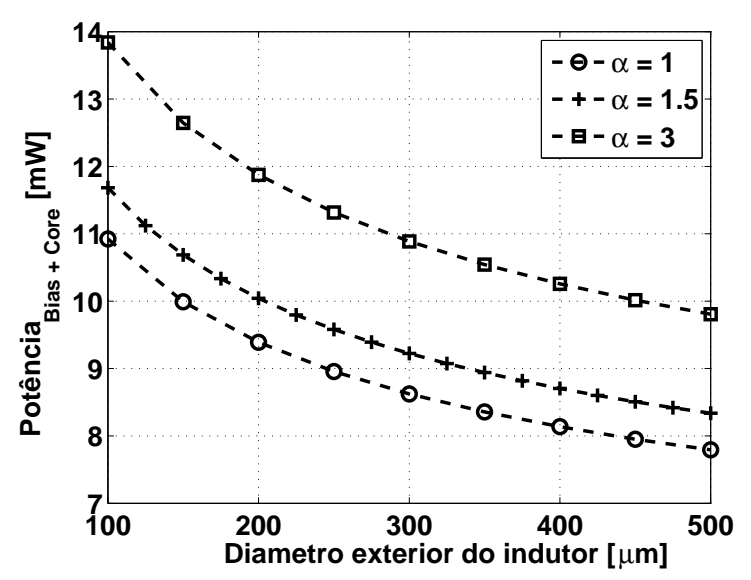

Figura 5.2: Consumo de potência Versus diâmetro exterior do indutor para diferentes fatores de oscilação.

figura observa-se que o impacto de $\alpha$ no mínimo consumo de potência do VCO é significativo. A figura 5.3 mostra qual foi o valor do fator de qualidade diferencial do indutor estimado pelo PG para cada diâmetro exterior do indutor. Desta figura observa-se que para diâmetros maiores que $300 \mu \mathrm{m}$ o fator de qualidade estimado por ASITIC não muda significativamente.

Por outro lado, a figura 5.4 mostra o consumo de potência para diferentes especificações de ruído de fase avaliados em dois casos. No primeiro caso, descrito com linha contínua, foi considerada a contribuição do ruído térmico pelos transistores dos pares NMOS e PMOS, o ressoador e o circuito de polarização. A restrição associada a estas considerações foi derivada no capítulo 3:

$$
\mathscr{L}(\Delta \omega)=\frac{K_{B} T\left(G_{I N D}+g_{v}\right)}{q_{\max }^{2}(\Delta \omega)^{2}}\left[1+\frac{\lambda_{n}+\lambda_{p}}{2}+\frac{\overline{i_{n, t a i l}^{2}}}{2 K_{B} T \Delta f} \Gamma_{r m s, t a i l}^{2}(\Phi)\right] \leq \text { PNspec }
$$

O outro caso, definido com linha tracejada, supõe que o ruído gerado no circuito de polarização não afeta o ruído de fase. Dessa forma, a restrição associada ao ruído de fase tem a seguinte forma:

$$
\mathscr{L}(\Delta \omega)=\frac{K_{B} T\left(G_{I N D}+g_{v}\right)}{q_{\max }^{2}(\Delta \omega)^{2}}\left(1+\frac{\lambda_{n}+\lambda_{p}}{2}\right) \leq \text { PNspec }
$$

A avaliação deste caso é importante pois permite determinar qual seria o melhor caso que poderia acontecer depois de aplicar alguma técnica de filtragem do ruído gerado pelo circuito de polarização [42], [44].

Finalmente, a figura 5.5 mostra o comportamento do mínimo consumo de potência do circuito ao variar a especificação do máximo diâmetro exterior do indutor para diferentes larguras máximas do transistor $M_{c m}$. Nesta análise o fator de oscilação foi ajustado a 1.5. Nesta curva observa-se que aumentando a largura deste transistor o consumo de potência diminui. 


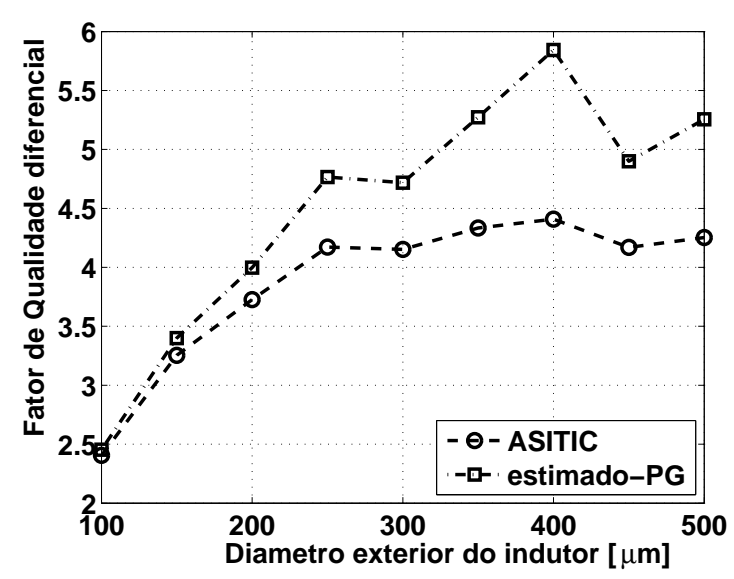

Figura 5.3: Fator de qualidade do indutor @ $2.45 \mathrm{GHz}$ para diferentes valores do diâmetro exterior do indutor.

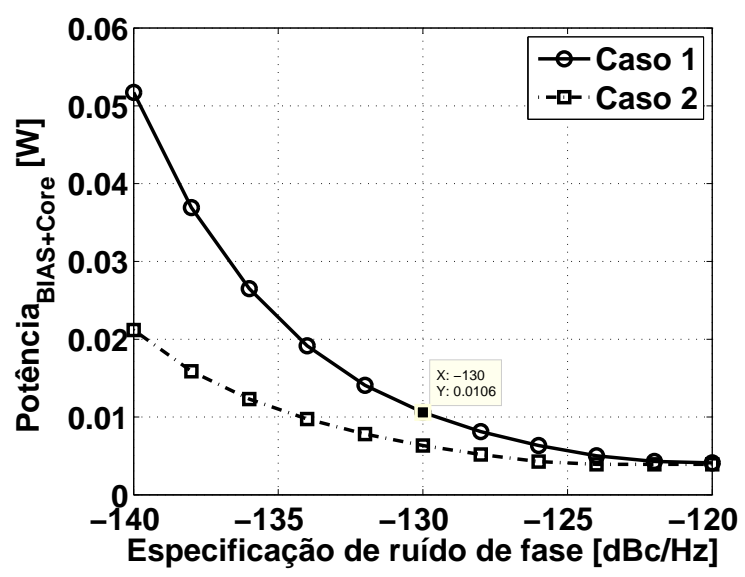

Figura 5.4: Consumo de potência para diferentes especificações de ruído de fase, considerando o ruído do circuito de polarização (linha contínua) sem considerar o ruído do circuito de polarização (linha tracejada).

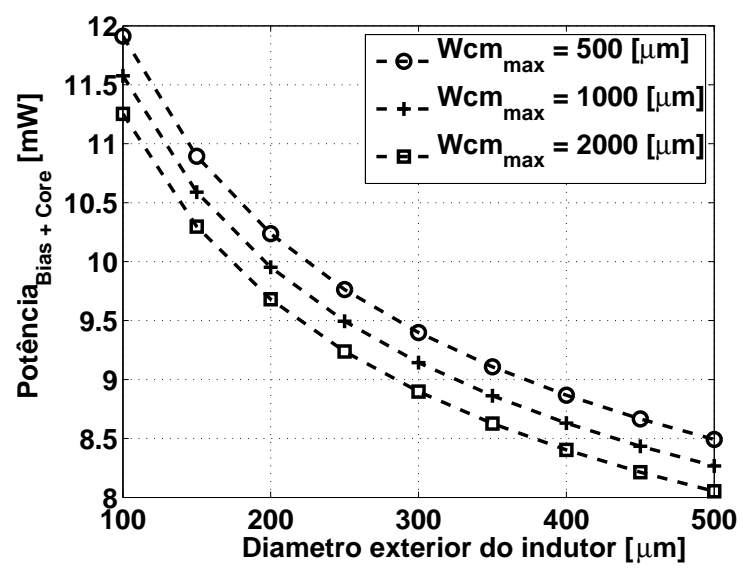

Figura 5.5: Consumo de potência para diferentes tamanhos do transistor $W_{c m}$. 


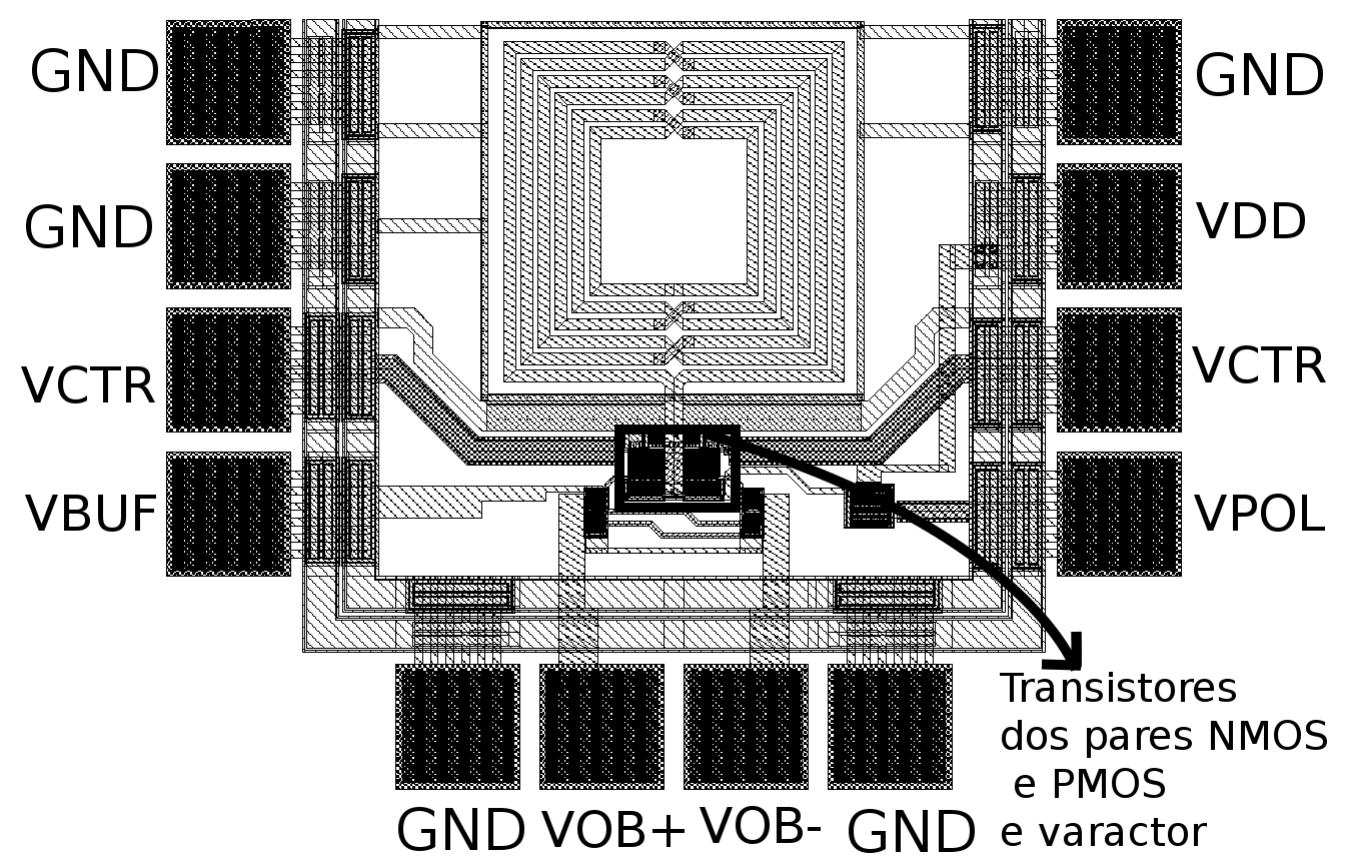

Figura 5.6: Layout do VCO com buffer diferencial.

\subsection{Layout e protótipo}

A figura 5.6 mostra o layout de um protótipo projetado para operar na banda de frequência de 2 a $2.5 \mathrm{GHz}$. Para uma frequência de $2.45 \mathrm{GHz}$ o ruído de fase a $3 \mathrm{MHz}$ simulado foi de $-128 \mathrm{dBc} / \mathrm{Hz}$. O consumo de potência do VCO foi $9.4 \mathrm{~mW}$ para $V_{D D}=3.0 \mathrm{~V}$. Para a etapa de saída do VCO (buffer) foi usado o circuito proposto em [46]; a figura 5.7 mostra o esquemático. O circuito é completamente diferencial e de drenos abertos. Os nós $V I N+$ e $V I N-$ são ligados aos nós de saída do VCO, e a saída do bloco VCO+buffer corresponde aos nós $V O B+$ e $V O B-$. Um buffer na saída do VCO é necessário para isolar os nós de saída da impedância de carga, e desta forma não alterar seu desempenho. Da mesma forma, a etapa de saída provê a corrente necessária à carga de saída nos testes experimentais; esta carga vai desde o PAD de saída até a

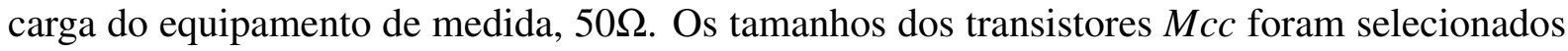
para ter uma amplitude de $1 \mathrm{~V}$ (diferencial pico) nos nós de saída $(V O B+$ e $V O B-$ ).

A figura 5.8 mostra o esquemático do testbench usado nas simulações póslayout. A corrente de referência será dada por uma resistência externa de $150 \Omega$ ligada ao nó $V$ pol que corresponde ao dreno de $M_{c m}$. Cabe destacar que para a fonte de alimentação da etapa de saída foi usado um PAD separado. Na figura 5.9 se mostra a corrente $I_{T A I L}$ e a tensão de saída do VCO+buffer obtidas mediante simulações póslayout do circuito. A figura 5.10 mostra o ruído de fase medido para o sinal entre os $V O B+$ e $V O B-$; para uma frequência da portadora de $2.45 \mathrm{GHz}$. Na mesma 


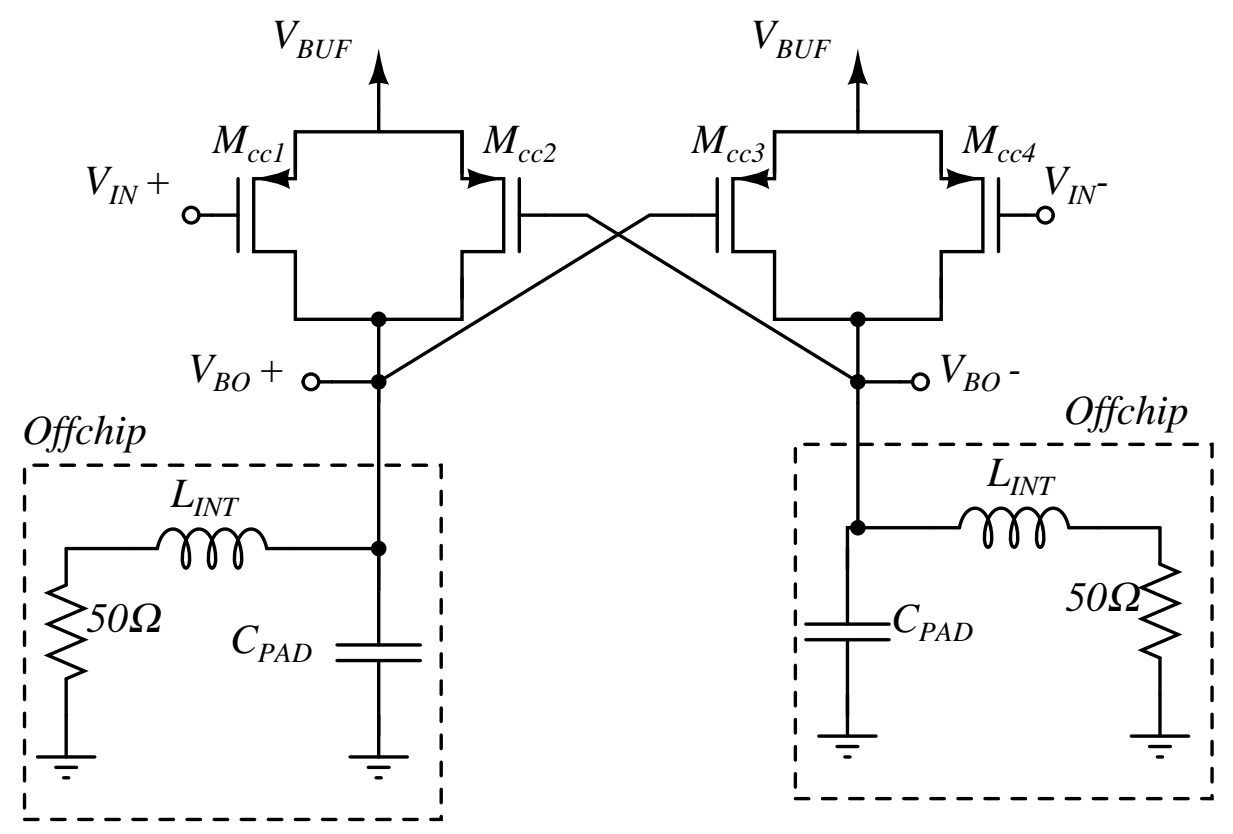

Figura 5.7: Etapa de saída do VCO.

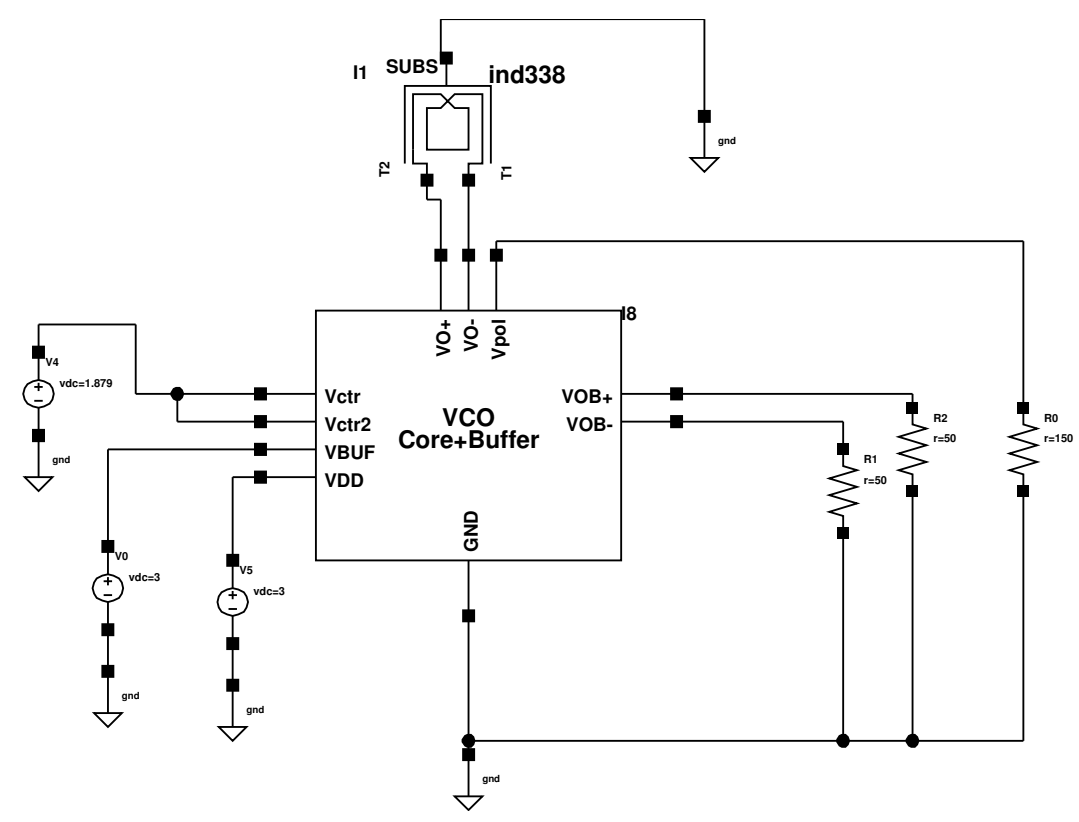

Figura 5.8: Testbench para simulações póslayout. 


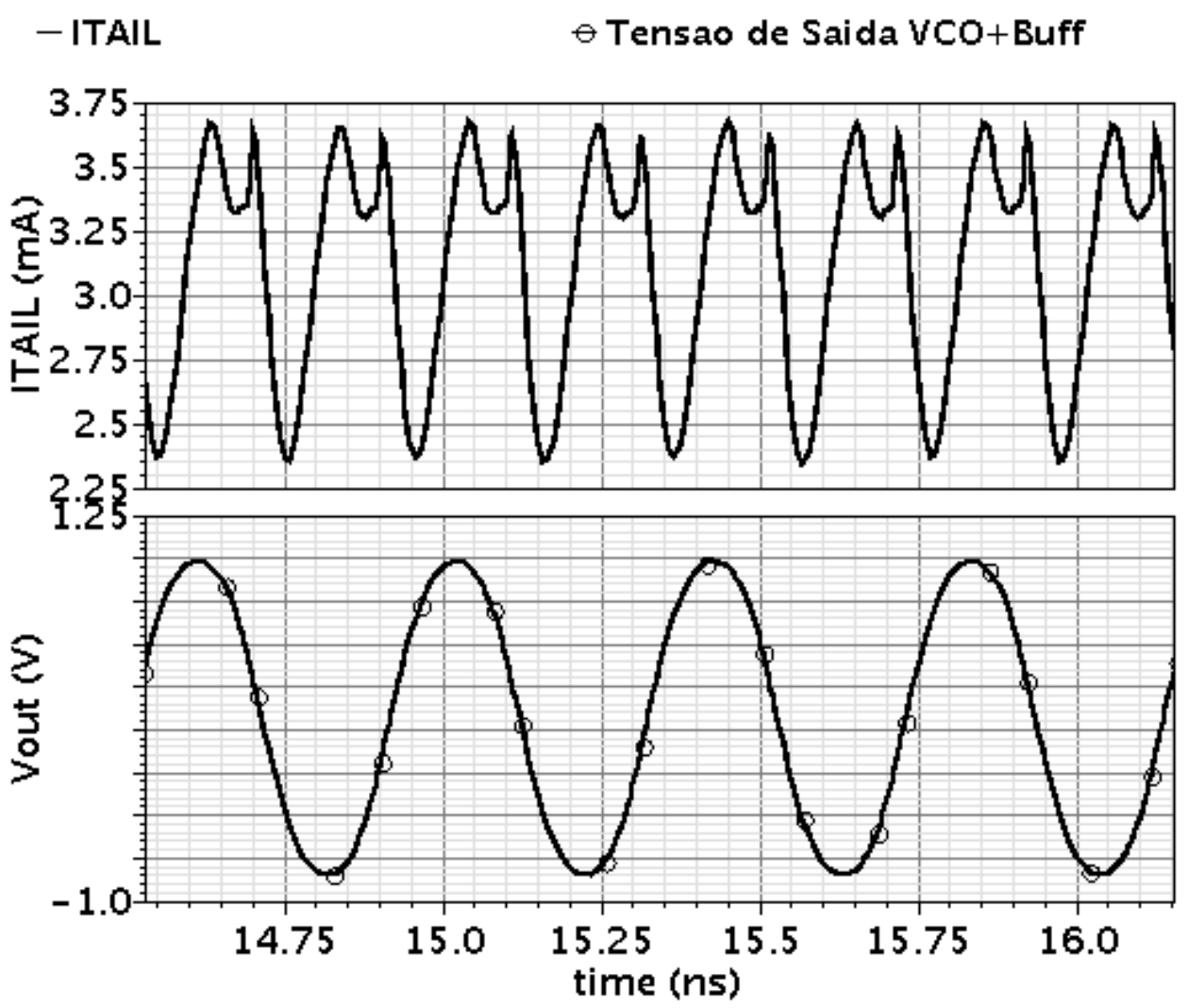

Figura 5.9: Corrente $I_{T A I L}$ e tensão diferencial na saída do buffer.

figura, observa-se o comportamento da frequência de oscilação com a tensão de controle $V_{C T R}$. Finalmente, na figura 5.11 se mostra uma microfotografia do protótipo fabricado.

\subsection{Resultados experimentais}

Esta seção descreve os resultados experimentais obtidos ao realizar testes sobre o protótipo fabricado. A figura 5.12 mostra uma foto dos equipamentos usado nas medidas. Os testes foram feitos ondie usando um microprovador de microondas cascade.

A polarização do circuito foi feita da seguinte forma. A corrente de referência foi gerada usando uma resistência offchip de $150 \Omega$ conectada ao pad VPOL através de uma ponta seca. Da mesma forma, a tensão de alimentação do VCO (pad $V D D)$, a tensão de alimentação do buffer (pad $V B U F)$ e a tensão de controle $(V C T R)$ foram ligadas ao circuito através de pontas secas.

Os pads com os sinais de saída do circuito (pads $V O B+$ e $V O B-$ ) foram acessados através de uma ponta de prova (terra-sinal-sinal-terra) da picoprobe (model 40A). Esta ponta permite 


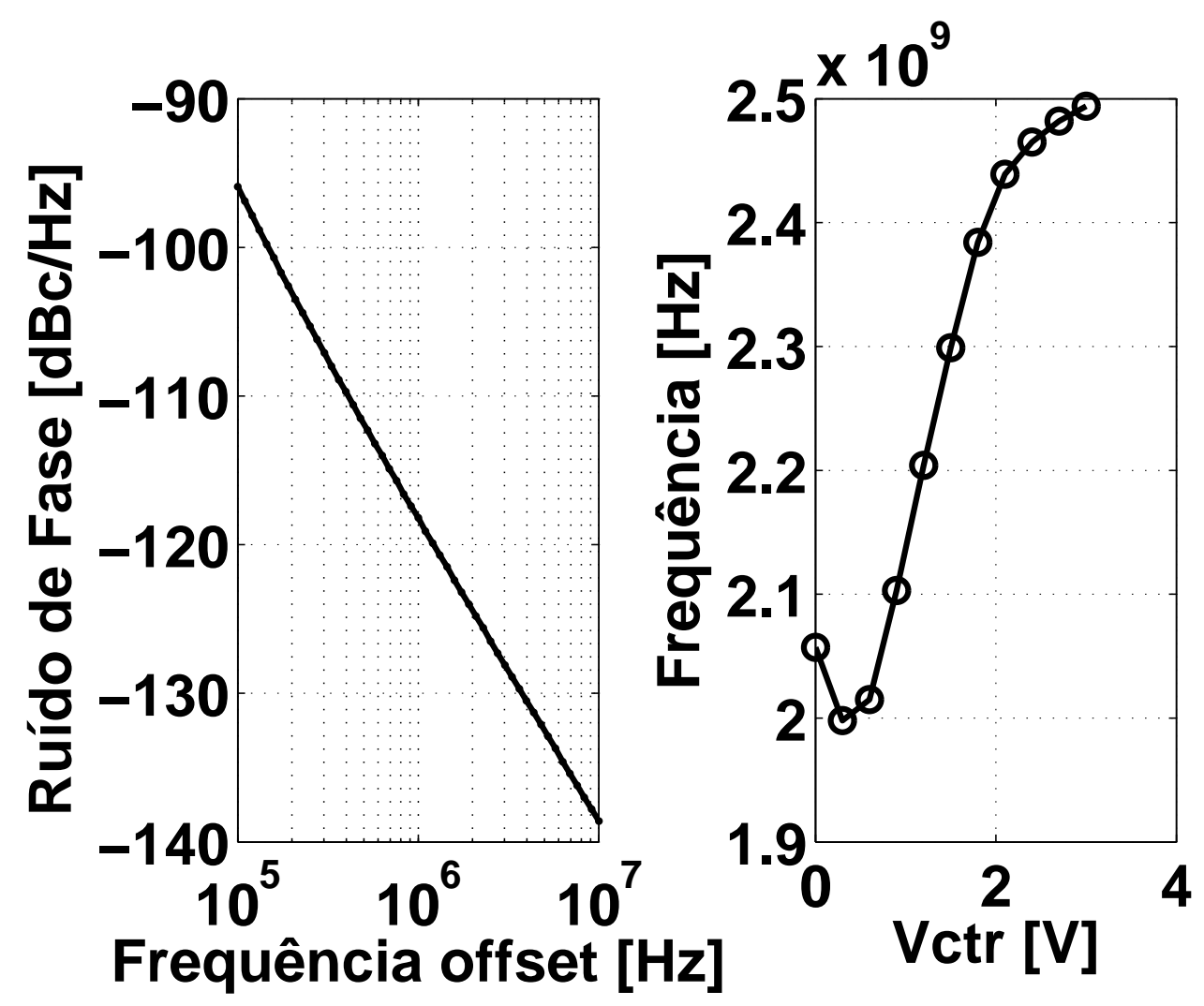

Figura 5.10: (Esquerda) Ruído de fase do VCO+buffer para uma frequência de oscilação de $2.45 \mathrm{GHz}$. (Direita) Frequência de oscilação versus tensão de controle $V_{C T R}$.

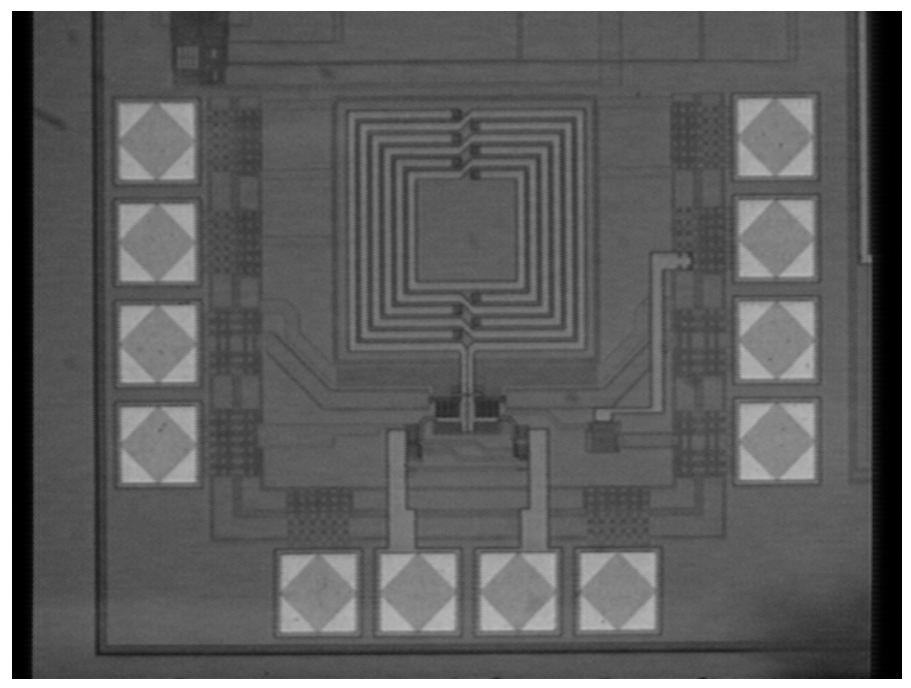

Figura 5.11: Microfotografia do protótipo fabricado. 


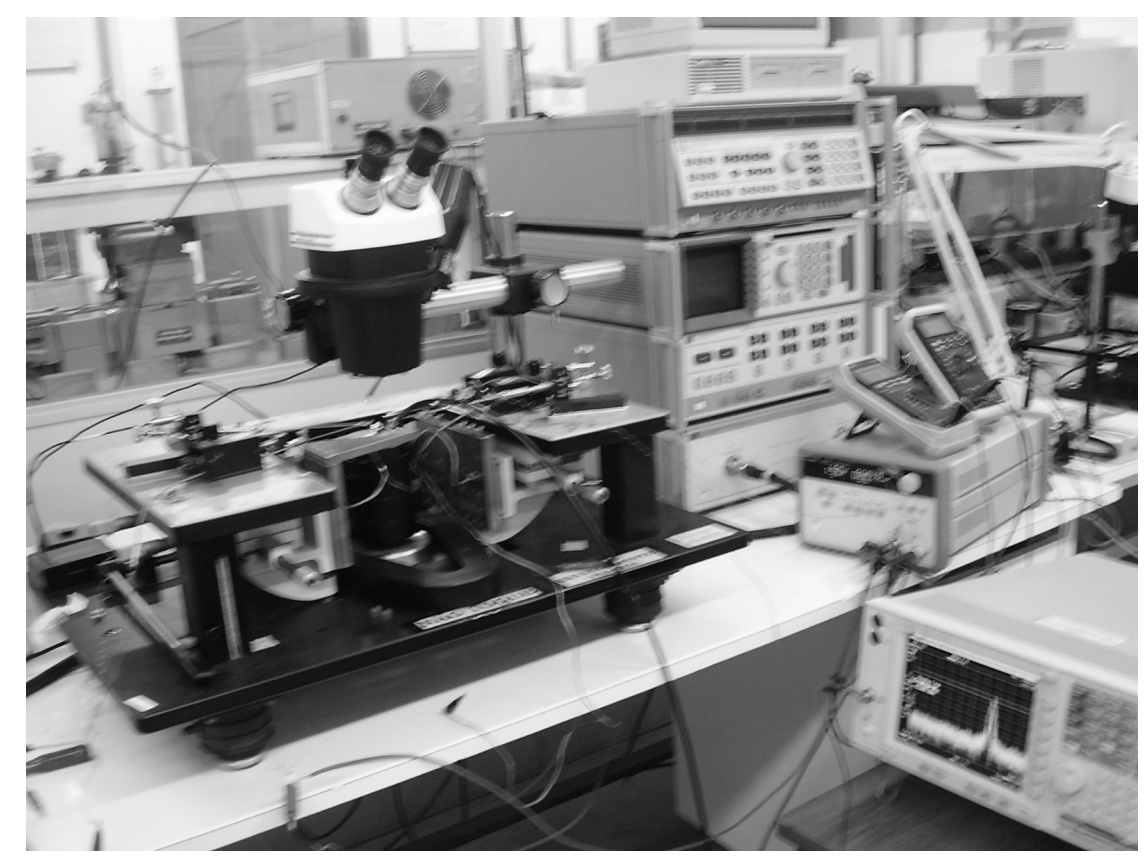

Figura 5.12: Estação de prova RF cascade

dispor das duas sinais de saída do circuito, assim uma delas (PAD VOB-) é ligada ao analisador de espectro (Agilent E4440A) através de um bias tee. A outra sinal (pad VOB+), e conectada a uma resistência de $50 \Omega$ a terra. Na foto da figura 5.13 é possível observar a conexão das pontas secas e da ponta de prova de RF.

A figura 5.14 mostra o espectro do sinal no pad $V O B-$. Para esta medida o analisador de espectro foi configurado para atenuar o sinal 10dB. Finalmente, modificando a tensão de controle de 0 a $3 \mathrm{~V}$, a frequência do sinal mudou de acordo com a figura 5.15. Da figura observa-se boa correlação da medida com as simulações póslayout do circuito. 


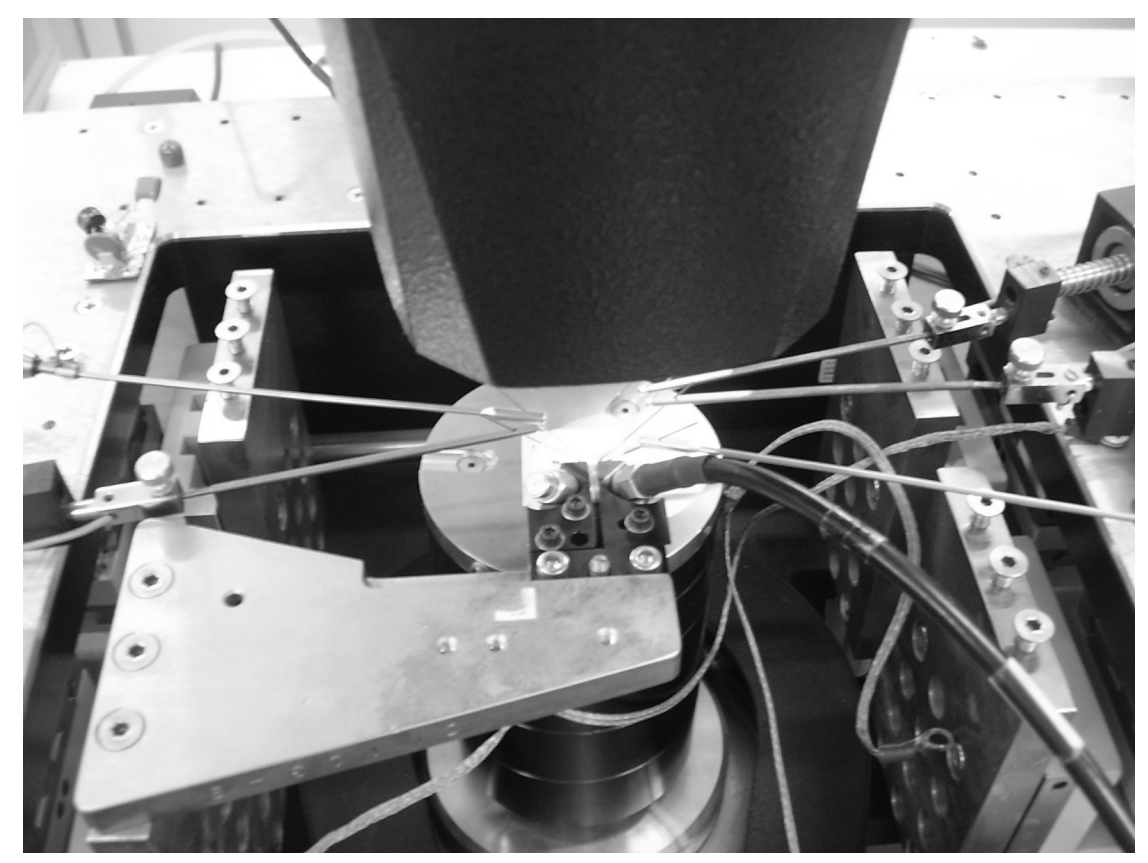

Figura 5.13: Medidas on-die do protótipo.

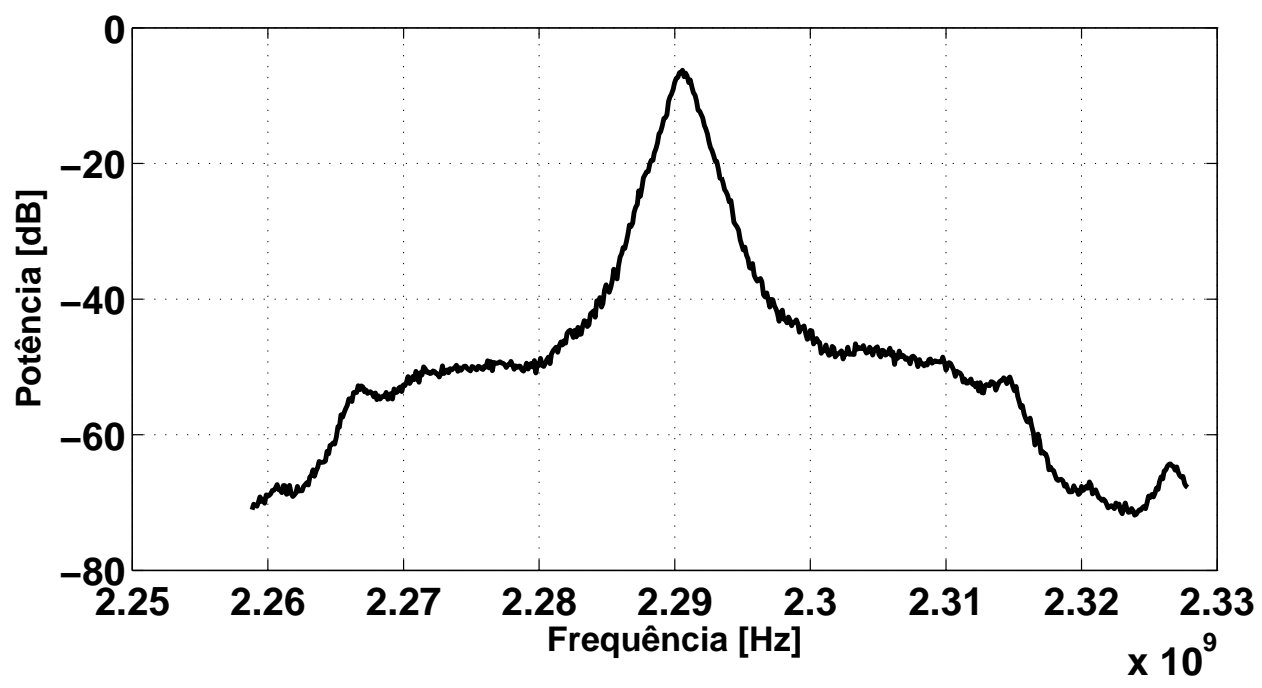

Figura 5.14: Espectro do sinal em uma das saídas do buffer. Frequência central: $2.293 \mathrm{GHz}$, Span: $69 \mathrm{MHz}$, Resolution Bandwith: $680 \mathrm{KHz}$ 


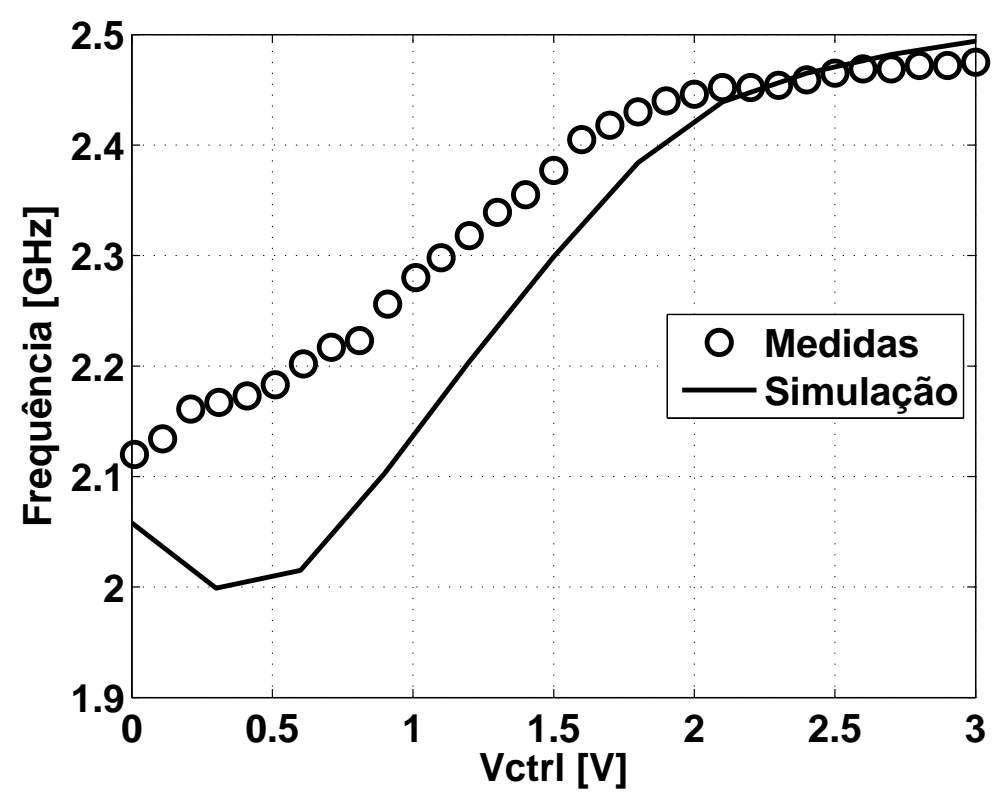

Figura 5.15: Faixa de sintonia do VCO 


\section{Conclusões e recomendações para trabalhos futuros}

O desenvolvimento de uma ferramenta para automação e otimização do projeto de um VCO LC complementar foram as principais metas perseguidas nesta dissertação. Nesse sentido, escolheu-se a programação geométrica como plataforma matemática e formulou-se o problema de projeto do VCO como um problema de otimização.

Antes de iniciar com o projeto do VCO, aplicou-se a metodologia ao projeto de um amplificador fonte comum com carga ativa. Durante este processo, identificaram-se as principais limitações da aplicação da programação geométrica no projeto de circuitos, e discutiramse estratégias apresentadas na literatura para lidar com estes problemas. Entre as limitações identificadas, está a necessidade de gerar modelos do transistor com funções compatíveis num programa geométrico. Assim, a partir de técnicas numéricas de ajuste e, sobre um espaço de projeto, geraram-se modelos, com funções compatíveis num programa geométrico, para parâmetros do transistor como: $V_{G S}, g_{m}, g_{d} s$, em função da polarização e da geometria dos dispositivos: $W, L, I_{D S}, V_{D S}$.

Para a topologia do VCO, expressões para a condição de oscilação, frequência de ressonância, faixa de sintonia, amplitude e ruído de fase em função de parâmetros do transistor e variáveis de projeto, foram apresentadas. Mostrou-se que especificações de projeto nos parâmetros de desempenho do VCO podem ser levados como restrições de um programa geométrico.

Observando que os elementos do modelo- $\Pi$ do indutor estão relacionados com a geometria da espira através de funções compatíveis com programação geométrica, derivou-se um modelo diferencial do indutor a partir dos elementos de um modelo- $\Pi$ simplificado. Mediante simulações em ASITIC, obtiveram-se os elementos do modelo- $\Pi$ simplificado de 18000 indutores simétricos num espaço de projeto. A partir desses valores, aplicaram-se técnicas numérica de ajuste e obtiveram-se modelos do indutor simétrico compatíveis com um programa geométrico. 
Usou-se um espelho de corrente PMOS para a polarização do VCO. Derivou-se uma expressão para a corrente de ruído térmico na saída do espelho. Foi proposta uma expressão para o ruído de fase que considera a contribuição do ruído térmico dos transistores dos pares, do circuito de polarização e do circuito tanque. Formulou-se um programa geométrico no software CVX que minimiza a potência do VCO sujeito a especificações sobre a amplitude, condição de oscilação, frequência, faixa de sintonia e ruído de fase. Elaborou-se um programa em MATLAB para automatizar este processo. Um VCO com ruído de fase de $130 \mathrm{dBc} / \mathrm{Hz}$ @ 3MHz, figura de mérito de $180 \mathrm{dBc} / \mathrm{Hz}$ na banda de frequência ISM $2.4 \mathrm{GHz}$ foi projetado e verificado mediante simulações em spectreRF da CADENCE, usando para isto os modelos fornecidos pela foundry para os transistores e o varactor. Elaborou-se o layout fabricou-se um protótipo. Resultados experimentais mostraram boa correlação com as simulações póslayout do circuito.

Como trabalhos futuros, recomenda-se estender a formulação feita do projeto do VCO e considerar o ruído de fase na região $1 / f^{3}$. Para isto é necessário considerar o ruído flicker dos dispositivos, assim como estudar os mecanismos de transformação desse ruído em ruído de fase. Por outro lado, é necessário continuar com os testes do circuito. Recomenda-se elaborar um setup de medida para a medição de ruido de fase do VCO. Para osciladores oscilando "livremente", recomenda-se usar métodos alternativos à medição direta com o analisador de espectro. 


\section{Referências Bibliográficas}

[1] GIELEN, G. Design methodologies and tools for circuit design in cmos nanometer technologies. Solid-State Device Research Conference, 2006. ESSDERC 2006. Proceeding of the 36th European, p. 21-32, Sept. 2006. ISSN 1930-8876.

[2] SREDOJEVIC, R.; STOJANOVIC, V. Optimization-based framework for simultaneous circuit and system design-space exploration: A high-speed link example. IEEE/ACM International Conference on Computer-Aided Design, November 2008.

[3] FARFÁN, A. Projeto e Implementação de um Oscilador Monolítico a 2,4GHz em Tecnologia CMOS 0,35um. Dissertação (Mestrado) - Escola Politécnica da Universidade de São Paulo, Janeiro 2004.

[4] GUARNIERI, L. et al. Eda tools for rf: myth or reality? Design, Automation and Test in Europe Conference and Exhibition, 2002. Proceedings, p. 292-293, 2002. ISSN 15301591.

[5] BOYD, S.; VANDENBERGHE, L. Convex Optimization. Cambridge: Cambridge University Press, 2004.

[6] MOSEK ApS. Mosek. Disponível em: <http://www.mosek.com/>.

[7] CVX: Matlab Software for Disciplined Convex Programming. 2008. Disponível em: $<$ http://www.stanford.edu/ boyd/cvx/ $>$.

[8] GRANT, M. C.; BOYD, S. P. Graph implementations for nonsmooth convex programs. Recent Advances in Learning and Control, v. 371/2008, p. 95-110, Dezembro 2008.

[9] GRANT, M. C.; BOYD, S. P. Disciplined convex programming. Liberti, L., Maculan, N. (eds.) Chapter in Global Optimization: From Theory to Implementation, Nonconvex Optimization and Its Applications, p. 155-210, 2006.

[10] MOHAN, S.; HERSHENSON, M.; BOYD, S.; LEE, T. Bandwidth extension in cmos with optimized on-chip inductors. Solid-State Circuits, IEEE Journal of, v. 35, n. 3, p. 346-355, Mar 2000. ISSN 0018-9200.

[11] HERSHENSON, M. del M. Design of pipeline analog-to-digital converters via geometric programming. Computer Aided Design, 2002. ICCAD 2002. IEEE/ACM International Conference on, p. 317-324, Nov. 2002. ISSN 1092-3152.

[12] COLLERAN, D. et al. Optimization of phase-locked loop circuits via geometric programming. Custom Integrated Circuits Conference, 2003. Proceedings of the IEEE 2003, p. 377-380, Sept. 2003. 
[13] LEE, J.; HATCHER, G.; VANDENBERGH, L.; YANG, C.-K. K. Evaluation of fullyintegrated switching regulators for cmos process technologies. System-on-Chip, 2003. Proceedings. International Symposium on, p. 155-158, Nov. 2003.

[14] HERSHENSON, M.; HAJIMIRI, A.; MOHAN, S.; BOYD, S.; LEE, T. Design and optimization of lc oscillators. In: . [S.1.: s.n.], 1999. p. 65-69.

[15] OLIVEROS, J.; CABRERA, D.; ROA, E.; NOIJE, W. V. An improved and automated design tool for the optimization of cmos otas using geometric programming. In: SBCCI '08: Proceedings of the 21st annual symposium on Integrated circuits and system design. New York, NY, USA: ACM, 2008. p. 146-151. ISBN 978-1-60558-231-3.

[16] BOYD, S.; KIM, S. J.; VANDENBERGHE, L.; HASSIBI, A. A tutorial on geometric programming. Optmization and Engineering, v. 8, n. 1, p. 67-127, 2007.

[17] YE, Y. Interior Point Algorithms: Theory and Analysis. New York: John Wiley and Sons, 1997.

[18] Y., C. et al. BSIM3v3 Manual. Berkeley: University of California, 1996.

[19] VANDERHAEGEN, J. P.; BRODERSEN, R. W. Automated design of operational transconductance amplifiers using reversed geometric programming. In: Proceedings of the 41st annual Design Automation Conference. New York, NY, USA: ACM, 2004. p. 133138. ISBN 1-58113-828-8.

[20] MAGNANI, A.; BOYD, S. Convex piecewise-linear fitting. Optimization and Engineering, 2008.

[21] KIM, J.; LEE, J.; VANDENBERGHE, L.; YANG, C.-K. K. Techniques for improving the accuracy of geometric-programming based analog circuit design optimization. Computer Aided Design, 2004. ICCAD-2004. IEEE/ACM International Conference on, p. 863870, Nov. 2004. ISSN 1092-3152.

[22] LC oscillator design (GP). 2005. Disponível em: $<$ http://www.stanford.edu/boyd/cvx/examples/circuit_design/ $>$.

[23] LEE, T. H. The Design of CMOS Radio-Frequency Integrated Circuits. Second. New York, NY: Cambridge, 2004.

[24] D.HAM; A.HAJIMIRI. Concepts and methods in optimization of integrated lc vcos. Solid-State Circuits, IEEE Journal of, v. 6, n. 36, p. 896-909, June 2001.

[25] MAGET, J. Varactors and inductors for integrated RF Circuits in standard MOS Technologies. Tese (Doutorado) - Institute of Electronics, University of Bundeswehr, Dezembro 2002.

[26] HAJIMIRI, A.; LEE, T. A general theory of phase noise in electrical oscillators. SolidState Circuits, IEEE Journal of, v. 33, n. 2, p. 179-194, 1998.

[27] HAJIMIRI, A.; LEE, T. Corrections to "a general theory of phase noise in electrical oscillators". Solid-State Circuits, IEEE Journal of, v. 33, n. 6, p. 928-928, Jun 1998. ISSN 0018-9200. 
[28] JANNESARI, A.; KAMAREI, M. Comments on "a general theory of phase noise in electrical oscillators". Solid-State Circuits, IEEE Journal of, v. 42, n. 10, p. 2314-2314, Oct. 2007. ISSN 0018-9200.

[29] LU, L.; TANG, Z.; ANDREANI, P.; MAZZANTI, A.; HAJIMIRI, A. Comments on "comments on "a general theory of phase noise in electrical oscillators. Solid-State Circuits, IEEE Journal of, v. 43, n. 9, p. 2170-2170, Sept. 2008. ISSN 0018-9200.

[30] TSVIDIS, Y. Operation and Modeling of The MOS transistor. Second. New York: McGraw-Hill, 1999.

[31] HAJIMIRI, A.; LEE, T. Design issues in cmos differential lc oscillators. Solid-State Circuits, IEEE Journal of, v. 34, n. 5, p. 717-724, May 1999.

[32] ANDREANI, P.; FARD, A. More on the 1/f2 phase noise performance of cmos differential-pair lc-tank oscillators. Solid-State Circuits, IEEE Journal of, v. 41, n. 12, p. $2703-2712$, dec. 2006. ISSN 0018-9200.

[33] YUE, C.; WONG, S. Physical modeling of spiral inductors on silicon. Electron Devices, IEEE Transactions on, v. 47, n. 3, p. 560-568, Mar 2000. ISSN 0018-9383.

[34] CAO, Y. et al. Frequency-independent equivalent-circuit model for on-chip spiral inductors. Solid-State Circuits, IEEE Journal of, v. 38, n. 3, p. 419 - 426, mar. 2003. ISSN 0018-9200.

[35] ANDREANI, P.; WANG, X.; VANDI, L.; FARD, A. A study of phase noise in colpitts and lc-tank cmos oscillators. Solid-State Circuits, IEEE Journal of, v. 40, n. 5, p. 1107 1118, may. 2005. ISSN 0018-9200.

[36] CHEN, J.; LIOU, J. Improved and physics-based model for symmetrical spiral inductors. Electron Devices, IEEE Transactions on, v. 53, n. 6, p. 1300-1309, June 2006. ISSN 00189383.

[37] CHEN, J.; LIOU, J. On-chip spiral inductors for rf applications: An overview. Journal of Semiconductor Technology and Science, v. 4, n. 3, p. 149-167, September 2004.

[38] MOHAN, S.; HERSHENSON, M. del M.; BOYD, S.; LEE, T. Simple accurate expressions for planar spiral inductances. Solid-State Circuits, IEEE Journal of, v. 34, n. 10, p. 1419-1424, Oct 1999. ISSN 0018-9200.

[39] CHAO, C.-J. et al. Characterization and modeling of on-chip spiral inductors for si rfics. Semiconductor Manufacturing, IEEE Transactions on, v. 15, n. 1, p. 19-29, feb. 2002. ISSN 0894-6507.

[40] DANESH, M.; LONG, J. Differentially driven symmetric microstrip inductors. Microwave Theory and Techniques, IEEE Transactions on, v. 50, n. 1, p. 332-341, Jan 2002. ISSN 0018-9480.

[41] NIKNEJAD, A.; MEYER, R. Analysis, design, and optimization of spiral inductors and transformers for si rf ics. Solid-State Circuits, IEEE Journal of, v. 33, n. 10, p. 1470-1481, Oct 1998. ISSN 0018-9200. 
[42] HEGAZI, E.; SJOLAND, H.; ABIDI, A. A filtering technique to lower lc oscillator phase noise. Solid-State Circuits, IEEE Journal of, v. 36, n. 12, p. $1921-1930$, dec. 2001. ISSN 0018-9200.

[43] JERNG, A.; SODINI, C. The impact of device type and sizing on phase noise mechanisms. Solid-State Circuits, IEEE Journal of, v. 40, n. 2, p. 360 - 369, feb. 2005. ISSN 0018-9200.

[44] BABAK, S.; KINGET, P. R. Tail current-shaping to improve phase noise in lc voltagecontrolled oscillators. Solid-State Circuits, IEEE Journal of, v. 41, n. 8, p. 1792-1802, August 2006.

[45] MAZZANTI, A.; ANDREANI, P. Class-c harmonic cmos vcos, with a general result on phase noise. Solid-State Circuits, IEEE Journal of, v. 43, n. 12, p. 2716 - 2729, December 2008.

[46] RAMIAH, H.; ZULKIFLI, T. Z. A. A low-phase noise and high output swing rf lc-vco in cmos technology. International RF And Microwave Conference Proceedings, p. 197 200, September 2006. 